\title{
Performance measures and performance targets in incentive systems : an empirical study of use and effects
}

Citation for published version (APA):

Moers, F. (2001). Performance measures and performance targets in incentive systems : an empirical study of use and effects. [Doctoral Thesis, Maastricht University]. Universiteit Maastricht. https://doi.org/10.26481/dis.20010704fm

Document status and date:

Published: 01/01/2001

DOI:

10.26481/dis.20010704fm

Document Version:

Publisher's PDF, also known as Version of record

Please check the document version of this publication:

- A submitted manuscript is the version of the article upon submission and before peer-review. There can be important differences between the submitted version and the official published version of record.

People interested in the research are advised to contact the author for the final version of the publication, or visit the DOI to the publisher's website.

- The final author version and the galley proof are versions of the publication after peer review.

- The final published version features the final layout of the paper including the volume, issue and page numbers.

Link to publication

\footnotetext{
General rights rights.

- You may freely distribute the URL identifying the publication in the public portal. please follow below link for the End User Agreement:

www.umlib.nl/taverne-license

Take down policy

If you believe that this document breaches copyright please contact us at:

repository@maastrichtuniversity.nl

providing details and we will investigate your claim.
}

Copyright and moral rights for the publications made accessible in the public portal are retained by the authors and/or other copyright owners and it is a condition of accessing publications that users recognise and abide by the legal requirements associated with these

- Users may download and print one copy of any publication from the public portal for the purpose of private study or research.

- You may not further distribute the material or use it for any profit-making activity or commercial gain

If the publication is distributed under the terms of Article 25fa of the Dutch Copyright Act, indicated by the "Taverne" license above, 


\section{Performance Measures and Performance Targets in Incentive Systems}

An Empirical Study of Use and Effects 


\title{
Performance Measures and Performance Targets in Incentive Systems
}

\author{
An Empirical Study of Use and Effects
}

\section{PROIFSCIIRIFT}

ter verkrijging van de graad van doctor aan de Universiteit Maastricht, op gezag van de Rector Magnificus, Prof. Dr. A.C. Nieuwenhuijzen Kruscman, volgens het besluit van het College van Decanen, in het openbaar te verdedigen op woensdag 4 juli $200 \mathrm{I}$ om 16.00 uur

door

Frank Moers 


\section{ACKNOWLEDGEMENTS}

I thank my three promoters for their support, comments, and suggestions, which helped me to improve the manuscript and finish it. I thank Frank Hartmann for 'pushing' me to pursue an academic career. With his enthusiasm, his critical 'supervisory evaluation style', and his friendship, he taught me the necessary research-skills and to go one step further. Ironically, I learned the most from those discussions where we didn't seem to agree. I thank Willem Buijink for his confidence, his unquestioned support, and for being the 'moderator' between the promoters. This gave me the freedom I needed to write the manuscript. I thank Ken Merchant for being supportive of my work but still challenging many of the things I was saying. Although we did not meet frequently, his contribution to my work has been substantial. I thank Carsten De Dreu, Hans Heijke, and Steven Maijoor for their evaluation and approval of the manuscript. I also thank Tom Groot for his supervision during my short stay at the Vrije Universiteit Amsterdam.

I thank my colleagues at the Department of Accounting \& Auditing of Maastricht University for creating a pleasant working environment. I especially thank Erik and Philip. I thank Hay Management Consultants, Ronald Borgts in particular, for their help in the sample selection. I also thank the Iluman Resource Managers of the firms that participated in this study and the respondents.

Last but not least, I thank my family for their support, but most of all, I thank Daniëlle. Words cannot express my gratitude. 


\section{CONTENTS}

\section{chapter 1}

INTRODTITION

1.1 Introduction 1

1.2 Management Control and Incentive Systems 2

1.3 Contributions 4

1.4 Overview of Dissertation 5

\section{chapter 2}

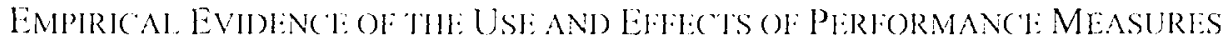
AND PLERTORMANCE TARGiTS

2.1 Introduction

2.2 Empirical Evidence

2.2.1 The use and effects of performance measures

2.2.2 The use and effects of performance targets

2.3 Summary and Research Opportunities

\section{chapter 3}

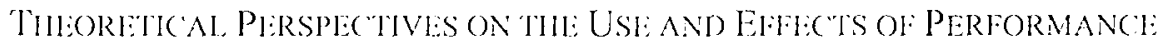

Measuris ani) PERformancti Targets

3.1 Introduction 21

3.2 The Use and Effects of Performance Measures 21

3.2.1 Economic focus 21

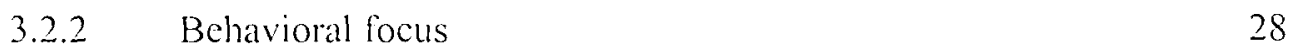

3.2.3 Explaining the use of performance measures 3 !

3.3 The Use and Effects of Performance Targets 34

3.3 .1 Economic focus 34

3.3.2 Behavioral focus 34

3.3.3 Examining the effects of incentive systems 37

\section{chapter 4}

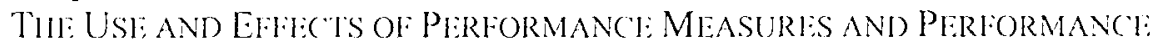

TARGLETS: HYPOTHESES DEVELOPMI:YT

4.1 Introduction 39

4.2 The Use of Performance Measures 40

4.2.1 Introduction 40

4.2.2 Hypotheses 40

4.3 The Effects of Performance Measures and Performance Targets 47

4.3.1 Introduction 47

$\begin{array}{lll}4.3 .2 & \text { Hypotheses } & 48\end{array}$

4.4 Summary 51 


\section{chapter 5}

RISSEAR(H METHOD)

$5.1 \quad$ Introduction

5.2 Sample 5.2

5.2.1 Sample of firms

5.2 .2 Sample of respondents 54

5.3 Questionnaire Design 55

5.3.1 Translation, pre-kest, and linal format 55

5.3.2 Distribution and follow up $\quad 57$

5.3 .3 Response rate 58

$5.4 \quad$ Proprietary Archical Data 58

$5.5 \quad$ Measurement Instruments 59

5.5 .1 Introductory remark $\quad 59$

5.5.2 Task uncertainty 59

$\begin{array}{ll}5.5 .3 & \text { Environmental uncertainty }\end{array}$

5.5.4 Decision-making authority 60

5.5.5 Performance measure characteristics

5.5.6 Performance measure use 63

5.5.7 Performance target difficulty $\quad 64$

5.5.8 Managerial risk aversion 64

5.5.9 Managerial short-term orientation $\quad 66$

5.6 Test for Non-response Bias 66

\section{chapter 6}

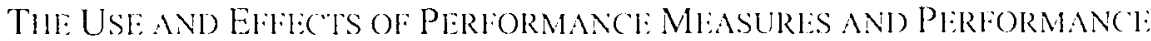

TARGLTS: EMPIRICAI RESUITS

$\begin{array}{lll}6.1 & \text { Introduction } & 69 \\ 6.2 & \text { The Use of Performance Measures } & 69 \\ 6.2 .1 & \text { Hypotheses } & 69 \\ 6.2 .2 & \text { Empirical results } & 70 \\ 6.2 .3 & \text { Sensitivity analysis and additional tests } & 75 \\ 6.3 & \text { The Effects of Performance Measures and Performance Targets } & 78 \\ 6.3 .1 & \text { Hypotheses } & 78 \\ 6.3 .2 & \text { Empirical results } & 78 \\ 6.3 .3 & \text { Sensitivity analysis } & 82\end{array}$

\section{chapter 7}

SUMMARY AND CONCLLSION

7.1 Introduction

7.2 Summary

7.2.1 The use of performance measures $\quad 86$

7.2.2 The difficulty of performance targets 89 
7.2.3 Managerial short-term orientation

7.3 Conclusion and Implications

7.4 Limitations

7.5 Directions for Future Research

\section{Appendices}

appendix $\Lambda$

LINIAR PIRINCIPAI-AGINT MOD)HI.

appendix $\mathrm{B}$

MEASUREMLNT INSTRUMI:ATS

appendix $\mathrm{C}$

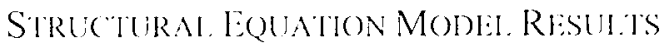

RIIFIRIINCI:S

117

SUMmaRY IN DUTCH

CURRICUILM VITAl: 


\title{
chapter 1
}

\author{
INTRODUCTION
}

\section{$1.1 \quad$ Introduction}

This dissertation empirically examines (i) the design of incentive systems for middle managers and (ii) the effects of incentive systems on middle managers' behavior.' It adidresses the use of pertormance measures and the setting of performance targets for incentive purposes and the effects that this has on managerial behavior. The purpose of this dissertation is to empirically examine what factors explain the use of linancial and non-financial performance measures and performance targets and how this use affects the behavior of managers.

In this dissertation, I use multiple disciplines to study the design and effects of incentive systems, although the purpose is not to, for example, integrate and/or compare dillerent paradigms. My intentions are more modest. The aim of the "multi-disciplinary' approach is to extend a certain research stream with the implications of another research stream studying the same problem but using a different perspective. "This extension is applied to two related research streams. First, I extend the behavioral-based literature on reliance on accounting performance measures with the implications of the

\footnotetext{
In the remainder of this dissertation. I use the term subordinate manager instead of middle manager.

"Therefore, the multi-disciplinary approach is a means 10 an end, wher than an end in itselt:
} 
cconomics-based literature on managerial compensation to examine the factors that explain the use of performance measures. This multi-disciplinary focus provides me with three general performance measure characteristics that are related to the use of performance measures. Further, it establishes uncertainty as the dominant contingency factor that has an effect on the characteristics of different performance measures and thus their use.

Second. I extend the economies-based literature on the incentive effects of perlormance measures with the implications of the behavioral-based literature on target-setting to study the effects of incentive systems. This multidisciplinary focus suggests that not only the use of performance measures for incentive purposes affect behavior but also the difficulty of the target associated with this performance measure. ${ }^{3}$ Since both performance measures and performance targets are part of the incentive system, as I discuss below, the question is raised how these are related and what (additional) incentive effects difficult performance targets have.

In summary, the purpose of this dissertation is to use multiple disciplines (1) to examine the factors that explain the use of performance measures and (2) to examine the simulaneous effect of performance measures and performance targets on managerial behavior. Therefore, this dissertation addresses the following two general research questions:

\section{(1) What factors explain the use of performance measures?}

(2) How do performance measures and performance targets, as part of the incentive system, affect behavior?

\subsection{Management Control and Incentive Systems}

The topic of this dissertation is part of the broader field of management control. Management control has been defined in the literature in a variety of ways and a universally accepted delinition of management control is still unavailable. However, despite the variely of definitions, all definitions provide the same common idea. To explain this common idea, 1 first make a distinction between the general concept of 'control' and the more specific concept of 'management control'.

Otley and Berry (1980) describe control as:

"The difliculy of performance targets relates to the degree to which the largets can be achicved. 
'...the wats in which organizations manage and regulate their affairs so as to remain viable and to achieve their chosen objectives" (p. 231).

This definition is based on the cybemetic concept of control. Although the underlying idea of the cybemetic control model is applicable to the control of managers, the major objection to this model is that management control involves human beings. That is, management control is not only control of human beings but also control by human beings. One consequence of this human involvement is that the mere fact that human behavior is observed may change the behavior of these human beings. the process of setting targets, using performance masures, and evaluating performance can therefore not be seen as a simple mechanical process ( $\Lambda$ nthony 1981). Since management control involves human beings, it can be defined as:

-...the process by which managers influence other members of the organization to implement the organization's strategies (Anthony 1981 . p. 8).

'This behavioral orientation is also emphasized by Lawler and Rhode (1976, p. 6) who state that:

'...the crucial aspect of any control system is its effect on behavior: ... The system needs to be designed in a way that assists, guides, and motivates management to make decisions and act in ways that are consistent with the overall objectives of the organization.

Management control is therefore about influencing the behavior of managers to ensure that they do what is best for the organization.

The key to effective management control is motivating employees. One way. though not the only way, to motivate employees is by implementing incentive systems. Incentive systems consist of three basic components (Merchant 1989). The first component is one or more measures of performance. Performance measures should provide information about the actions that managers have taken, even though these measures are likely to be affected by factors other than the manager's actions. Examples of performance measures are retum on investment, product quality, and customer satisfaction.

The second component of the incentive system is the target that will be used to evaluate actual performance. These targets are necessary to distinguish

"In contrast, observing an apple falling from a tree does not change the behavior' of the apple. 
'good' from 'bad' performance and to provide managers with incentives to attain a certain target. Targets can be based on internal or external benchmarks, such as budgets or performance of similar entities.

linally, the third component of the incentive system is the rewards given to managers. These rewards can be linked to performance to provide managers with incentives to improve perfomance. Fxamples of rewards are salary increases, bonuses, promotion, and increased autonomy.

In this dissertation, I focus on three types of performance measures: (1) financial performance measures, (2) internal non-financial performance maasures, and (3) external non-financial performance measures. This classification is partly based on the literature (c.g.. Larcker 1981; Gordon and Narayanan 1984; Itner et al. 1997) and partly on the interviews with human resouree managers of the firms participating in this study (see chapter 5). The financial performance measures are defined as the 'traditional' financial performance measures, such as return-on-assets, net income, and cash flows." The internal non-linancial performance measures consist of performance measures that are directly related to the tasks performed. Examples of these performance measures are productivily, efficiency, and successfu! implementation of projects. The external non-financial performance measures are defined as those performance measures that reflect performanee in the market. Examples of these performance measures are market share, market growth, and customer satisfaction.

With respect to the second and third component of the incentive system, I focus on the difliculty with which performance targets can be achieved but I do not specifically examine how different types of rewards affect managerial behavior. Rather, I examine those performance measures and performance targets that are used to determine different types of rewards, such as salary increases, bonuses, and promotion.

\subsection{Contributions}

In anticipation of the empirical results, I briefly state the contributions that this dissertation makes to the literature. First, it explains the choice of performance measure characteristics and empirically examines how these affect the use of performance measures. Second, it simultancously investigates the use of performance information of both a financial and non-financial nature. Third, this dissertation examines how different types of uncertainty affect the

\footnotetext{
SAll examples presented with respect to each type of performance measure are measures actually used for incentive purposes by the participating lirms.
} 
characteristics of performance measures. Fourth, it investigates the incentive effects of both performance measures and performance targets. Fifth, it tests the theoretical claim that non-financial performance measures provide managers with incentives to be long-term oriented. Sixth, it examines the role of risk aversion in setting performance targets. Finally, it combines the implications of the economics-based literature and the behavioral-based literature, which provides a more complete analysis.

\subsection{Overview of Dissertation}

The remainder of this dissertation is organized as follows. In chapter 2, I review the empirical evidence of the use and effects of performance measures and performance targets to identify research opportunities. In chapter 3, I discuss different theoretical perspectives on the use and effects of performanee. More specifically, I discuss agency theory, contingency theory, and goal theory, which are the theories underlying the research streams relevant for this dissertation. In chapter 4, I develop hypotheses, which are empirically tested using the rescarch method described in chapter 5 . In chapter 6 , I present the empirical results and I conclude this dissertation with a summary and conclusion in chapter 7. 


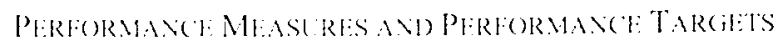




\section{chapter 2}

\section{EMPIRICAL EVIDENCE OF THE USE AND EFFECTS OF Performance Measures and Performance TARGETS}

\subsection{Introduction}

In this chapter, I provide an overview of the economics-based and behavioral-based empirical managerial incentives literature. I focus on a selection of papers that are representative of the literature. For more complete reviews and discussions of the literature, see, for example, Briers and Hirst (1990), Pavlik et al. (1993), Hartmann and Moers (1999), Murphy (1999a), Prendergast (1999). I lartmann (2000), and Ittner and Larcker (2000). Rather than discussing the literature by theory, I discuss it by topic. This creates an opportunity for using multiple disciplines to study the same problem, which is likely to lead to more insight (Merchant et al. 2000). The topics that are discussed are the use of performance measures and the use of performance targets for incentive purposes and the effects that this has on managerial behavior and performance.

\subsection{Empirical Evidence}

\subsubsection{The use and effects of performance measures}

The assumption that managers will direct their behavior towards the performance measures used has long been recognized in both the behavioral and economics literature (e.g., Locke et al. 1968; Holmström 1979). The choice of performance measures is therefore crucial for providing managers with the 
'comect incentives. The empinical licrame predominanty focuses on pertormance measures and incentives at the (1:O level. Lambert and lareker (1987) examine the use of stock marketbased pertormance measures (stock

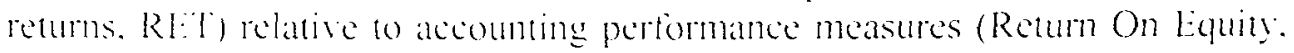
ROI:). How specifically. they examine the extent to which the use of RET relative to ROE is related to the relative noise in the perfomance measures. the slage of investment. and the extent to which the manager's wealth is tied to stock price. The empirical results indicate that the use of RET relative to ROF is positively influenced by the ratio of the time-series variance of ROE to RET. the correlation between ROL and RET. and the stage of invesment and negatively influenced by the extent to which the mamager's wealth is tied to stock price.

A second study investigating the use of accounting performance measures in top execulive compensation is Sloan (1993)! Sloan (1993) examines whether compensation is more sensitive to accounting earnings (1) the higher the noise in slock retums relative to eamings and (2) the lower the correlation between the noise in stock returns and noise in accounting earnings. The empirical results show that the use of accounting earnings increases with increases in the rative noise and decreases in the comelation. Sloan (1993) interprets these results as consistent with the idea that although accounting earnings are noisier measures than stock retums. they are used in executive compensation contracts to shield executives from market-wide movements in stock price. That is accounting aamings reflect firm-specilic changes in stock price rather than marketwide changes. However. Lambert (1993, p. 122) states that Sloan's additional tests suggest that earnings are used because they are informative about the manager s actions over and above stock retums.

The studies by Lambert and Larcker (1987) and Sloan (1993) examine the use of accounting performance measures in executive compensation either in an absolute sense or relative to market performance measures (stock returns). Bushman et al. (1996) examine the relative use of individual performance measures in determining (EO annual bonuses. They state that individual performance measures will be used for incentive purposes when various valueenhancing activities are not (fully) retlected in corporate financial measures. Lsing a proprictary database from Hewitt Associates, Bushman et al. (1996) find that the relative use of individual performance measures increases with the firm's growth and investment opportunities, product developmen cycle. and product life eycle. The use of these performance measures is, however. not related to the noise in either accounting earnings or stock retums.

Ittner et al. (1997) investigate the use of financial perfomance measures (e.g. net income). relative to the use of non-financial performance measures 
(c.g.. customer satisfaction) in determining the amnual bonus of CEOs. They examine the extent to which the relative use of non-financial performance measures is related to the use of an innowation-oriented strategy, quality strategy, regulation, linancial distress, noise in financial performance, and the power of cl:Os. 2 Lsing the incentive weights stated in proxy statements and conlidential compensation consulting surveys, they lind that the relative use of non-linancial performance measures is positively affected by the use of an imnovation-oriented strategy, quality strategy, regulation, and noise in financial performance but not affected by financial distress. ('ontrary to expectations, they find that the power of CEOS is negatively related to the relative use of nonfinancial measures.

The above four studies all examine the use of performance measures at the (EO) level. For more complete reviews of the CEO incentive literature. I refer to the papers by Pavlik et al. (1993) and Murphy (1999a).

The accounting literature, however, has so far paid much less attention to explaining the use of performance measures at lower levels in the organization. Govindarajan (1984) examines the effect of environmental uncertainty on the extent to which subjectivity is used in evaluating business-unit managers. The empirical results indicate that environmental uncertainty increases the percentage of the total bonus that is based on subjectivity. Govindarajan interprets these results as consistent with the assumption that linancial performance measures become less controllable as environmental uncertainty increases. Therefore, increased environmental uncertainty increases the need for superiors to rely on alternative performance measures in evaluating and compensating managers, such as subjective performance evaluation.

Bushman et al. (1995) study the use of aggregate performance measures in compensating business-unit managers. ${ }^{3}$ By aggregate performance measures they mean performance measured at an organizational level higher than the business-unit level, for example, the firm-level. The empirical results show that interdependence, proxied by diversification and intralirm sales, increases the relative use of aggregate performance measures. This result can be explained by the fact that interdependence will lead to spillover effects of managers' actions and performance measures at a higher organizational level will be informative about these spillover ellects. ${ }^{+}$

2 The power of the CEO relates to the degree to which the CEO can infuence the Board of Directors. More powerful CEOs can force more attention to non-financial performance measures.

For an in-depth discussion of the paper by Bushman et al. (1995), see Lanen (1995).

+ Spillover effects mean that the decisions made by the manager of deparment $X$ have an impact on the performance of department $r$. Therefore. the performance of deparment $Y$ is 
Keating (1997) addresses a problem similar to that of Bushman et al. (1995). Keating (1997) investigates the determinants of the use of division accounting metrics, firm accounting metrics, and firm stock price metrics in the evaluation of division managers. The factors that are hypothesized to affect the use of these performance measures are (1) two types of interdependencies, (2) correlation beween division earnings and division value, (3) division growth opportunities, (4) firm growth opportunities, (5) division size, and (6) correlation between firm stock returns and market returns. The results from the empirical analysis, first of all, show that the use of division accounting metrics increases with the correlation between division earnings and division value and decreases with the division growth opportunities. Second, the use of firm accounting metrics decreases with firm growth opportunities and the impact that other managers have on the manager's division and increases with the impact that the division manager has on other divisions. Finally, the use of firm stock price metrics increases with division size and the correlation between firm stock returns and market returns.

... The papers discussed so lar focus on the use of performance measures and their determinants. These performance measures are intended to have an effect on performance and managerial behavior. Empirical research in accounting predominantly focuses on the incentive effects of financial performance measures. Banker et al. (1996a) examine the performance improvements following the implementation of an incentive plan in a retail firm. The incentive plan consists of a quarterly bonus plan based on sales for sales consultants, sales department supervisors, and managers. They gather data from 15 stores with an incentive contract and 19 'control' stores without the incentive contract. Their results indicate that the sales for stores that work under the incentive contract increases after the implementation of the bonus plan and that this increase is higher for larger stores. Furthermore, the performance impact tends to persist and increase over a time. Finally, the incentive effect in the fourth quarter, which is characterized by the employment of temporary personnel, is lower, which suggests that the incentive plan is less effective for temporary workers.

In a related study using the same research site, Banker et al. (1996b) examine how the performance improvements following the implementation of the incentive plan are moderated by contextual factors. More specilically, they examine the moderating effect of competition, upscale markets, and level of monitoring. They find that the sales and profit improvements following the implementation of the incentive plan are higher the greater the intensity of

influenced by the manager of department $X$ and, as a result, provides information about the decisions made by this manager. 
competition, the more upscale the market, and the lower the existing level of monitoring. The effect of the incentive plan on improvements in customer satisfaction is greater, the more upscale the market.

Recently. rescarchers have started to investigate the performance effects of adopting residual income-based incentive plans. Proponents of economic income measures claim that these performance measures provide better incentives to maximize sharcholder value than traditional accounting performance measures (e.g., Stern et al. 1995). The empirical evidence, however, provides mixed results. Wallace (1997) compares the performance of adopters and non-adopters of residual income-based incentive plans. He finds that adopters of residual income-based incentive plans exhibit greater changes in residual income, over one year, than control tirms matched on industry and size. Hogan and Lewis (1999) extend the study by Wallace (1997) and examine the long-run performance impact of incentive plans based on economic profits (e.g., residual income). They find that the operating performance and stock pertomance of adopters of economic profit plans increase significantly in the year of adoption and the four years following the adoption. However, they also find that the adopters of these particular incentive plans are relatively poor performers. An examination of the performance improvements of adopters compared 10 a control sample of non-adopters, matched on size and past prolitability, shows no significant differences. As a result, it is not clear whether incentive plans based on economic profit like measures provide better incentives to create shareholder value than incentive plans based on traditional financial performance measures.

In contrast to the studies discussed above, Govindarajan and Gupta (1985) and Banker et al. (2000) examine the performance effects of using non-financial performance measures. Govindarajan and Gupta (1985) investigate whether linking performance measures 10 business-unit strategy will improve performance. Following the contingency theory perspective, they hypothesize that short-run performance measures will be more effective for business-units following a harvest strategy, while long-run performance measures will be more elfective for business-units following a build strategy. Their empirical results show that the use of long-run performance measures increases the performance of 'build business-units' but decreases the performance of 'harvest businessunits'. However, the performance effect of using short-run performance measures is not significantly different between 'buitd business-units' and 'harvest business units', which suggests that short-run performance measures are equally effective for all business-units.

\footnotetext{
"The short-run performance measures are similar to financial performance measures, while the long-run performance measures are similar to non-financial performance measures.
} 
Banker et al. (2000) examine the performance effects following the implementation of an incentive plan that includes non-financial performance measures. They analyze archival data from 18 hotels of a hotel chain, which moved from an incentive plan that was based on financial performance measures to an incentive plan that included measures of customer satisfaction. Their findings indicate that customer satisfaction improves significantly after the implementation of the incentive plan and that the measures of customer satisfaction are leading indicators of financial performance. Further, financial performance also improves significantly due to the implementation of the incentive plan, which suggests that the incentive plan has a direct eflect and an indirect effect, working through customer satisfaction, on financial performance.

Related to this stream of research are studies that examine the effect of performance measure use on various aspects of managerial behavior. The accounting literature pays a considerable amount of attention to the effects of earnings-based incentive plans on earnings management. In general, the studies by llealy (1985), Gaver el al. (1995), and Holthausen et al. (1995) provide mixed evidence with respect to the extent to which earnings-based incentive plans provide managers with incentives to make accrual decisions, i.e., changing reported income, that maximize their bonus. Guidry et al. (1999) state that these mixed results are partly due to the use of aggregated data from a large number of lirms. They provide a more powerful test by examining carnings management by business-unit managers using business-unit-level data. Guidry et al (1999) compare the accrual behavior of three portfolios of business-unit managers: (1) managers who did not earn a bonus (LOW), (2) managers who received the maximum bonus (UPP), and (3) managers who received some bonus, but lower than the maximum (MID). The bonus-maximization hypothesis predicts that managers in the LOW and UPP portfolios will make income-decreasing accrual decisions, while managers in the MID portfolio will make incone-increasing accrual decisions. The empirical results are consistent with this hypothesis and indicate that business-unit managers manipulate reported income to maximize their bonus.

Similarly, Merchant (1990) studies the eflect of linancial controls on data manipulation and management myopia of profit center managers. His results show that an increased use of financial controls leads profit center managers to pull profits from future periods by deferring expenditures and accelerating sales. Furthermore, financial controls discourage new ideas and provide profit center managers with incentives to be short-tem oriented.

While the studies by Merchant (1990) and Guidry et al. (1999) examine the (assumed) dysfunctional consequences of incentive plans, Wallace (1997) examines the (assumed) functional consequences. In his study of residual income-based incentive plans, Wallace (1997) examines the investment, 
financing, and operating decisions of managers. He finds that, compared to the control firms, adopters of residual income-based incentive plans tend to increase asset disposition, decrease new investments, increase share repurchases, and utilize assets more intensively. Whether or not these decisions actually increase sharcholder wealth is not clear (Wallace 1997, p. 287). However, these decisions are consistent with the incentives provided by the incentive plan, leading to the conclusion that 'what you measure is what you get'.

Another important stream of research on the effects of performance measures on managerial behavior is the reliance on accounting performance metisures (RAPM) literature. The question that this literature tries to answer is how RAPM affects performance and job-related attitudes of lower-level managers under different circumstances. The circumstances investigated either explicitly or implicitly relate to uncertainty (Hartmann 2000) and the general line of reasoning in this literature is that accounting performance measures $(\triangle P M)$ are less appropriate when uncertainly is high. Hirst (1983), for example. examines the effect of RAPM on job-related tension and social withdrawal under different levels of task uncertainty. He finds that RAPM results in higher (lower) job-related tension under conditions of high (low) task uncertainty, but that social withdrawal is unaffected.

Brownell (1985) examines the appropriateness of RAPM for different functional areas, i.e., marketing and $R \& D$. The different functions are associated with different levels of task and environmental uncertainty, where R\&D is characterized by higher levels of uncertainty relative to marketing. Brownell (1985), however, finds that the effect of RAPM on performance is not affected by functional area.

Imoisili (1989) investigates the effect of RAPM on performance, stress, and attitudes toward the budget for different levels of task uncertainty and task interdependence. The empirical results indicate that both task uncertainty and task interdependence do not affect the relationship between RAPM and any of the outcome variables.

Finally, Dunk (1992) tests the prediction that $\triangle P M$ are more appropriate for evaluating production managers when the production process becomes more automated. His results show that the effect of RAPM on subunit performance is more positive the more the production process is automated.

The results of the above four studies are representative of the overall results in the RAPM literature, i.e., it is unclear how uncertainty affects the appropriateness of APM. For an elaborate literature review of the RAPM literature, I refer to the recent paper by Hartmamn (2000). 


\subsubsection{The use and effects of performance targets"}

Although there is a large body of literature on the use of performance measures, far less attention has been paid to the use of perlormance targets (sce Ittner and Larcker (2000) for a similar remark). Only a small number of papers exists on the use of performance targets in CEO incentive eontracts. For example, Puffer and Weintrop (1991) examine the role of performance expectations in (1:O turnover. They expect that the Board of Directors will evaluate the performance of CLOs compared to certain targets and will base their dismissal decision on whether performance has met the target. Their cmpirical results show that actual earnings compared to performance expectations, proxied by analysts' eamings forecasts, are a significant predictor of CEO turnover. Furthermore, accounting performance and market performance per se are not significantly related to CEO turnover. These results suggest that performance targets are a relevant component of C'EO incentive contracts.

Murphy (1999b) examines the type of performance targets used in CEO incentive contracts and the effects that these have. He distinguishes between 'internally determined' targets (e.g., prior year performance) and 'externally determined' targets (e.g., peer perfomance). The main difference between these two types of targets is that internally determined targets can be influenced by plan participants, while externally determined targets are relatively unaffected by plan participants. Murphy (1999b) finds that CEOs who are evaluated based on internally determined targets are more likely to smooth earnings and thus have less variable bonus payouts compared to CEOs who are evaluated based on externally determined targets. He states that these results are due to the fact that internally determined targets allow ratcheting, while this effect is absent when using externally determined targets.

Indjejikian et al. (2000) examine the degree to which the earned bonus exceeds the target bonus, which they label 'abnormal' bonus. Using Hewitt's compensation survey data, they find that, on average, earned bonuses exceed target bonuses, which implies that targets are achievable on average. Furthermore, they show that targets do not fully incorporate past performance, i.e., the ratchet principle is not fully applied, since abnormal bonuses are positively serially correlated. Finally, Indjejikian et al. (2000) find that the

\footnotetext{
"This section predominately focuses on the diffeulty" of performance targets. Although. the RAPM literature addresses target-related issues, it does not address the issue of difficulty and therefore it was discussed in the previous section.

Ratcheting occurs when performance targets are adjusted upward (downward) when actual perfomance in the previous period excecds (falls short of) targeted performance. In chapter 3 , I discuss the ratcheting principle more fully.
} 
magnitude of the abnormal bonus is positively related to measures of information asymmetry, which suggests that if managers have private information, they will bias targets downward leading to achievable targets.

Other research at the (EO) level that is somewhat related to the use of performance targets is the literature on relative performance evaluation. Leonomic theory suggests that relative performance evaluation is valuable if the performance of peers is (party) affected by the same exogenous factors as the performance of the manager being evaluated (Holmström 1982). However, despite the theoretical argumentation in favor of relative performance evaluation (RPli), the empirical results provide mixed evidence (Antle and Smith 1986; Gibbons and Murphy 1990; Janakiraman et al. 1992). Most of these studies assume that RPE is equally relevant for all firms. One exception to this is a recent study by DeFond and Park (1999). DeFond and Park (1999) investigate the effect of competition on the use of RPE in CEO dismissal decisions. They find that RPE-based accounting performance measures are significantly related 10 CEO turnover in high competition industries but not related to CEO turnover in low competition industries. These results suggest that lirms apply RPE, taking into account the environmental conditions.

For lower levels in organizations only limited evidence exists on the use and effects of performance targets. The most influential study on target setting is the field study by Merchant and Manzoni (1989). Merchant and Manzoni (1989) gather data from 54 profit centers in 12 firms and examine the use and achievability of budget targets. They find that most firms use more than one financial target for incentive purposes and managers are paid bonuses for cxceeding a certain threshold. Nine firms also include an upper bound, where no additional bonuses are paid for exceeding the upper bound. The most interesting finding of their study is that most profit center managers in their sample reach their target eighty to ninety percent of the time, which leads to the conclusion that the targets are highly achievable. The finding that targets are highly achievable is inconsistent with the prescriptions in management accounting textbooks, which suggest that targets should be reached less than fifty percent of the time. However, Merchant and Manzoni (1989) state that superiors set targets keeping in mind the possible effects that these have on managerial behavior. That is, difficult performance targets will increase motivation in the current 'period' but they will destroy motivation in future 'periods' because the targets are simply unachicvable. Furthermore, highly achievable targets are set to reduce the incentives to manage earnings, while less achievable targets are set to promote decisions that lead to short-term profits.

Simons (1988) investigates the effect of organizational characteristics on the difficulty of budget goals. He finds weak support for his hypothesis that, due to the assumed differences in information processing capabilitics, the budgets of 
prospector firms are more difticult than the budgets of defender firms. Furthermore, he finds that the difficulty of budget goals is positively related to the use of ex post monitoring controls and budget-based compensation. These results suggest that firms use additional controls to set difficult budget goals and are more likely to do this in situations where managers have incentives to bias targets downward. Consistent with Merchant (1985), Simons linds that budgetary participation is positively related to difficult budget goals, even after controlling for the use of ex post monitoring controls. Finally, Simons (1988) shows that the positive effect of difficult targets on task performance found in the psychological goal setting literature (see Locke and Latham (1990) for an overview) extends to the lirm level. That is, target difficulty increases firm performance.

Shields et al. (2000), on the other hand, do not find a direct relationship between target difficulty and job performance but rather an indirect effect. More specilically, they find that target difficulty increases stress, which subsequently decreases performance. Shields et al. (2000) state that this relationship might be one reason for firms to set achievable targets, as the study by Merchant and Manzoni (1989) indicates.

Related to the issue of the difficulty of performance targets is the issue of budgetary slack." Merchant (1985) examines how manufacturing managers' propensity to create budgetary slack is related to the importance placed on meeting the budget, the extent of participation, the predictability in the production process, and superior's ability to detect slack. The empirical results show that the propensity to create budgetary slack decreases with the extent of participation, the predictability in the production process, superior's ability to detect slack and the use of budgets in evaluating managers. One explanation for this last finding can be found in the positive correlation between the importance placed on meeting the budget and superior's ability to detect slack (Merchant 1985 , p. 205). The more important the budget is for evaluating managers, the more likely it is that superiors will detect slack (Williamson 1964), which decreases managers' propensity to create slack.

In a recent study, Van der Stede (2000) finds similar results. Van der Stede (2000) examines control systems at the business-unit level and finds, consistent with Merchant (1985), that the use of rigid budgetary controls decreases budgetary slack. He further finds that budgetary slack and managerial short-term orientation are negatively correlated, which suggests that managers are less short-term oriented if the targets allow them to do so. Finally, Van der Stede (2000) shows that past performance is positively related to 'current'

"Budgetary slack leads to a higher probability of achieving the budget. Therefore, budgetary slack and budget difficulty are negatively correlated or antonyms. 
budgetary slack. This finding is consistent with the idea that good performers are subsequently 'rewarded' with slack, which gives these managers more liexibility and discretion (Merchant and Manzoni 1989).

Leone and Rock (1999) examine the use of ratcheted targets and the effects that these have on bonus maximizing behavior. Using archival data from a large multinational firm, they find that the targets of business unit managers ratchet. The empirical results further show that if business unit managers perceive that targets ratchet, rather than being static, the bonus maximizing discretionary accruals are lower. Finally, they show that the accrual behavior of managers is better explained under the assumption that ratcheting takes place than under the assumption that targets are static.

\subsection{Summary and Research Opportunities}

The available empirical evidence of the use and effects of performance measures and performance targets is summarized in table 2.1. Table 2.1 makes a distinction between the empirical evidence available at the highest level in the organization (CEO level) and levels lower in the organization (subordinate level). The focus of this dissertation is on the subordinate level and therefore I discuss the research opportunities at this level. I refrain from discussing the research opportunities at the CEO level until chapter 7.

The overview shows that the empirical evidence at the subordinate level is dominated by the RAPM literature, which studies the contextually determined effects of financial performance measures. Further, by taking a closer look at table 2.1, the following 'gaps' can be identified. First, regarding the performance dimension, there is lack of cmpirical evidence on the use and effects of non-financial performance measures and targets. Second, regarding the incentive system components, the emphasis seems to be on performance measures with only little attention being paid to performance targets. Finally, regarding the use versus effects of performance measures, the empirical literature does not pay much attention to explaining the use of performance measures. Ovcrall, table 2.1 shows that there are a number of under-investigated areas in the literature.

Although I organized the discussion of the empirical literature by topic, organizing it by disciplinary focus would have led to a similar overview and the same under-investigated areas. Merchant et al. (2000) state that research on incentive systems can be characterized as narrowly focused on either the economic sciences or the behavioral sciences. They examine the extent of this problem by using a citation and content analysis of incentive systems rescarch in accounting. Their results, first of all, show that most of the papers analyzed can 
be classified as either economics-based or behavioral-based, which indicates that relatively little cross-fertilization has taken place. Second, the analysis indicates that the economies-based papers predominately focus on the CEO level, while the behavioral-based papers predominately focus on the subordinate level., ${ }^{9,11}$ Finally, the majority of the behavioral-based papers includes outcome variables (effects) in their study, while only a minority of the cconomics-based papers does so. These results of Merchant et al. (2000) are consistent with implications of table 2.1 .

Obviously, the mere existence of under-investigated areas in the literature and the lack of cross-fiertilization are not sufficient reasons to explore these areas. However, in my opinion, the above identified under-investigated areas are worthy of attention for the following reasons. First, the lack of empirical research on non-financial performance measures is problematic since these measures are becoming increasingly important in firms (Banker et al. 2000). Examining the use of non-financial performance measures and the effects that these have is therefore valuable. Second, performance targets, and the difficulty associated with these targets, can have significant incentive effects, as evidenced by the goal setting literature (Locke and Latham 1990). However, accounting studies on incentive effects predominately rely on agency theory and, as a result, examine the effects of performance measures. Given that (1) incentive systems consist of both performance measures and performance targets and (2) that both components have incentive effects, examining the simultaneous impact of the two components can lead to a significant contribution to the litcrature. To make this contribution, however, the agency theory-based 'incentive effects studies' should be extended with the implications of 'target difficulty studies', which are based on goal theory. Finally, the lack of attention given to explaining the use of performance masures seems to be driven by methodological issues not theorelical." RAPM studies, which apply zcontingency theory, examine the conditional effects of using (accounting) performance measures. However, this

"The four major research streams defined in the notes of table 2.1 can be classified as lollows. The 'managerial compensation studies' and 'incentive effects studies' are economics-based papers, while the 'RAPM studies' and 'target difficulty studies' are behavioral-based papers.

10) The focus on the CEO level by 'economists' and on the subordinate level by 'behaviorists' can (partly) be explained by their training (Merchant et al. 2000). Doctoral programs for economists primarily emphasize conometrics, while doctoral programs for behaviorists primarily cmphasize survey and ficld rescarch methods. As a result, economists focus on large databases containing publicly available data (c.g., S\&P's ExecuComp), while behaviorists gather their 'own' data, which is less difficult at the subordinate level than at the CEO level.

"I explain this point more fully in chapter 3. 
cmphasis on the 'conditional effects of use' is different from the emphasis of earlier contingency studies that examine the 'conditions that affect use'. Given the slow progress in the RAPM area (Hartmann and Moers 1999; Hartmann 2000 ), it is useful to go back to the basic premise of contingency theory and study the factors that explain the use of performance measures. ${ }^{12}$ Furthermore, the RAPM literature can benefit from incorporating the implications of the 'managerial compensation studies', since these studies, and especially the agency theory applicd, focus on the factors that determine the use of performance measures.

\section{Table 2.1}

Number of empirical studies on the use and effects of performance measures and performance targets at different organizational levels

\begin{tabular}{|c|c|c|c|c|}
\hline & & & CEO level & Subordinate level \\
\hline \multirow{4}{*}{$\begin{array}{l}\text { Financial } \\
\text { Performance }\end{array}$} & \multirow[b]{2}{*}{ Measures } & Use & Substantial $(A)$ & Little \\
\hline & & & Substantial (B) & Substantial $(B-C)$ \\
\hline & \multirow[b]{2}{*}{ Targets } & Use & Little & L_ille \\
\hline & & Efrects & Little & Some (D) \\
\hline \multirow{5}{*}{$\begin{array}{l}\text { Non-financial } \\
\text { Performance }\end{array}$} & \multirow{3}{*}{ Mealsures } & Use & Some (A) & Litle \\
\hline & & & & \\
\hline & & Effects & - & Little \\
\hline & \multirow{2}{*}{ Targets } & Use & - & - \\
\hline & & Effects & - & - \\
\hline
\end{tabular}

Notes:

AISO level: highest level in the organization:

Subordinate level: organizational levels below the CEO level, for example, business unit, division. and department.

b (A): Managerial compensation studies: these studies focus on explaining the use of performance measures. Theortical basis: economics (agency theory):

(13): Incentive effects studies: these studies examine the incentive effects provided by performance measures. Theoretical basis: comomics (agency theory):

(C): R.APH studie; these studies examine the contextually determined effects of Relying on Accounting Performance Measures. Theoretical basis: behavioral (contingency theory):

(D): Target difficulty studies; these studies examine the effects of the diffeulty with which performance targets can be achieved. Theoretical basis: behavional (goal theory).

12 Notice that studying the factors that explain the use of management accounting practices does not preclude cxamining the effects of management accounting practices. It simply means that a different model should be applied (see Luft and Shields (2000) for an overview of different 'structural models'). 
This dissertation tries to contribute to the literature by adding empirical evidence to all three under-investigated research areas identified above. In order to make this contribution, I combine the implications of the theories underlying the four major research streams mentioned in table 2.1. In the next chapter, I therefore describe the three theories that are relevant to this dissertation, i.e., agency theory, contingency theory, and goal theory. 


\section{chapter 3}

\section{TheOretiCAL PERSPECTIVES ON THE USE AND EFFECTS of PERformance MeAsures and PERFormance TARGETS}

\subsection{Introduction}

In the previous chapter, I provided an overview of the empirical literature on the use and eflects of performance measures and performance targets and identified opportunities for further research. In this chapter, I describe the three theorics relevant for this dissertation, i.e., agency theory, contingency theory, and goal theory, and show, in a general way, how the implications of these theories can be combined to address these research opportunities. In chapter 4,1 ann more specific and develop hypotheses based on these theories.

\subsection{The Use and Effects of Performance Measures}

\section{2 .1 Economic focus}

The cconomics-based empirical papers discussed in the previous chapter use agency theory in developing hypotheses. Therefore, I restrict myself to describing the principal-agent model to analyze the economic focus on incentive systems. 


\section{Principal-agent model'}

The principal-agent model (herealter written as $\mathrm{P} / \Lambda$ model) is an economic model based on expected utility analysis. Expected utility assumes economic rationality and complete, transitive, and smooth preferences (Demski 1994). The P/A model normally assumes a risk-neutral principal and a risk and work averse agent. The basic issue of the P/A problem is to design an optimal contract which trades-off risk sharing and incentives. Risk sharing relates to the allocation of risk with respect to an uncertain outcome, while incentives ensure that the agent will take actions desired by the principal. The theory proposes generally that incentive contracts are written based on jointly observable signals. 2Jointly observable means that both the principal and the agent observe, verily and agree on the signal being used. In its simplest form, a jointly observable outcome $x$ is used as contracting variable. The relationship between the action of the agent $(a)$ and the outcome $(x)$ can be described by $x=x(a, 0)$, in which $O$ is a random variable that reflects the elfect of uneontrollable factors. The agent's compensation $(s)$ is defined as some function of the outcome $x$, i.e., $s=s(x)$. The utility function of the principal is $G(w)$, where $w$ is the wealth of the principal characterized by $x-s(x)$. The utility function of the agent is $H(s(x),(a)=U(s(x))-V(a)$, where $U(s(x))$ is the utility of compensation and $V(a)$ is the disutility of effort to the agent. The question that the P/A model tries to ansiver is: what incentive contract maximizes the utility of the principal subject to the constraints that (1) the agent is paid at least his opportunity cost and (2) he chooses the 'right' action. This can be formally stated as:

$$
\begin{gathered}
\max _{s \mid x \rightarrow a n} \int(f(x-s(x)) f(x \mid a) d x \\
\text { subject to } \int U(s(x)) f(x \mid a) d x-V(a) \geq M \\
a \in \arg _{a} \max \int U(s(x)) f(x \mid a) d x-V(a)
\end{gathered}
$$

The density function $f(\cdot)$ relates to the distribution of $F(\cdot)$, which is the distribution of $x$ given $a{ }^{3}$ The first constraint is called the individual

\footnotetext{
1 The discussion in this section is based on the results from the analytic literature. This literature analyzes 'economic problems' by way of mathematical models in order to explain certain observed practices and/or predict the occurrence of certain practices.

${ }^{2}$ See for an exception, for cxample, Baiman and Rajan (1995).

"Both $F(\cdot)$ and $f(\cdot)$ are twice differentiable and $F_{a}(x \mid a) \leq 0$, for all $x \in X$, $a \in A$, which means

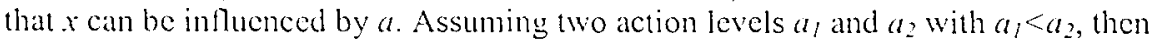
$F\left(x \mid a_{l}\right) \geq F\left(\left(x \mid a_{2}\right)\right.$ for all $x$.
} 
rationality' or 'participation' constraint. It simply states that the expected utility of the agent should be higher than or equal to that what he can get elsewhere. i.c., $M$. 'The second constraint is the 'incentive compatibility' constraint, which implies that the agent will maximize his effort in a way that his marginal revenue (i.e., compensation) equals his marginal cost (i.e., disutility of effort). The second constraint can therefore be restated to:

$$
\int U(s(x)) f_{a}(x, a) d x=V^{\prime}(a)
$$

This is called the lirst-order approach. ${ }^{4}$

The type of incentive contract that is optimal predominantly depends on the amount of information asymmetry. Information asymmetry can exist with respect to the actions of the agent and the 'state of nature', i.e., the uncontrollable factors. In the following, I focus on information asymmetry with respect to the agent's actions.

If the actions of the agent can be jointly observed, then no incentive problem exists and the P/A model breaks down to one of optimal risk sharing. In this case the optimal incentive contract is characterized by

$$
\frac{\left({ }^{\prime}(w)\right.}{U^{\prime}(s(x))}=\lambda .
$$

In other words, the optimal incentive contract pays the agent a fixed wage.

Assume that the principal wants the agent to take action $\hat{a}$. To ensure that the agent takes the desired action, the principal can design a forcing contract, which pays the agent a straight salary if and only if â is observed, i.e.,

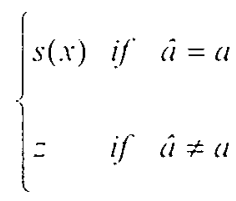

This means that action $a_{2}$ dominates action $a_{3}$ in terms of first-order stochastic dominance. Thus, the high action level leads to a higher probability of a high outcome than the low action level. This is also known as the monotone likelihood ratio condition (MLRC).

${ }^{4}$ The use of the first-order approach is not always valid in analytical modeling. See for a discussion of the validity of this approach, for example, Rogerson (1985). 
in which $=$ is a sulficient penalty. The principal can simply observe what action the agent has taken and reward him if he has aken the correct action and penalize him if he has not. This situation is the first-best situation.

If the principal is unable to observe the actions of the agent or it is too costly to do so, then it is impossible to contract on this information since it is not jointly observable. This is called the 'moral hazard' problem. Moral hazard is a necessary but not a sulficient condition for the existence of a control problem. In general, three other requirements should be met (see c.g., Demski 1994): (1) the agent should be risk averse, (2) the outcome should be affected by uncontrollable factors, and (3) there should be an inherent conflict of interest." Without risk aversion, the agent is able to carry all the risk and internalize the goals of the principal. On the other hand, if the outcome is not affected by uncontrollable lactors, then the agent's actions can be perfectly deduced from the outcome observed, which brings us back to the first-best situation. Finally, if there is no conflict of interest, then there is nothing to control, in terms of making sure that the agent takes the right action. Assuming that all the above requirements are met and there exists a control problem, the optimal incentive contract is characterized by

$$
\frac{G^{\prime}(w)}{U^{\prime}(s(x))}=\lambda+\mu \frac{f_{a}(x \mid a)}{f(x \mid a)}
$$

That is, the optimal incentive contract consists of a fixed component (i) and a variable component, which depends on the outcome $x\left(\mu\left(f_{d}(\cdot) / f(\cdot)\right)\right.$. The higher the outcome $x$, the higher the agent's compensation. Although this contract is optimal, given the circumstances, it is a second-best solution. The contract is not only aflected by the risk-sharing problem, but also by the incentive problem, which leads to the following trade-off: to ensure that the agent provides effort, his compensation depends on the outcome $x$; however, this allocates risk to the agent for which he needs to be compensated because he is risk averse; as a result, the expected compensation cost increases with the unobservability of the agent's actions.

\section{Holmström's informativeness principle and extensions}

Analytical research with respect to the use of performance measures goes back to the article by Holmström (1979), who extends the results introduced by Mirrlees (1974, 1976). Holmström's finding is known as the informativeness principle, and it is intensively used in accounting research. The informativeness

5 The inherent conflict of interest is reflected by the work aversion of the agent, i.e., the personal cost of effort. 
principle states that only those performance measures are valuable that are informative about the agent's actions. This means that the performance measure should be sensitive to the 'level of effort. If the principal can choose from a portiolio of performance measures, $x_{1}, \ldots, x_{n}$, then the performance measures for which the following formal statement applies, should be used for incentive purposes

$$
\begin{aligned}
& \partial f_{a}\left(x_{1}, x_{2}, \ldots, x_{n} \mid a\right) \\
& \partial x_{i} f\left(x_{1}, x_{2}, \ldots, x_{n} \mid a\right)
\end{aligned} \mid 0
$$

in which $x_{i}$ is a performance measure and $f_{u}(\cdot) / f(\cdot)$ is the MLRC. This statement indicates that higher levels of $x$, are associated with higher levels of effort, given all $x \neq x_{i}$. The principal can use performance measure $x_{i}$ to provide the agent with incentives to exert effort. If the above partial derivative is equal to zero, then the performance measure is not informative about the agent's actions and therefore useless for incentive purposes.

Thus, the informativeness principle gives an indication of which performance measures are valuable and which are not. However, knowing the performance measures to be used for incentive purposes does not answer the question of how much weight to put on each measure. Banker and Datar (1989) extend the results of Holmström (1979) and examine the optimal incentive weights. In order to describe their results, I apply the linear $\mathrm{P} / \mathrm{A}$ model (Holmström and Milgrom 1987, 1991). ${ }^{6}$ Assume that the agent is given a linear incentive contract of the following form

$$
s(x)=\alpha+\beta x
$$

where $\alpha$ is a fixed wage, $\beta$ is the incentive weight, and $x$ is the performance measure. Furthermore, the performance measure is characterized by

$$
x=f a+\theta
$$

where $a$ is the action of the agent, $f$ is the marginal impact of the agent's action on the performance measure $x$, and $O$ reflects the impact of uncontrollable factors, with $O \sim N\left(0, \sigma^{2}\right)$. More specifically, Banker and Datar (1989) label $f$

\footnotetext{
"Banker and Datar (1989) do not apply the linear P/A model. However, with respect to the characterization of the incentive weight, the linear $P / A$ model yields results identical to those of Banker and Datar (1989). See appendix $A$ for a description and discussion of the linear P/A framework.
} 
"sensitivity" and $\sigma^{2}$ "noise'? They state that a performance measure is valuable if it is sensitive to the level of effort (cf. Holmstrom 1979) but that the weight will be small if it is noisy. Therefore, Banker and Datar's 'sensitivity' is similar to Holmström's inlormativeness' and, in order to avoid confusion, I restrict myself to using the term 'in formativeness' in the remainder of this dissertation.

Given the assumptions of the model, the incentive weight is characterized by (see appendix $A$ )

$$
\beta=\frac{f^{2}}{f^{2}+r \sigma^{2}}
$$

where $r$ is the agent's coefficient of constant absolute risk aversion (CARA). The effect of the performance measure characteristics, informativeness and noise, on the incentive weight can be examined by computing partial derivatives. These partial derivatives indicate that the incentive weight increases with in formativeness and decreases with noise (see appendix A).

Consistent with most of the analytical research, the above model assumes that the performance measure $x$ is also the outcome relevant for the principal. Feltham and Xie (1994) uscfully extend the analytical literature by examining situations in which the outcome relevant for the principal cannot be contracted upon because, for example, the full consequences of the agent's actions are not observable in the short-term. This relates to the issue of performance measure congruence. To analyze this situation, Feltham and Xie (1994) assume that the agent can take wo actions, $a_{1}$ and $a_{2}$. Further, they assume that the outcome $x$, which is relevant for the principal, cannot be jointly observed and therefore the incentive contract depends on performance measure $y$. The outcome $x$ and performance measure $y$ are characterized by

$$
\begin{aligned}
& x=f_{1} a_{1}+f_{2} a_{2}+O_{x} \\
& y=g_{1} a_{1}+g_{2} a_{2}+O_{y}
\end{aligned}
$$

Performance measure $y$ is congruent if it provides an effort allocation over the two actions that is identical to the effort allocation that would be provided by the outcome $x$. The effort allocations of outcome $x$ and performance measure $y$ are respectively

\footnotetext{
'Assuming that the possible outcomes of $x$ are normally distributed, then 'sensitivity' indicates the extent to which increases in effort increases the mean of the Nomal Distribution, while 'noise' indicates the variance of the Normal Distribution. See appendix A for a graphical representation.
} 


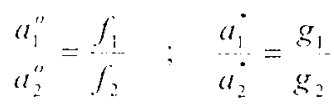

Based on these effort allocations, Felthan and Xie (1994) characterize performance measure congruence by

$$
\delta=\left|f_{1} g_{2}-f_{2} g_{1}\right|^{2}
$$

The higher $\delta$ the more the effort allocation of performance measure $y$ differs from that of outcome $x$ and thus the less congruent the performance measure is. Subsequently, they show that the use of non-congruent performance measures leads to suboptimal effort allocation, which decreases the value to the 'agency'. However, because the incentive weight cannot be written as a function of $\delta$ in their model, it is impossible to examine the effect of congruence on the incentive weight.

In summary, the P/A model analyzes the design of incentive contracts and identifies the factors that are relevant for this design. The results of the $\mathrm{P} / \mathrm{A}$ model indicate that incentive contracts are designed when information asymmetry exists and that informativeness, noise, and congruence are relevant for the design. However, informativeness and noise are the only performance measure characteristics that have a 'predictable' impact on the use of performance measures in the sense that an increase in informativeness (noise) of a performance measure leads to an increase (decrease) in its use. Given the purpose of this dissertation to explain the use of performance measures, I therefore focus on these two performance measure characteristics. Figure 3.1 summarizes the agency theory focus on the use of performance measures.

Figure 3.1

Agency theory focus on the use of performance measures

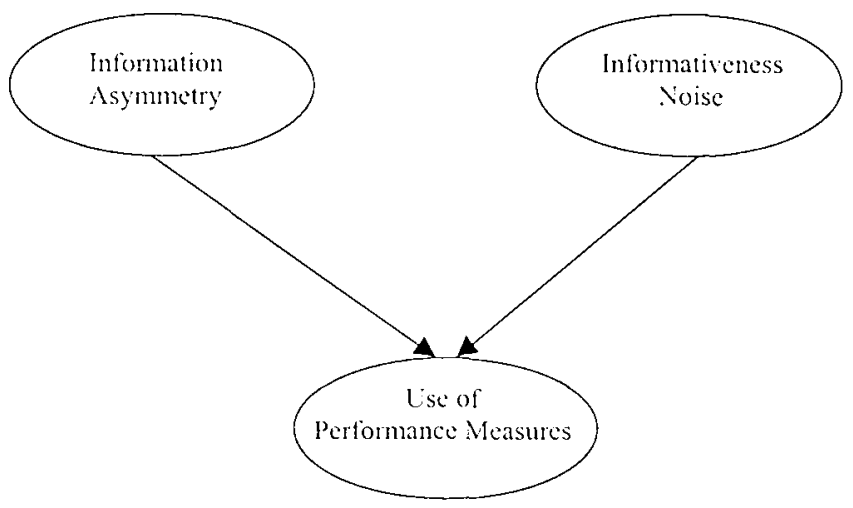




\subsubsection{Beharioral foctus}

Behavioral research in accounting goes back to the fifties and starts with a study by Argyris (1952), who examines the impact of budgets on people. Subsequent behavioral studies on the use and effects of budgets are, for example. Hofstede (1967) and DeCoster and Fertakis (1968). The more recent behavioral focus on incentive systems, represented by the RAPM studies, is based on contingency theory, which stems from the organizational literature. In order to describe this focus, I first discuss the control framework of Ouchi (1979) and then turn to contingency theory.

\section{Ouchi's control fiamework}

Ouchi (1979) describes a simple conceptual framework for the design of control systems. He begins his paper with stating that:

"The problem of organization is the problem of obtaining cooperation among a collection of individuals or units who share only partially. congruent objectives' (p.833).

In other words, there is a lack of goal congruence between subordinates and superiors and control systems need to be implemented to make sure that the organization moves towards its objectives. Two different types of control strategies can be used for this purpose. First, the control system can focus on performance evaluation (outcomes), which emphasizes monitoring, measuring and evaluating 'performance'. Second, the control system can focus on reducing the divergent preferences of the organizational participants, which emphasizes selection, training, and socialization. These two control strategies are interrelated in the sense that divergent preferences can be tolerated by the organization if the performance evaluation system is 'precise', while 'imprecise' performance evaluation systems can be tolerated if preferences almost converge (Ouchi 1979).

The choice between the two control strategies critically depends on the ease with which performance can be measured and evaluated. Ouchi's framework, presented in figure 3.2, suggests the following. Within the strategy of performance evaluation, either behavior can be measured or the outcome of those behaviors, i.e., behavior measurement or output measurement. Behavior measurement can be used if the knowledge of the transformation process is perfect. In this case, tasks can be programmed and behaviors can be explicitly delined, measured, and evaluated. On the other hand, output measurement can

"Ouchi's (1979) framework specifically addresses the conditions that affect the feasibility of different controls and is based on the work of Thompson (1967) on uncertainty. 
be used if the organization is able to measure the outputs of behavior. The use of behavior versus output measurement depends on the information characteristics of the task (Eisenhardt 1985). If the knowledge of the transformation process is imperfect and there exists no ability to measure outputs, then the perfomance cvaluation strategy is not feasible. The organization faced with these circumstances has to rely on socialization processes, labeled 'clan' control, to reduce the divergence of preferences.

Figure 3.2

Ouchi's framework of the determinants of control system design

\begin{tabular}{|c|c|c|c|}
\hline & \multicolumn{2}{|c|}{ Knowledge of the transformation process } \\
\hline & & Perfect & Impertect \\
\hline & High & $\begin{array}{l}\text { Behavior and output } \\
\text { measurement }\end{array}$ & Output measurement \\
\hline & Low & Behavior measurement & 'Clan' control \\
\hline
\end{tabular}

Ouchi (1979) argues that because performance evaluation will never be precise and individuals' goals will never be perfectly congruent, organizations have to find that:

'...balance of socialization and measurement which most efficiently permits a particular organization to achieve cooperation among its members' (p. 846).

As the conceptual framework shows, this most efficient balance is different for organizations with different information characteristics.

\section{Contingency theory}

The observation that a particular control system is more suited for some organizations than for others, is the core issue of contingency theory. Contingency theory stems from the organization literature and more specifically from the studies by Burns and Stalker (1961), Woodward (1965), Lawrence and Lorsch (1967), Thompson (1967), and Perrow (1970). In general, the contingency theory of organization assumes that there is no single organizational structure that is best for all organizations. For example, organizations facing more dynamic and uncertain environments have a need to decentralize responsibilities in order to cope with these circumstances. As a result, the 
contingency theory of organization predicts that environmental conditions affect organizational design.

The application of contingency theory in management accounting is partly due to its predecessor in the organization literature and partly due to conflicting cmpirical evidence (Otley 1980)." The management accounting equivalent of contingency theory simply states that there is no universally appropriate accounting system. More specifically, Otley states that:

'... a contingency theory must identifi specific aspects of an accomting system which are associated with certain defined circumstances and demonstrate an appropriate matching' (1980, p. 413).

lor example, the 'specific aspect' of an accounting system is the use of accounting performance measures, while the 'defined circumstances' is environmental uncertainty. What constitutes an 'appropriate matching', however, is ill defined. This is reflected by a large number of studies that discuss and comment on alternative forms of fil (e.g., Schoonhoven 1981; Drazin and Van de Ven 1985; Venkatraman 1989; Hartmann and Moers 1999). However, Hartmann (1997) claims that the contingency theory of the appropriateness of accounting performance measures is not a theory of 'choice' but a theory of "eflects'. That is, it takes the use of accounting performance measures as given and examines its behavioral effects under different circumstances. $A$ s a result, fit in this literature can be defined as follows: ${ }^{10}$

The effect of the use of accounting performance measures on the incidence of subordinates' functional behavior is higher in situation $X$ than in situation $Y$.

This description of fit reflects the general prediction underlying the RAPM studies, where the situation ' $\mathrm{X}$ ' and ' $Y$ ' is determined by the contingency variable chosen.

The dominant contingency factor used in both the contingency theory of organization and the contingency theory of management accounting is uncertainty (see e.g., Galbraith 1977; Hartmann 2000). Uncertainty is assumed to affect the controllability of accounting performance measures in the sense

"An incentive example of this is the contingency literature on reliance on accounting performance measures (RAPM), which tries to solve the 'conflicting' empirical results of Hopwood (1972) and Otley (1978) (Kren and Liao 1988).

10 This description of fit in the RAPM litcrature is consistent with the literature's excessive use of 'moderated regression analysis' (sce Hartmann and Moers 1999). 
that these performance measures are less controllable the greater the uncertainty. The controllability principle, which is paramount in the RAPM literature (Hartmann 2000), states that managers should only be held responsible for things they can control. If managers are held responsible for things they cannot control, they will experience distress, which leads to decreased 'job satisfaction" and increased 'job related tension'. The reason why managers will experience distress is that uncontrollable performance measures are affected by factors beyond their control, which leads to disagreement with the evaluation criteria being used and perceptions of 'unfaimess'. As a result, the RAPM studies predict that the effect of RAPM on, for example. job-related tension is more positive for higher levels of uncertainty.

In summary, contingency theory, as applied in RAPM studies, focuses on the effects of RAPM and RAPM is treated as an exogenous variable. Finally, the predictions underlying these studies are predominately based on uncertainty and how uncertainty affects the performance measure characteristic controllability. Figure 3.3 summarizes the RAPM contingency focus on the use of performance measures.

\section{Figure 3.3}

RAPM contingency focus on the use of perfomance measures
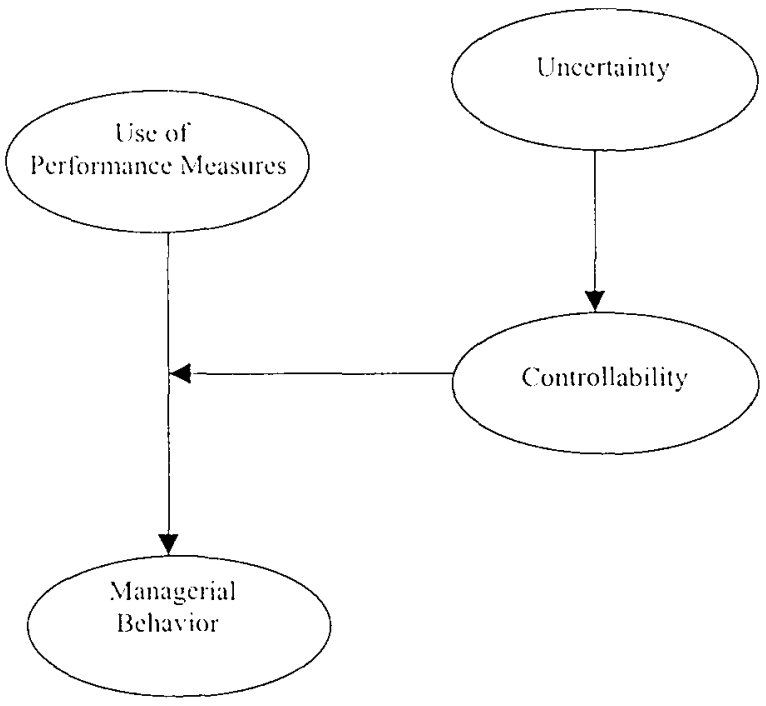

\subsubsection{Explaining the use of performance measures}

The overview of the empirical literature in chapter 2 indicated that there is little evidence of the factors explaining the use of performance measures at the subordinate level. Furthermore, I stated that methodological issues drive this 
lack of attention not theoretical. The original contingency studies in the organization literature are concerned with how environmental conditions affect the design of organizations. In other words, they examine the factors that explain differences between organizations in terms of their design. Similarly, the first contingency studies in accounting are concerned with examining the factors that explain the design of accounting information systems. These studies include both empirical papers (e.g.. Bruns and Waterhouse 1975; Hayes 1977) and theoretical papers (e.g., Gordon and Miller 1976; Waterhouse and Tiessen 1978). 'These studies therefore treat the contingency factors as antecedent' variables, which affect the design of accounting systems. In his critical review of the contingency studies in accounting, Otley (1980) states that what is missing in almost all of these studies is an outcome variable that reflects organizational effectiveness. However, the 'minimum necessary contingency framework' that Otley proposes still contains the basic assumption that the contingency variables affect the design of accounting systems. It is therefore surprising that the RAPM studies treat the 'accounting system' only as an exogenous variable and the contingency variables as 'moderators'. Although treating RAPM as an endogenous variable and the contingency variable as a moderator is consistent with the type of fit previously described, I propose that this type of fit is the result of using moderated regression analysis. That is, rather than letting a theoretically derived type of fit determine the statistical test, the statistical test has determined the type of lit used in the RAPM literature. Most of the RAPM studies have been concerned with, what is called, the "search for the magic moderator' instead of being concerned with having a solid theoretical basis. An implicit assumption underlying the RAPM studies is that:

'...many organizations (or individuals or subunits) that should' use a particular management accounting practice in fact do not do so, but instead use a practice that redaces performance or increases stress, conflict, misrepresentations, etc. ' (Luft and Shields 2000).

Why this 'out-of-equilibrium-type condition' is assumed, is left uncxplained. More importantly, contingency theory, at least implicitly, assumes an 'equilibrium-type condition'. Why has the RAPM literature moved away from this assumption? Why has this literature not applied the basic premise of contingency theory and try to explain the 'conflicting' results of Hopwood (1972) and Otley (1978) with respect to differences in RAPM between both samples?"1 I prefer to be consistent with the theory and examine the factors that

In Hopwood's sample $44 \%$ of the managers was evaluated using 'non-accounting' information, while in Otley's sample only $3 \%$ of the managers was evaluated in this way. 
are related to the use of performance measures under the assumption that most superiors that should' use a particular performance measure in fact do so (cf. luft and Shields 2000). Even if equilibrium is not achieved but there is a 'moveto-equilibrium', this 'move' should be observable. If this equilibrium assumption is incorrect, the study will simply fail to find the predicted results (Luft and Shields 2000).

Given the above explanation for the lack of attention given to explaining the use of performance measures, I think it is useful to return to the basic premise of contingency theory and examine the effect of uncertainty, being the dominant contingency factor. on the design of incentive systems. Since uncerlainty is assumed to affect the characteristics of performance measures, it is further useful to incorporate the implications of agency theory because agency theory can be used to specify the characteristics of performance measures that are relevant for designing incentive systems (L ambert and Larcker 1987). In Part A of chapter 4, I therefore combine the implications of contingency theory and agency theory to develop hypotheses regarding the factors that explain the use of linancial and non-financial performance measures. Figure 3.4 presents the framework for subsequent analysis.

\section{Figure 3.t}

Framework for studying the use of performance masures

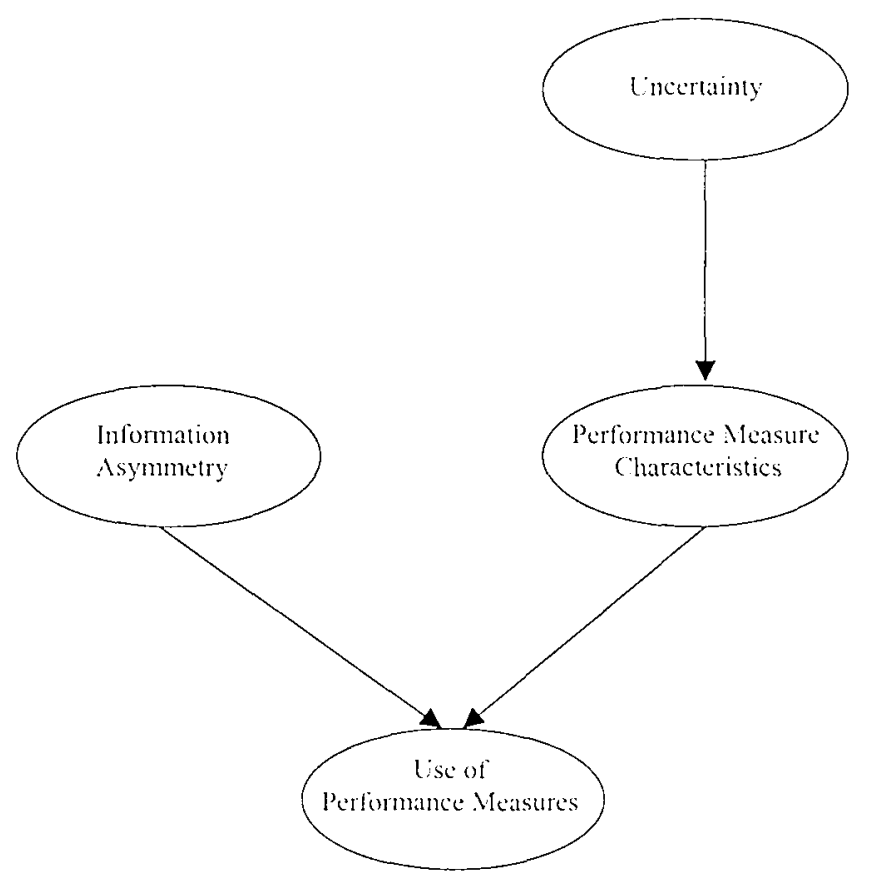




\subsection{The Use and Effects of Performance Targets}

\subsubsection{Economic focus}

It is diflicult to describe the economic focus on performance targets since economists almost always neglect this component of the incentive system (for a similar remark see Merchant el al. (2000)). Traditionally, the outcome of the $\mathrm{P} / \mathrm{A}$ model presents an optimal incentive contraet based on some measure of performance and the agent is told to 'do his best', i.e., maximize the value of that particular performance measure. In other words, performance targets do not play a role in traditional $P / A$ models.

The only economic analysis of performance targets relates to the ratchet principle introduced by Weitzman (1980). The ratchet effect occurs when the performance target in year $t+l$ is adjusted upward when actual performance exceeds targeted performance in year $t$. Therefore, the agent is rewarded for improved performance in year / through higher bonuses, but penalized through more difficult performance targets in year $t+l$. The agent trades-off increased bonuses with higher targets, which results in decisions that lead to less performance variability. However, the ratchet principle does not indicate how targets should be set in the lirst place or when and why ratcheted targets should be used. It only indicates how the agent is expected to react when an unknown target is ratcheted. As a result, the economic focus does not provide any clues with respect to the use and effects of performance targets per se.

\subsubsection{Behavioral focus}

The behavioral focus on performance targets can be analyzed by describing the theory underlying the target difficulty studies, i.e., goal setting theory. ${ }^{12}$ The basic premise of goal setting theory is that goals are immediate regulators of human action. Therefore, goal setting affects behavior and subsequently performance. There are two implications of goal setting theory that are relevant for this dissertation. First, goal setting theory states that there is a linear relationship between goal difficulty and performance. This linear relationship is presented in figure 3.5 and is labeled the goal difficuly function. The goal difficulty function indicates that when goals become more difficult, performance will increase. $A$ large number of experimental studies have consistently shown the presence of this linear function, although the function levels off when goal difficulty is so high that the subjects reach the limits of their ability. ${ }^{13}$

\footnotetext{
${ }^{12}$ For a complete discussion of goal setting theory, 1 refer to Locke and Latham (1990).

13 The goal difficulty function presented in ligure 3.5 therefore portrays a narrow range of goal difficulty. The 'complete' function is non-linear (see e.g., Morchant (1998, p. 388)).
} 
Figure 3.5

Goal difficulty function

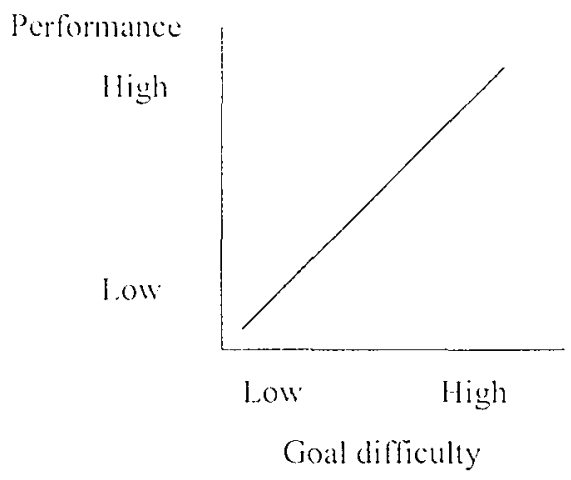

The second implication of goal setting theory is that specilic, hard goals lead to a higher level of performance than vague goals, such as "do your best" or no goals at all. ${ }^{\text {th }}$ This implication of goal setting theory has also convincingly been shown in a large number of experimental studies. The general explanation for the prediction that specific, hard goals lead to higher performance than vague, 'do your best' goals is as follows. The ambiguity underlying 'do your best' goals gives people the opportunity to interpret any level of performance as consistent with doing one's best. People will therefore be more satisfied with a given level of performance, even though they could have performed even better. Specific, hard goals, on the other hand, only provide one single goal that needs to be beaten. People will therefore only be satisficd if they beat that particular hard goal and will strive for attaining that particular goal.

Although goal setting theory states that (more difficult) goals affect performance, the question still remains why this relationship exists. That is. what mechanisms ensure that goals improve performance? Locke and Latham (1990) describe two different mechanisms, i.e., universal task strategies and task specific strategies. The universal task strategies consist of three relatively direct mechanisms, (1) direction of attention, (2) effort, and (3) persistence, which relate to the attributes of motivated action. ${ }^{15}$ First, goals direct attention to those activities for which goals have been assigned. Activities for which no goals have been assigned are interpreted as less relevant and the attention of the individual is therefore focused on goal-relcvant aclivities. Furthermore, more specific goals

\footnotetext{
It No goals can be interpreted as implicit 'do your best' goals.

15 The attributes of motivated action are direction (choice), intensity, and duration (locte and Latham 1090, p. 201).
} 
make it easier for individuals to direct their attention than more general goals. Obviously. performance will improve on dimensions that have the attention of the individual in question. Second, assuming suflicient ability, the more demanded from an individual, the greater the expended effort. Since a more difficult goal demands more from an individual. goal difficulty has a positive effect on the expended effort, which has a positive effect on performance. Third. given goal commitment, individuals will continue to expend effort until the assigned goal is attained. That is, goals lead to a persistence of expended effort over a certain period of time, where more diflicult goals lead to greater persistence and thus higher performance.

(ioal setting also improves performance more indirectly through its effect on task specilic strategies. Two different types of lask specific strategies exist: stored task specilic strategies and new lask specilic strategies. Stored task specilie strategies relate to the skills of an individual and are due to learning and experience with respect to a specific task. New task specific strategies relate to the development of new ways to solve problems not encountered before in order to cope with these problems. Goal setting affects performance in an indirect way in that it leads to the development and/or execution ol task specific strategies.

In summary, goal setting affects performanee through its effect on universal task strategies and task specific strategies. This relationship is graphically displayed in ligure 3.6.

\section{Fisure 3.6}

Mediating mechanisms of goal-performance relationship

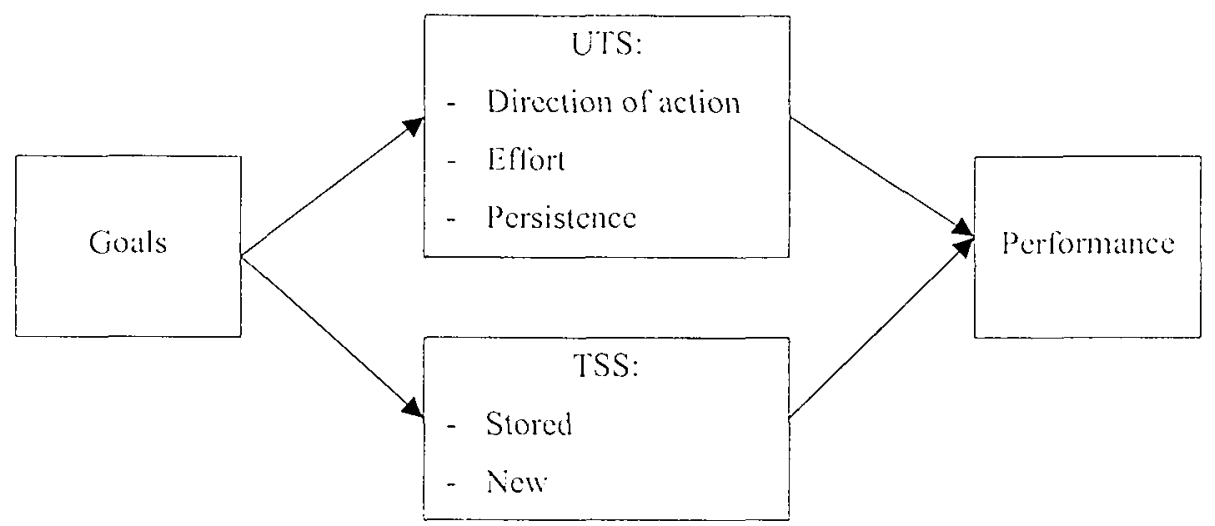

Vites:

* ITS: Lniversal Task Stmategies

ISs: latsk Specitic Strategies 
Finally, since performance targets are goals, the predictions of goal theory with respect to the effects of goals in general apply equally well to the effects of performance targets in incentive systems. That is, performance is higher when pertormance largets are used compared to when they are not used. Further, a more difficult performance target increases performance through its effect on, for example, effort. More generally, goal setting theory predicts that performance targets have significant incentive effects.

\subsubsection{Examining the effects of incentive sistems}

Combining the implications of agency theory and goal theory. with respect to the effects of incentive systems, leads to the following observations. First, agency theory predominantly ignores the use and effects of performance largets in incentive systems. At best it can be stated that it assumes the assignment of "do your best' goals. Goal theory, on the other hand, shows that performance targets have significant incentive effects and that the assignment of specilic, hard goals leads to higher performance than the assignment of "do your best' goals. 'This implies that simply using performance measures for incentive purposes without emphasizing performance targets might not be very efficient. in terms of providing sufficient incentives to promote certain types of behavior.

Second, the effects of performance targets, as predicted by goal theory, are similar the effects of performance measures, as predicted by agency theory. lor example, goal theory states that goals direct attention to goal-relevant activities and increase effort. Similarly, the $\mathrm{P} / \mathrm{A}$ model states that managers direct their attention to those aspects of the job that are being measured and expend more effort on these activities. The question ean then be raised how performance measures and performance targets are related and which component of the incentive system actually alfects behavior.

Finally, although goal theory predicts that more difficult goals improve performance, it decreases the probability of attaining targeted performance. $\Lambda$ pplying this to an incentive situation implies that managers are less likely to receive their 'incentive payment' when targets become more difficult. From an economic perspective, this means that managers have to bear increased risks when performance targets are more difficult, which affects the trade-off between incentives and risk sharing.

Given the above discussion and the literature's emphasis on the incentive effects of performance measures, I think it is useful to combine the implications of agency theory and goal theory to examine the effects of incentive systems, which include performance measures and performance targets. In Part B of chapter 4, I therefore use agency theory and goal theory to develop hypotheses regarding the effects of performance measures and performance targets on managerial behavior. 


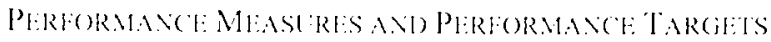




\section{chapter 4}

\section{ThE USE AND EFFECTS OF PERFormanCE MEASURES And PERFormance TARgets: Hypotheses \\ DEVELOPMENT}

\subsection{Introduction}

In the previous chapter, I indicated that it could be fruitful to combine the implications of the economics-based literature and the behavioral-based literature to study the design and effects of incentive systems. In this chapter, I develop hypotheses based on the implications of agency theory, contingency theory, and goal theory. The development of hypotheses is split into two parts. The first part relates to the factors that explain the use of performance measures for incentive purposes, while the second part relates to the incentive effects of performance measures and performance targets. More specifically, as stated in the introductory chapter, I focus on three types of performance measures: (1) financial performance measures, (2) internal non-financial performance measures, and (3) external non-financial performance measures.' In Part A, I develop hypotheses related to the factors that explain the use of these three types of performance measures. In Part B, I develop hypotheses related to the effect of financial and external non-financial performance measures and performance targets on managerial short-term orientation. 


\section{Part A}

\subsection{The Lse of Performance Measures}

\subsubsection{Introduction}

In the following section, I discuss the effect of information asymmetry and performance measure characteristics on the use of the three types of performance measures. Further, I examine how the performance measure characteristics are affected by uncertainty. Following the discussion in chapter 3, there are three reasons for focusing on information asymmetry, perfornance measure characteristics and uncertanty. First. the type of incentives used depends on the level of information asymmetry, where increased information asymmetry increases the need for output measurement, which is the focus of this dissertation. Second. performance measure characteristics, such as controllability, informativeness, and noise, underlic most predictions in incentive studies in accounting. Although the theoretical predictions are based on performance measure characteristics, no structured attempt has been made so far to actually incorporate these characteristics in empirical research. Third, uncertainly is the core concept upon which organizational design frameworks are based (Galbraith 1977). Hartmann (2000) states that uncertainty is the underlying variable of most empirical studies investigating the use and effects of financial performance measures. Furthermore, he states that the effects of unecrtainty are not well-understood (Hartmann 2000, p. 471).

\subsubsection{Hypotheses}

Both the economics-based literature and the behavioral-based literature either explicitly or implicitly state that the performance measure characteristics should explain the use of performance measures and that performance measures should be used when behavior cannot be observed or measured. In this dissertation. I examine the effect of information asymmetry, informativeness. controllability, and measurement accuracy on the use of performance measures. Furthemore, I examine the effect of task uncertainty on informativeness and environmental uncertainty on controllability.

\section{Information as?mmetry (decision-making authority)}

The reason why firms design compensation contracts based on performance measures instead of on managerial actions is because managerial actions cannot be observed, they are too costly to observe, or because superiors cannot interpret what they are observing. This information asymmetry due to the 'unobservability' of managerial actions increases the need for performance measures. Information asymmetry occurs when decision rights are allocated 
downward in the organization, i.e., decision-making authority is decentralized. This increase in decision-making authority creates a need to evaluate the outeomes of the decisions made lower in the organization. Decision-making authority, as a proxy for information asymmetry, will therefore lead to a demand for performance measurement and the use of any feasible performance measures available. Ilowever, increased decision-making authority also increases the demand for more aggregate information (Chenhall and Morris 1986). Providing managers with more decision-making authority implies that managers will take more actions, which results in increases in information asymmetry. Since it is too costly to have performance measures for each type of action (Banker and Datar 1989: Ittner and Larcker 1999), there exists an increased preference for more aggregate performance measures. i.e., performance measures that provide (some) information about an increased 'number' of actions. Financial performance measures are more aggregate than both internal and external nonfinancial performance measures, since the outcomes of all actions finally need to end up in the financial results. This implies that the usefulness of financial performance measures increases, white the usefulness of the non-financial performance measures decreases as decision-making authority increases. As a result, information asymmetry has a differential effect on the use of the three lypes of performance measures. The existence of information asymmetry, due to the allocation of decision rights, has a positive effect on the use of all three lypes of performance measures, while the need for aggregation, due to increased information asymmetry, has a positive effect on the use of financial performance measures and a negative effect on the use of internal and external non-financial performance measures. Because it is unclear a priori whether the information asymmetry aspect' or the 'aggregation aspect' will dominate, no directional hypotheses can be stated with respect to the non-financial performance measures. The above arguments lead to hypotheses $1 \mathrm{a}-1 \mathrm{c}$.

Hla: Decision-making authority (i.e., the resulting information asymmety) increases the ase of financial performance measures.

IIb: Decision-making anthority (i.e., the resulting information asymmetryy is not related to the use of internal non-financial performance measures.

H/C: Decision-making anthority (i.e., the resulting information asimmetry is not related to the use of extemal non-financial performance measures. 


\section{Performance meessure characteristics ${ }^{2}$}

Previous studies have used a number of performance measure characteristics in developing hypotheses. As described in chapter 3, from an economic point of view, the pertormance measure characteristics informativeness and noise have a predictable impact on the use of performance measures. Informativeness is delined as the marginal contribution of the manager's actions to the expected outcome of a performance measure. Noise, on the other hand, is defined as the variance in the outcome of a performance measure due to 'random events'. Obviously, these characteristics have a specific meaning in principal-agent models. However, intuitively informativeness relates to the degree to which manager's decisions have an impact on performance, while noise relates to the degree to which uncontrollable factors have an impact on performance. The greater the informativeness, the more weight is put on the performance measure, while the greater the noise, the less weight is put on the performance measure.

The performance measure characteristic discussed in chapter 3 that is used in behavioral-based research is controllability. The controllability principle states that managers should only be held responsible for things they can control (Merchant 1989). That is, the manager should not be held responsible for the impact of uncontrollable factors on performance. The greater the impact of the uncontrollable factors, the lower the controllability and the less emphasis should be put on that particular performance measure. Although noise is specifically defined in principal-agent models, the intuitive interpretation is identical to that of controllability and both are sometimes even used as synonyms (see e.g., Merchant 1989, p. 87).

In an extensive field study, Merchant (1989) finds that the controllability principle is not strictly applied in practice. He concludes that the most important factor explaining the use of performance measures is the degree of influence the manager has, irrespective of the impact of uncontrollable factors (Merchant 1989, p. 106). That is, if the manager's decisions have an impact on the outcome of the performance measure, then that performance measure will be used for incentive purposes. These results are consistent with the more intuitive interpretation of informativeness described in the principal-agent models. It futher suggests that informativeness and noise/controllability are two separate performance measure characteristics.

Finally, Merchant (1989) identifies a performance measure characteristic that has received almost no attention in the empirical literature, i.e., measurement accuracy. Measurement accuracy consists of two components: verifiability and objectivity. Verifiability means that the measures can be

\footnotetext{
2 This section contains a repetition of a part of chapter 3 for reasons of clarily.
} 
'substantially duplicated by independent measurers using the same measurement methods" (Merchant 1989, p. 26), i.e. the measurement dispersion is small. Objectivity. on the other hand, means that the measurement is free from personal bias" (Merchant 1989, p. 26). Inaccurate performance measures make it more difficult to elicit the manager's performance from the measure and should therefore be used less. Notice that this prediction is identical to that with respect to the impact of uncontrollable factors. However, there is a conceptual difference between accuracy and noise/controllability in the sense that the first is due to the measurement process, while the second is due to factors affecting the outcomes of day-to-day operations.

Although all of the performance measure characteristics described above are different in a strict sense, there are some important similarities. In general, for the purpose of examining the factors that explain the use of performance measures, a distinction can lirst of all be made between (1) the impact that a manager has on performance and (2) the impact that uncontrollable factors have on performance. 'This implies that 'performance' can be characterized by (see chapter 3)

$$
x=f a+\theta
$$

The third and last general performance measure characteristic is the degree to which the performance measure is objective and verifiable, which implies that the performance measure $\left(x^{m}\right)$ measures performance with error (cf. Hemmer 1996a), i.e.,

$$
x^{m}=x+\varepsilon
$$

Therefore, the performance measure can be characterized by

$$
x^{m}=f u+0+\varepsilon
$$

In summary, the previous discussion indicates that there are three general performance measure characteristics, which I label (1) informativeness, (2) controllability, and (3) measurement accuracy."

Following the cconomics-based literature and the behavioral-based literature, I predict that the use of performance measures depends on the performance measures' characteristics. More specilically, informativeness,

'I use the labels 'informativeness' and 'controllability' to make a clear distinction between the performance measure characteristic emphasized in respectively the economics-based literature and behavioral-based litcrature. 
controllability, and measurement accuracy increases the use of the performance measure in question. These predictions are summarized in hypotheses $2 \mathrm{a}-2 \mathrm{c}$.

H2a: the ase of financial performance measures increases with their (i) informativeness, (ii) controllability, and (iii) measwement "aceraract:

112b: the use of internal non-financial performance measures increases with their (i) informativeness, (ii) controllability; and (ii) measurement accuracy:

H2a: the use of external non-financial performance measures increases with their (i) informativeness, (ii) controllability; and (ii) measurement accuracy:

\section{Uncertainn}

Uncertainty is one of the most important variables in organizational design frameworks and it is also the dominant concept in performance cvaluation and compensation research. The litcrature makes a distinction between two types of uncertainty based on its source, i.e., envirommental uncertainty and task uncertainty (e.g., Fisher 1995; Hartmann 2000). Environmental uncertainty is defined as the uncertainty due to factors in the organization's environment, while task uncertainty is defined as the uncertainty due to the complexity and diversity of the task performed. These constructs have predominantly been used in the behavioral-based literature, although related constructs are available in the economics-based literature (Ittner and Larcker 2000). The general assumption made in the literature is that both environmental uncertainty and task uncertainty negatively affect the usefulness of financial performance measures because both types of uncertainty decrease the controllability of these measures. However, there are two problems with this assumption. First of all, empirical rescarch has not always made a distinction between environmental uncertainty and task uncertainty (Hartmann 2000) and it is not at all clear if both types of uncertainty affect the controllability of financial performance measures. Second, an implicit assumption underlying this stream of research is that the two types of uncertainty have no effect or a positive effect on altemative performance measures. Below, I argue that the two types of uncertainty have an effect on different characteristics of financial performance measures and that these effects also partly apply to non-financial performance measures. I lirst discuss the effect of task uncertainty on informativeness and subsequently the effect of environmental uncertainty on controllability.

Task uncertainty is a job characteristic that reflects the complexity and diversity of the task performed. The RAPM literature has assumed that high task 
uncertainty situations are, in part, characterized by an increase in the performance impace of factors beyond the control of the manager, which decreases the usefulness of (accounting) performance measures. However, I propose that this interpretation of task uncertainty is incorrect and mainly due to the literature's inability to clearly distinguish between different types of uncertainty (Hartmann 2000). Increased task uncertainty indicates more uncertainty about the way in which a certain objective should be achieved. This does not mean that 'other factors' have more inlluence on performance, but rather that the actions chosen by managers are crucial to task performance. Locke and latham (1990, p. 260) state that:

'...in more complex tasks, the plans, tactics, and strategies ased by the individual plan a larger role in task performance than ther do in simpler tasks where the mumber of different strategies is more limited and are generally known to all performers.'

Lambert and larcker (1995) make similar arguments in a study examining compensation contracts for senior-level hospital administrators. They state that:

Hospitals with complex service offerings to the patient are inherently more difficult to manage. As a result, the profitability of these hospitals is more sensitive to the amount of effort provided by the hospital administrator' (emphasis added).

Thus, in more complex and diverse tasks, the manager's decisions are of greater importance to task performance. However, the degree to which task uncertainty increases the ability of managers to improve performance, i.e., increase informativeness, depends on what measure of performance is used. If the performance measure is internal oriented and related to the task, the time-span between providing effort and observing performance becomes shorter, which increases the ability of managers to see how their efforts translate into performance. Related to this issue is that the ability of managers to improve performance is increased by the amount of feedback they receive. Feedback information facilitates learning and allows managers to update their strategies, which makes performance more effort-sensitive (Sprinkle 2000). As a result, task uncertainty increases the informativeness of those performance measures

\footnotetext{
"Hirst (1983), for example, measures 'lask uncertainty' by combining scales that reflect both lask uncertainly and environmental uncertanty. Similarly, Brownell (1985) uses the functional area of managers to reflect differences in both task uncertainty and emvironmental uncertainly.
} 
that are internal oriented and for which leedback can be provided on a frequent basis. The conditions of internal orientation and provision of frequent feedback are present in the internal non-linancial performance measures and to a lesser extent also in the financial performance measures, but are absent in the external non-financial performance measures. Therefore, task uncertainty increases the informativeness of both financial and internal non-linancial performance measures, but is not related to the informativeness of external non-financial perlormance measures. These predictions are summarized in hypotheses $3 a-3 c$.

H3a: task ancertainty increases the informativeness of financial performance measures.

H3b: task ancertainty increases the informativeness of internal nonfincuncial performance measures.

H3a: task uncertainty is not retated to the informativeness of external non-financial performance measures.

As already stated above, environmental uncertainty is assumed to decrease the usefulness of financial performance measures because it decreases the controllability of these measures. Environmental uncertainty increases the unpredictable impact of uncontrollable factors on performance, which makes it more difficult to judge ex-post whether good or bad financial performance is due to changing envirommental conditions or due to managerial performance. Although this argument seems to be valid, there is no reason to assume that this relationship only applies to financial performance measures. It is very likely that this relationship also applies to the internal and external non-financial performance measures. For example, unpredictable changes in customers' behavior can have an uncontrollable impact on the degree to which these customers are satisfied with the firm's products and services, which might consequently affect markel share. In a similar vein, technological developments and changes in suppliers' behavior can have an uncontrollable impact on the efficiency and effectiveness of the task performed. As a result, internal and external non-financial performance measures contain the same defects as linancial performance measures in the sense that increased environmental uncertainty decreases the controllability of these performance measures. These predictions are summarized in hypotheses $4 a-4 c$.

114a: environmental ancertainty decreases the controllability of financial performance measures.

114b: environmental uncertainty decreases the controllability of internal non-financial performance measures. 
H4t: environmental uncentainty decreases the controllability of external non-financial performance measures.

\section{Part B}

\subsection{The Effects of Performance Measures and Performance Targets}

\subsubsection{Introduction}

In this palt of chapter 4, I develop hypotheses regarding the effect of (non-)financial performance measures and performance targets on managerial short-term orientation." Managerial short-term orientation is defined in this dissertation as an orientation towards short-term financial results. Consequently. 'short-term incentives' imply incentives to improve short-term financial results, while 'long-term incentives' imply incentives to improve long-term financial results.

The number of lirms using non-financial performance measures for incentive purposes is increasing (Banker et al. 2000). Although there are a number of reasons why firms use non-financial performance measures, the primary reason is that some of them are leading indicators of financial performance (Kaplan and Norton 1992). That is, compensation based on nonfinancial performance measures provides managers with incentives to improve long-term financial performance, i.e., decrease managerial short-term orientation. Financial performance measures, on the other hand, are predominantly 'backward-looking' and lack predictive ability to explain future performance and therefore provide managers with incentives to improve shortterm financial performance, i.e., short-term incentives. However, despite the increased use of non-financial performance measures and the above 'claims', the literature review in chapter 2 shows that there is only little empirical evidence of the effects of these performance measures on managerial short-term orientation.

Chapter 2 further shows that the accounting literature on incentives predominantly focuses on the use and effects of performance measures and neglects another important component of incentive systems, i.e., performance targets. Firms usually set explicit targets for managers and evaluate performance compared to target (Merchant et al. 2000). The type of target used can have a

\footnotetext{
Although managerial short-term orientation is only one aspect of managerial behavior, it dominates the theoretical and empirical accounting literature on incentive systems (e.g.. Govindarajan and Gupta 1985; Lambert and Larcker 1987; leltham and Xic 1994: Hemmer 1996 a; Banker et al. 2000). Therefore, I focus on this iype of behavior
} 
significant impact on perfomance and managerial behavior. For example, Merchant et al. (2000) state that the effect of incentives is likely to be dependent on performance target difficulty. Altematively, more difficult targets increase the risk the managers have to bear and less difficult targets may be the outcome of the trade-off between incentives and risk sharing when managers are risk averse (Merchant and Manzoni 1989). However, the empirical evidence of the use and effects of difficult performance targets in general is limited and no empirical evidence exists with respect to the use and effects of non-financial performance targets.

\subsubsection{Mrpotheses}

One of the primary reasons for incorporating non-financial performance measures is that some of them are leading indicators of financial performance and provide managers with incentives to be long-term oriented (Ittner and Larcker 1998b). In the following, I focus on external non-financial performance measures because empirical research indicates that these measures are leading indicators of linancial performance and should therefore provide managers with long-term incentives (Ittner and Larcker 1998a; Banker et al. 2000)." For example, increasing customer satisfaction requires a manager to focus on providing service, which leads to repeat purchases and thus to improving longterm profitability (Iemmer 1996a). This long-term orientation is relatively absent in the incentives provided by financial performance measures. For example, managers can increase financial performance in the short-term by accelerating sales or by providing sales pressure, which might be detrimental to long-term performance. The limited empirical evidence available is consistent with this argument and shows that the use of financial performance measures for incentive purposes leads managers to shorten their time-horizon (Merchant 1990; Van der Stede 2000). Although managerial short-term orientation is not dysfunctional in every circumstance (see e.g., Merchant and Manzoni 1989, p. 552 ) it is often harmful, and incorporating non-financial performance measures can reduce it. Given the agency theory prediction that managerial effort is determined by the incentives provided, the literature suggests that financial performance measures provide managers with short-term incentives, while

\footnotetext{
"The internal non-financial performance measures are excluded because it is unclear whelber or not these measures are leading indicators. For example, the litcrature suggests that quality initiatives have not led to improved performance (Itner and Larcker 1995). Furthermore, for the purpose of this dissertation, it is sufficient to restrict the attention to the external nonfinancial performance measures. Finally, none of the empirical results presented in chapter 6 are affectad by the inclusion of the intemal non-financial performance measures.
} 
external non-financial performance measures provide managers with long-term incentives, which leads to the following hypotheses.

H5a: The ase of financial performance measures for incentive purposes increases managerial short-term orientation.

H5b: The use of external non-financial performance measures for incentive purposes decreases managerial short-term orientation.

A similar line of reasoning applies to the target difficulty associated with the financial and extemal non-financial performance measures. That is, given the implications of goal theory, more difficult financial (external non-linancial) performance targets increase (decrease) managerial short-term orientation. Once again, it is not clear a priori if this type of behavior increases or decreases longterm performance. For example, difficult financial performance targets might provide managers with incentives to be more efficient (functional) or to defer expenditures with respect to maintenance (dysfunctional) in order to reach their target. On the other hand, Ittner and Larcker (2000) state that non-financial performance measures are likely to be characterized by diminishing returns at higher performance levels. This means that difficult non-financial performance targets provide managers with incentives to provide 'service', but 'too difficult' targets will lead to decreased performance because the associated costs with this increased 'service' will exceed the benefits. Although the effect of target difficulty on performance is unclear, this does not alter the prediction that a more difficult financial (external non-financial) performance target increases (decreases) managerial short-term orientation. Furthermore, under the assumption that firms make optimal decisions regarding the design of incentive systems, no performance effects are expected. As a result, I state the following hypotheses.

Hoa: The difficulty of financial performance targets increases managerial short-term orientation.

Hob: The difficulty of external non-financial performance targets decreases managerial short-term orientation.

All of the studies reviewed in chapter 2 examine performance measures and performance targets in isolation (e.g., Banker ct al. 2000; Merchant and Manzoni 1989). However, it is very likely that firms set targets dependent on the degree to which the performance measures are used for incentive purposes. Simons (1988), for example, finds that targets are more difficult when these are also used for incentive purposes in a so-called budget-based compensation scheme. Other findings in the budgetary control literature provide similar 
results. For example. Merchant (1985), Dunk (1993), and Van der Stede (2000) all find that an increased emphasis on budgets for evaluation purposes decreases budgetary slack. In general, the empirical results indicate that an increased use of a particular performance measure for incentive purposes increases the difficulty of the larget associated with that performance measure. Two explanations can be given for this positive relationship. First, given the rational expectations of superiors, performance targets will be more difficult when linked to rewards in order to offset the incentives given to subordinates to build in slack to maximize their rewards. Second, an increased use of performance measures for incentive purposes increases the likelihood of detecting and curtailing slack (Williamson 1964), which results in more difficult targets. Focusing on the effects of both financial and external non-financial performance measures, the above findings lead to the following hypothesis.

\section{H7: The use of financial (external non-financial) performance measures for incentive purposes increases the difficult! of the financial (external non-financial) performance target.}

Finally, making rewards contingent on performance not only provides managers with incentives but also increases the risk they have to bear. Increasing the difficulty of the performance target further increases this risk because it becomes more difficult to carn a 'bonus'. Agency theory states that the use of performance measures for incentive purposes depends on the trade-off between incentives and risk sharing and is affected by the risk aversion of the agent. Although Moers and Peck (2000) show that risk aversion affects the use of performance measures in CEO incentive contracts, it is unlikely that this prediction holds for managers lower in the organization. Most firms design incentive contracts for their 'lower-level' managers based on characteristics of the firm and the individual's job because it is simply too costly to design incentive contracts based on personal characteristics. Since discretion is given to the superior in setting performance targets for individual managers, it might be more efficient to adjust the performance targets for the level of risk aversion. For example, Merchant and Manzoni (1989, p. 550) state that less difficult targets may be the outcome of the trade-off between incentives and risk sharing when performance measures are used for incentive purposes. If superiors indeed set less difficult performance targets to adjust for the risk imposed on the manager, then risk aversion plays a role in setting performance targets. Similarly, Young (1985) finds that risk averse managers build in more budget slack than non-risk averse managers, probably as a response to uncertainty. Although superiors are likely to be aware of this behavior, they might allow 'some' slack in order to reduce the risk imposed on the manager. This implies 
that although the use of performance measures increases the difficulty of performance targets, this effect will be lower the higher the risk aversion of the manager. The above argumentation leads to hypothesis 8 .

H8: The effect of the use of financial (crternal non-financial) performance measures for incentive purposes on the difficults of the financial rexternal non-financial) performance target is less positive for higher levels of managerial risk aversion.

\subsection{Summary}

The hypotheses developed in Part $A$ and $B$ are summarized, in a general sense, in figure 4.1 . The next chapter describes the research method used to test these hypotheses, while the empirical results are presented in chapter 6 . 


\section{Figure t.l}

Overvicw of relationships subject to cmpirical lesting

EU TU

DEC CON INF ACC

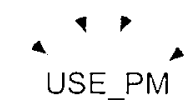

RISK

AVERS.

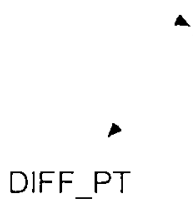

TIME

Vites:

- $\quad \mathrm{I}: !=$ envirommental uncertainty:

Tl) :s task uncertainty:

D)I:C = decision-making authority:

CON = controllability of performance measures;

$\mathrm{INT}=-$ in formativeness of performanec measures:

$\mathrm{ACC}=$ measurement accuracy of performance measures:

USE P PM = use of performance measures:

RISK AVERS. = managerial risk aversion;

DIFP PT = difficuly of performance target:

TIVI: = managerial short-tem orientation. 


\section{chapter 5}

\section{RESEARCH METHOD}

\subsection{Introduction}

To test the hypotheses developed in the previous chapter, I gathered data from multiple sources. The data sources used consist of interviews, questionnaires and proprietary archival data. Survey data are available for 114 Dutch managers employed in 6 firms, while proprietary data are available for 96 Dutch managers employed in 5 firms. This chapter presents details on the sample selection and data collection.

\subsection{Sample}

\subsubsection{Sample of firms.}

This dissertation focuses on the use of performance measures in the evaluation and compensation of managers. That is, rather than explaining why firms use incentive systems, this dissertation addresses which performance measures are used given the firm's trade-off to use an incentive system. As a result, eligible firms must have an incentive system in place, which renders random sampling inappropriate. In order to select the frrms of interest, I used the following procedure. I conlacted Hay Management Consultants (HMC), which is one of the major compensation consultants in the world and as such the market leader in The Netherlands. The majority of the clients of HMC are firms that have implemented or are planning to implement variable compensation 
systems. HMC provided a list of clients that were eligible for this study. which contained the name of the firm, name of the Human Resource Manager, firm address, and celephone number.

I called the IIuman Resource (IIR) Managers of fifty firms to explain the research study and solicit their participation. Participation, at first, meant giving an interview. Out of the fifty firms. fifteen $(30 \%)$ agreed to an interview. Noteworthy is that the majority of the firms (17) that did not agree to participate were firms that were currently implementing a new or 'updated' variable compensation system, which they characterized as 'politically sensitive'. Other reasons for non-participation were time constraints (11), reorganizations (5), and mergers (2).

The interview with the IIR managers served two purposes. First, the interview was used to get a better understanding of the performance evaluation and compensation system in place. It was important to examine if performance evaluation and compensation were an issue and to what extent variable compensation was important. This facilitated a more specilic selection of firms relevant to this study. Second, the interview was used to ask the HR manager to support the research and to be its 'champion' within the firm.

During the interviews, the content of participation was discussed in more depth. I explained that participation implied (1) the selection of respondents, (2) the distribution of questionnaires by intemal mail, (3) the attachment of a letter of endorsement by the HR manager or a higher-level official, (4) administrative support for follow-up procedures, and (5) the provision of a detailed description of the respondent's annual bonus plan. Of the fifteen firms interviewed, six declined further collaboration. The reasons why these firms did not participate were that they did not allow me to go 'into the firm' (4 firms) or that they did not have an annual bonus system (2 firms). Of the nine firms that agreed to participate, three requested a more tailor-made study. To assure uniformity of the research design, I decided to design a separate study for each of these firms and to exclude them from the current study.' As a result, the final sample consists of six firms. Descriptive statistics are provided in table 5.1.

\subsubsection{Sumple of respondents}

After the firms agreed to participate in the study, the HR manager of each firm selected the sample of respondents. The selection of respondents by the HR manager instead of the researcher has two benefits. First, the research is designed to assure anonymity. Although anonymity can be assured even if the researcher makes the selection, the respondents might not perceive this to be

1 The three studies are a (1) field study, (2) archival study, and (3) questionnaire study complemented with archival data. To date these studies are still in progress. 
true. This can result in either biased responses or no responses at all. Second, the HR managers are able to make a random selection of respondents that are eligible to participate. This random selection is difficult, if not impossible, to achieve by the rescarcher because of data restrictions.

In making the selection, the HR managers were given four criteria on which they should base their selection. First, the respondents should have managerial responsibilities, either as head of a functional department or as head of a division, business unit or something similar. To assure a minimum level of managerial responsibilities, the respondent's job design should have a 'score' greater than 400 Hay-points. ${ }^{2}$ Second, the respondent should have an amnual bonus plan. Third, the respondent should have experienced at least one annual performance evaluation cycle. Finally, to control for cultural differences, the respondents should be native Dutch.

The IIR managers were asked to select as many respondents as possible within the above four constraints. The selection by the HR managers resulted in 202 managers that were asked to participate in the study. The number of managers per organization ranged from 10 to 75 .

Table 5.1

Descriptive statistics of participating froms

\begin{tabular}{llrr}
\hline Firm & Activity & Sales $(x$ fl. 000$)$ & \# of employees \\
\hline A & Provision of financial services & Not available & $1,690)$ \\
B & Trade of machincry and provision of & $6,109,248$ & 12,207 \\
& technical services & & \\
C & Provision of life and indemnity insurance & $2,577,777$ & 1,275 \\
D & Trade of pharmacentical products & 433,128 & 401 \\
E & Production of food products & $6,663,161$ & 7.482 \\
F & Financial leasing & Not available & 354 \\
\hline
\end{tabular}

\subsection{Questionnaire Design}

\subsubsection{Tianslation, pre-test, and final format}

The language used in the questionnaire was Dutch. The reason for choosing the Dutch language was first of all that not all managers were familiar enough with the English language to design an English questionnaire. Second, to elicit a response from the managers, the study was presented to the individual

\footnotetext{
2 The Hay-points are based on the Hay Guide Chart Profile Method, a system that compares the value of jobs based on multiple factors such as accountability and know-how (Flannery et al. 1996, p. 20). A score greater than 400 relates to higher-level personnel.
} 
managers as a 'Dutch study'. The choice of the Dutch language meant that some of the measurement instruments that have previously been used in Anglo-Saxon research had to be translated. I lartmann (1997) uses some of these measurement instruments in a Dutch study. For the translation procedure for these variables, I refer to his study. For the remaining variables, I used the following procedure to assure a correct translation. First of all, I translated the remaining AngloSaxon instruments into Dutch and designed the first draft of the questionnaire. This draft was presented to one of my supervisors who possesses fluency in Dutch and English and is very familiar with the area of rescarch. Ile judged the translated instruments and provided a back translation for questions that were not stated in a clear way. This back translation was compared to the original instruments and minor adjustments were made.

After linalizing the translation of some of the Anglo-Saxon measurement instruments, a second full draft was designed and presented to seven Dutch accounting colleagues. All seven colleagues were asked to comment on the draft with respect to layout, wording, understandability, and content validity of the instruments developed for this study. 'This resulted in a minor revision of the layout and wording and a third draft was prepared. As a final test, this third draft was pre-tested with all six HR managers of the participating firms. All six HR managers were theoretically eligible to fill in the questionnaire and therefore representative of the sample. The HR managers were asked to comment on the content, layout, and understandability of the questionnaire. In a follow-up telephone call, I discussed the questionnaire with the HR managers and explained the constructs. This pre-test led to only minor changes in wording. Finally, I asked the estimated time to complete the questionnaire. All six HR managers agreed that it was possible to fill out the questionnaire in approximately 30 minutes.

After all the necessary adjustments were made, the final version of the questionnaire was designed and printed. To maximize the response rate, I designed the final questionnaire according to the guidelines of Dillman's (1978) Total Design Method. ${ }^{4}$ The guidelines of the Total Design Method had implications for the format and layout of the questionnaire and the complete package that was send to the respondents. Attached to each questionnaire was a cover letter printed on university stationary with a handwritten signature. The cover letter explained the research project and requested the participation of the respondent. It further guaranteed anonymity of the responses and that no individual responses would be disclosed to any third party, which included

\footnotetext{
The translated variables taken from Hartmann (1997) are envirommental uncertainty, task uncertainty, and larget difficulty.

the procedure used in this dissertation is similar to that used by fartmann (1997).
} 
members within their own organization. The letter ended with thanking the respondents in advance for their participation in this study.

The final questionnaire was a twenty-page booklet in A4 format digitally printed on high quality paper. The cover page of the booklet contained the name of the research project 'Beoordelen en Belonen' (in English: Performance Evaluation and Compensation) and the name of the university. The first two pages of the questionnaire explained the purpose of the study, provided instructions for filling out the questionnaire, and stated that filling out would lake approximately 30 minutes. It further contained my full name, address, email, and telephone number. The final page of the questionnaire was a blank page that could be used by the respondents to express their opinion about the questionnaire.

Finally, the package contained a self-addressed prepaid answering envelope and a self-addressed pre-stamped postcard. The postcard gave the respondents the opportunity to indicate that they filled out the questionnaire and wished to receive a summary of the research results.

\subsubsection{Distribution and follow-up)}

The complete package containing the cover letter, questionnaire, envelope, and postcard was delivered in person to the HR managers of all participating firms. Each package contained a unique code for each respondent, which was also printed on the final page of the questionnaire. The HR managers were given a codebook, which contained the codes of the questionnaires delivered. The HR managers were asked to write down the name and internal address of each respondent on the envelope and behind the corresponding code in the codebook. This coding procedure served two purposes. First, it allowed the questionnaires to be traced without violating the anonymity of the respondents. Second, any archival data that were individual-specific could be linked with the questionnaire data by using the codes instead of the names of the respondents, which would once again not violate the anonymity principle. The HR managers were finally asked to attach their letter of endorsement to each package and send the packages to the respondents by internal mail.

I contacted the HR managers by telephone to ask if and when they had send the packages to the respondents. A package of follow-up postcards was given to each HR manager approximately two weeks after the distribution of the questionnaire. The postcard thanked those who filled out the questionnaire and requested once again the participation of those who did not. All posteards contained a handwritten signature. As with the questionnaires, the postcards were send by the HR managers to the respondents by internal mail. I checked the mailing of the postcard by a follow-up telephone call to make sure that all cards were sent. 


\subsubsection{Response rate}

Of the 202 questionnaires that were distributed, 114 were returned directly to me. This corresponds to an overall response rate of $56 \%$. This response rate is satisfactory and comparable to the response rates reported in previous accounting studies. The response rates for the individual firms ranged from 33 $100 \%$. More details on the response rates are provided in table 5.2.

Of the 114 questionnaires returned, nine have missing data. Because the presence of missing data can be an indication of inappropriateness of the questionnaire for the respondent in question, I delete the nine questionnaires with missing data listwise (Oppenheim 1992). The number of usable questionnaires is therefore 105.

Table 5.2

Sample, respondents, and response rate per firm

\begin{tabular}{lrrr}
\hline Firm & Sample & $N$ & Response rate \\
\hline A & 10 & 10 & $100 \%$ \\
B & 49 & 31 & $63 \%$ \\
C & 25 & 14 & $56 \%$ \\
D & 75 & 36 & $48 \%$ \\
E & 15 & 5 & $33 \%$ \\
F & 28 & 18 & $64 \%$ \\
\hline Total & 202 & 114 & $56 \%$ \\
\hline
\end{tabular}

\subsection{Proprietary Archival Data}

Five firms provided archival data with respect to the annual bonus contract of the respondents, which were used to validate the survey-based measures of performance measure use. Four firms have uniform contracts for their managers with respect to the relative use of financial versus non-financial performance measures, although the number of performance measures in each category can vary between managers. ${ }^{5}$ However, I have no data with respect to the number of performance measures for each of the respondents in these four

5 Increasing the number of performance measures can dilute incentives. Assume the following: $50 \%$ of the bonus of both manager $X$ and manager $Y$ depends on financial performance, while $50 \%$ depends on non-financial performance. Further assume that manager $X$ is evaluated based on one financial performance measure and one non-financial performance measure, while manager $Y$ is evaluated based on one financial performance measure and five non-financial performance measures. Although the explicit relative use of financial performance measures is identical between both managers, the implicit relative use of financial performance measures will be higher for manager $Y$. 
firms. One firm has manager-specific contracts, which were provided to me." As a result, archival data are available for 96 managers in five firms (firm A-E). After listwise deletion of the nine questionnaires with missing data, survey and proprietary data are available for 87 managers.

\subsection{Measurement Instruments}

\subsubsection{Introductory remark}

The measurement instruments used in the questionnaire are taken either from previous accounting studies or are newly developed. More specifically, the instruments used to measure task uncertainty, environmental uncertainty, decision-making authority, performance target difficulty, risk aversion, and short-term orientation are taken from previous accounting studies, while the instruments used to measure the performance measure characteristics and performance measure use are newly developed. ${ }^{7}$ All instruments, except for the performance measure characteristics, are described in appendix $B{ }^{8}$

Since the data are obtained through questionnaires, all measures are perceptual measures. That is, each measure reflects the individual respondent's perception of the variable in question. As a result, the responses are individualspecific, not firm-specific. Although, I do not specifically label each variable, for example, perceived task uncertainty or perceived environmental uncertainty, it should be kept in mind that all variables are in fact perceptions.

\subsubsection{Task uncertainty:}

The instrument to measure task uncertainty is taken from Hartmann (1997). This instrument, developed by Withey et al. (1983), contains nine statements with respect to the analyzability (complexity) and variability (diversity) of the respondent's tasks. A five-point fully anchored scale is used to indicate the level of agreement with each of these nine statements. Confirmatory factor analysis indicates that all nine items load significantly on the latent variable, although three items have relatively low factor loadings. A principal component analysis with oblique rotation reveals an indication of multi-

\footnotetext{
"The archival data can be linked to the questionnaire data through codes. Each questionnaire contains a unique code that is printed on the final page of the questionnaire. The HR manager of each firm provides the archival data mentioning the codes instead of the respondent's name, which does not violate the anonymity principle.

' I use confirmatory factor analysis for the measures used in previous research and principal component analysis ('exploratory factor analysis') for the newly developed measures.

"The instrument used to measure the performance measure characteristics is described in section 5.5.5.
} 
dimensionality. However, the factors identilied do not comespond to the dimensions of analyzability and variability that are sometimes seen as important independent factors (see e.g.. Brownell and Hirst 1986). Since the principal component analysis does not reveal clear independent factors and all items load significantly on the latent variable, I compute task uncertainty by summing and averaging the standardized scores of the nine items."

\section{5 .3 Envirommental ancertaint!}

I construct the environmental uncertainty variable by taking the instrument used by Hartmann (1997). This instrument is derived from the scales used by Govindarajan (1984) and Merchant (1990) and consists of live attributes with respect to the respondent's work environment. The tive attributes relate to the behavior of (1) customers, (2) competitors, and (3) suppliers, as well as (4) technological developments and (5) political and/or legal changes. Ten items are used to indicate to what extent each of these five attributes are predictable and have an impact on the work and performance of the respondents. $\Lambda$ six-point fully anchored scale is used, which consists of a five-point scale to indicate the extent of predictability and impact and an additional option that can be used to indicate that the specific factor is not part of the respondent's environment.

Similar to the way in which Khandwalla (1972) and Libby and Waterhouse (1996) measure competition, I compute the environmental uncertainty variable by multiplying, for each attribute, the ratings on impact by predictability and taking the square root of the product. "Confimatory factor analysis indicates that all but one product term load significantly on the latent variable. The attribute 'political and/or legal changes' does not load on the above construct and is therefore deleted from the measurement instrument. As a result, I measure environmental uncertainty by summing and averaging the standardized scores of the remaining four attributes.

\subsubsection{Decision-making anthority}

I measure decision-making authority by taking the scale used by Gordon and Narayanan (1984). The instruments asks the respondents to indicate the extent to which they have decision-making authority with respect to (1) development of new products and services, (2) hiring and firing of personnel, (3)

\footnotetext{
"In computing all constructs with multiple items, I use unit-weighted average standardized scores because these have preferred psychometric properties relative to regression estimates of factor scores (Grice and Harris 1998).

${ }^{10}$ The scores for impact and predictability are such that higher scores for impact mean higher impact, while higher scores for predictability mean lower predictability. The logic underlying the multiplication is that given the impact of the attributes, increased unpredictability makes it more difficult to control for this impact, which increases uncertainty.
} 
selection of large investments, (4) budget allocations, and (5) pricing decisions. A five-point fully anchored scale is used to indicate the level of authority. Confirmatory factor analysis shows that all five items load significantly on the latent variable decision-making authority. I compute the decision-making authority construct by summing and averaging the standardized scores of the five items.

\subsubsection{Performance measure characteristics}

To date no attempt has been made to measure the characteristics of performance measures. In order to measure the performance measure characteristics, I therefore develop new constructs. The survey questionnaire contains, for each type of performance measure, 15 statements concerning the performance measure characteristics. A five-point fully anchored scale is used to indicate the level of agreement with these statements. The 15 statements are based on the literature with respect to the controllability principle (e.g., Merchant 1989) and the principal-agent model. The statements relate to the extent to which each type of performance measure is influenced by (1) the manager's actions and (2) hactors outside the control of the manager, as well as the extent to which the measure is objective and verifiable and they are designed to measure the constructs informativeness, controllability, and measurement accuracy. Table 5.3 lists all 15 items. A priori it is expected that items $a$.-c. will measure controllability, $f .-k$. informativeness, and $l .-o$. measurement accuracy.

Principal component analysis with oblique rotation reveals four factors with eigenvalues greater than 1, explaining $59 \%$ of the total variance. Table 5.3 shows how each of the 15 items load on the four factors. The results indicate that there are three 'independent' constructs, i.e., factor 1-3, while factor 4 seems to be a mixture of factor 1 and 3 . Examining the items loading on factors 1-3 reveals that the items loading on factor 1 relate to the impact the manager has on performance, while the items loading on factor 2 and 3 relate to respectively the objectivity and verifiability of the measure and the impact of uncontrollable factors. In general, the principal component analysis seems to be consistent with the expectation that the 15 items contain the constructs informativeness (factor 1), controllability (factor 3), and measurement accuracy (factor 2). The only item that does not load on one of the first three factors is item $g$.

I measure the constructs informativeness, controllability, and measurement accuracy by summing and averaging, for each type of performance measure separately, the standardized scores of the items that relate to respectively factor 1 , factor 3 , and factor 2 . 


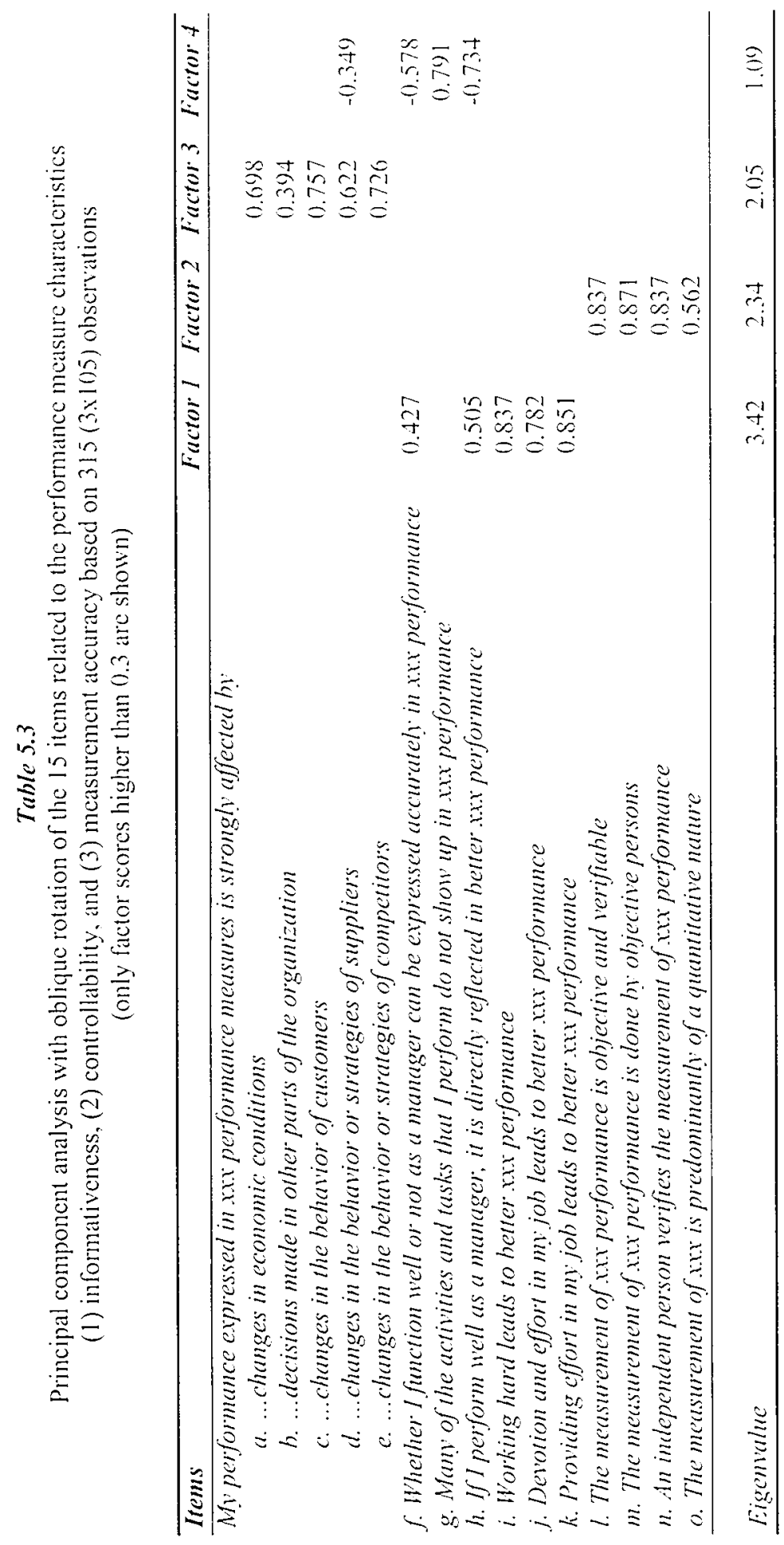




\subsubsection{Performance measure use}

The extent to which each type of performance measure is used for incentive purposes is measured using eight items. These items relate to the use of the performance measures for (1) evaluation purposes, (2) monetary compensation, and (3) non-monetary rewards. A five-point fully anchored scale is used to indicate the importance of each type of performance measure for performance evaluation and compensation purposes. Principal component analysis reveals one factor with an eigenvalue greater than 1, cxplaining $58 \%$ of the total variance. I compute the construct performance measure use by summing and averaging the standardized scores of the eight items for each type of performance measure.

To test whether these survey-based constructs of performance measure use are consistent with the relative reliance on financial performance measures (\%l:PM) stated in the annual bonus contract, I split the sample into two groups of approximately equal size based on the median reported \%PPM. For each subsample, I compare the use of financial performance measures with the use of the two non-linancial performance measures using a paired-sample t-test.

\section{Table 5.4}

Paired sample t-lest with respect to differences between the use of financial and non-financial performance measures $(n=87)$

\begin{tabular}{|c|c|c|c|c|}
\hline \multirow[b]{3}{*}{ Performance measure } & \multicolumn{4}{|c|}{$\begin{array}{c}\text { Relative reliance on financial performance measures } \\
\text { in anmal bomas connact }\end{array}$} \\
\hline & \multicolumn{2}{|c|}{ l.ow } & \multicolumn{2}{|c|}{ lligh } \\
\hline & Mean use & Difference & Mean use & Difference \\
\hline \multirow{2}{*}{ Financial } & -0.375 & & 0.388 & \\
\hline & & $-0.463^{* * *}$ & & $0.688^{* * *}$ \\
\hline Internal non-financial & 0.088 & & -0.300 & \\
\hline \multirow[t]{2}{*}{ Financial } & -0.375 & & 0.388 & \\
\hline & & $-0.331^{* * *}$ & & $0.565^{* * *}$ \\
\hline Extomal non-financial & -0.044 & & -0.177 & \\
\hline \multirow[t]{2}{*}{ Internal non-financial } & 0.098 & & -0.300 & \\
\hline & & 0.132 & & -0.123 \\
\hline Extcmal non-financial & -0.044 & & -0.177 & \\
\hline
\end{tabular}

Notes:

$\cdots, \cdot$ is significant at respectively the $1 \%, 2 \frac{1}{2} \%, 5 \%$, and $10 \%$ level (one-tailed).

The results, shown in table 5.4, indicate that for the 'low-\%FPM' subsample the use of financial performance measures is indeed significantly lower than the use of the non-financial performance measures (one-tail $p<0.01$ ). For the 'high- $\% \mathrm{FPM}$ ' sub-sample the use of financial performance measures is 
significantly higher than the use of the non-linancial performance measures (one-tail $p<0.01$ ). Further. for both sub-simples there is no significant difference between the use of the two non-financial performance measures. These results provide some evidence that the survey-based measures are consistent with the weights stated in the annual bonus contract.

In section 5.4. I stated that four firms have uniform annual bonus contracts with respect to the relative use of linancial versus non-linancial performance measures, although the number of performance measures in each category can vary between managers. To test whether respondents within each firm report tirm-specific incentives, i.c., corporate policy, rather than managerspecitic incentives. I examine the distribution of responses for each of these four firms. The results show that, although the mean response is consistent with corporate policy, there is no clustering of responses and there is significant variation in responses within each firm. These results suggest that the firms in question create manager-specific incentives and that the respondents report these manager-specific incentives.

\subsubsection{Performance target difficulty}

The instrument to measure the construct performance target difficulty is based on Kenis (1979) and contains five items. A live-point fully anchored scale is used to indicate, for each lype of performance measure, the extent to which the performance targets are difficult to achieve and require a high amount of effort. Confirmatory factor analysis shows that all five items load significantly on the latent variable. I compute the construct performance target difliculty by summing and averaging the standardized scores of the five items for each type of performance measure. In a related study, I find that the correlation between this survey-based measure and archival data on the actual achievement of targets is significantly negative (one-tail $p<0.05$ ), which indicates that the instrument measures what it is supposed to measure.

\subsubsection{Managerial risk aversion}

Comparable to Young (1985), I measure risk aversion by giving the respondent the option to choose between two alternative compensation contracts: (1) a fixed salary of 100,000 or (2) a lixed salary of 80,000 with a probability of receiving a bonus of 40,000 . I ask the respondents to indicate how large the probability of receiving the bonus should be before they prefer alternative two to alternative one. The probability reflects the manager's risk aversion, where a higher probability means higher managerial risk aversion. 


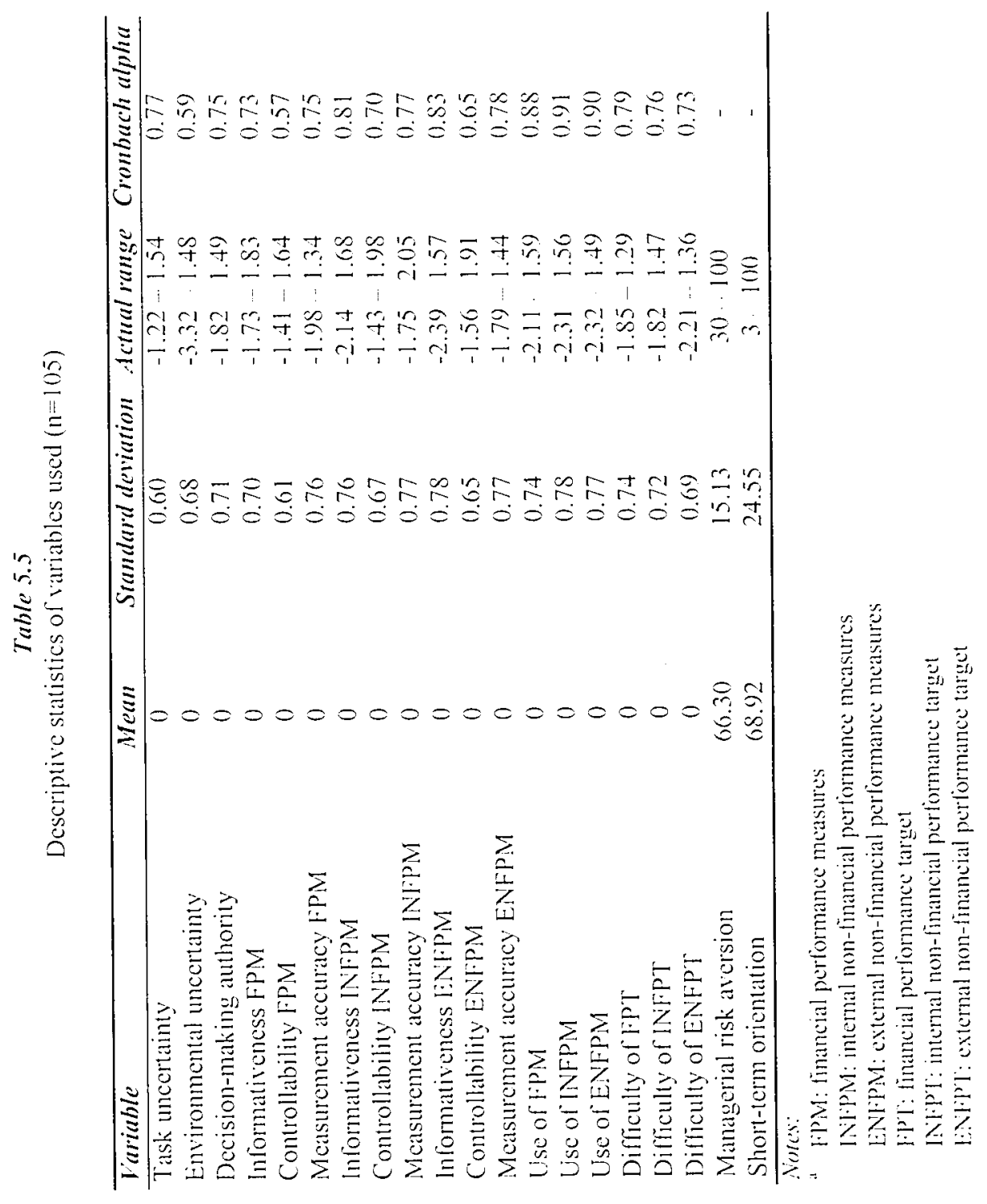




\subsubsection{Managerial short-term orientation!}

The degree to which managers are short-term oriented is measured with the time-orientation instrument used by Merchant (1990) and more recently by Van der Stede (2000). The instrument asks respondents to indicate the percentage of their time that is devoted 10 activities of which the outcome will show up in the linancial results within (1) one month or less, (2) one month 10 one quarter. (3) one quarter to one year, and (4) one year to live years. Managerial short-term orientation is computed by summing the percentages of the first three categories, i.e., effects within one year.

Descriptive statistics for all variables are presented in table 5.5 .

\subsection{Test for Non-response Bias}

Because the response rate is not $100 \%$, though satisfactory, I conduct a test for non-response bias. In general, two possibilities exist for testing for nonresponse bias. The first possibility is to obtain additional information about nonrespondents. The benelit of this procedure is that you are actually examining non-respondents. There exist, however, two problems with this procedure. First, there is no theory available that states what type of information is relevant for testing for non-response bias. This means that the choice of the additional information is purely ad-hoc. Second, gathering the additional information is time-consuming and might break the promise of anonymity (Brownell 1995).

A second possibility is to compare the means of each of the variables of interest to the study for early and late respondents. The assumption underlying this test is that non-respondents are likely to be more similar to late respondents than to early respondents (Brownell 1995). If no significant differences are found between early and late respondents with respect to the variables of interest, then this suggests that there is no bias from non-response. The problem with this test is obviously the extent to which the above assumption actually holds. However, the benefit of using this test is that the variables of interest are compared instead of variables that are chosen on an ad hoc basis. For these reasons, I use the second option to test for non-response bias.

I split the sample at the firm-specific median response time and calculate a t-test for differences in means for each of the variables of interest to this study. The results, shown in table 5.6, indicate that there are no significant differences between early and late respondents for any of the variables, which suggests the absence of non-response bias. 
Tuble 5.6

Analysis of bias from non-response

\begin{tabular}{|c|c|c|c|c|}
\hline \multirow[b]{2}{*}{ Variables } & \multicolumn{2}{|c|}{ Mean score? } & \multirow[b]{2}{*}{ t-value } & \multirow[b]{2}{*}{$p$-value } \\
\hline & Early responders & Late responders & & \\
\hline Task uncertainty & 0.012 & -0.092 & 0.826 & 0.411 \\
\hline Enviromental uncertainty & 0.005 & 0.035 & -0.232 & 0.817 \\
\hline Decision-making authority & 0.104 & -0.023 & 0.850 & 0.397 \\
\hline Informativeness FPM & -0.000 & -0.083 & 0.550 & 0.584 \\
\hline Controllability FPM & 0.032 & $-(0.015$ & 0.368 & 0.714 \\
\hline Measurement accuracy $\mathrm{PPM}$ & 0.011 & -0.027 & 0.224 & 0.823 \\
\hline Infomativeness INFPM & 0.036 & -0.209 & 1.531 & 0.129 \\
\hline Controllability INFPM & 0.028 & -0.047 & 0.538 & 0.592 \\
\hline Measurement accuracy INFPM & 0.030 & -0.123 & 0.888 & 0.377 \\
\hline Informativeness ENFPM & -0.068 & -0.151 & 0.493 & 0.623 \\
\hline Controllability ENFPM & -0.049 & 0.048 & -0.668 & 0.506 \\
\hline Measurement accuracy ENFPM & 0.018 & -0.090 & 0.019 & 0.538 \\
\hline Use of FPM & 0.056 & -0.031 & 0.567 & 0.572 \\
\hline Use of INFPM & -0.058 & -0.071 & 0.081 & 0.936 \\
\hline Usc of ENFPM & -0.006 & -0.114 & 0.036 & 0.520 \\
\hline Dilficulty of FPT & 0.030 & -0.017 & 0.296 & 0.768 \\
\hline Difficully of INFPT & -0.075 & -0.030 & $-(0.287$ & 0.775 \\
\hline Difficulty of ENFPT & -0.056 & -0.031 & -0.168 & 0.867 \\
\hline Managerial risk aversion & 65.90 & 65.97 & -0.021 & 0.984 \\
\hline Short-term oricntation & 70.12 & 69.62 & 0.095 & 0.924 \\
\hline
\end{tabular}




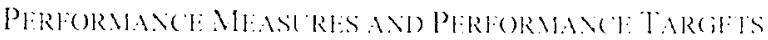




\section{chapter 6}

\section{ThE USE AND EFFECTS OF PERFormance MEASURES AND PERFORMANCE TARGETS: EMPIRICAL RESULTS}

\subsection{Introduction}

In this chapter, I test the hypotheses developed in chapter 4 using the data described in chapter 5 . The empirical analysis is split into two parts consistent with the way in which I developed the hypotheses in chapter 4 . In section 6.2 , I report the empirical results of Part $\Lambda$, which relate to the use of performance measures. In section 6.3, I report the empirical results of Part $B$, which relate to the effects of performance measures and performance targets.

\section{Part A}

\subsection{The Lse of Performance Measures}

\subsubsection{Hypotheses}

The hypotheses that are tested in Part A are hypotheses 1 through 4 . For completeness, I restate these hypotheses below.

Hla: decision-making authority (i.e., the resulting information asymmetry) increases the use of financial performance measures.

$H / b$ : decision-making anthority ti.e., the resulting information asymmetry) is not related to the use of internal non-financial performance measures. 
Hla: decision-making authority (i.e.. the resulting information astrmmetry) is not related to the use of external non-financial performance measures.

1/2a: the use of financial performance measures increases with their (i) informativeness, (ii) controllability. and (iii) measurement accuracy.

H2b: the use of internal non-financial performance measures increases with their (i) informaniveness, (ii) controllubilit!? and (iii) measurement aceuracy.

H2a: the use of external non-financial performance measures increases with their (i) informativeness, (ii) controllabilit!? and (iii) measurement acearacy.

H3a: ask uncertainty increases the informativeness of financial performance measures.

H3b: task uncertainty increases the informativeness of internal nonfinancial performance measures.

H3c: task uncertaint? is not related to the informativeness of external non-financial performance measures.

H4a: environmental uncertainty decreases the controllability of financial performance measures.

H4b: environmental ancertainty decreases the controllability of internal non-financial performance measures.

H4c: environmental uncertainty decreases the controllability of external non-financial performance measures.

\subsubsection{Empirical results}

The hypotheses stated in the previous section are tested by estimating the empirical model presented in figure 6.1 using $A$ mos 4.0. ${ }^{1}$ Because of sample size limitations, I estimate the empirical model for each type of performance measure separately. Furthermore, I treat all variables in the model as observed variables rather than latent variables. The significance levels reported in this chapter are based on bootstrapping (Noreen 1989; Mooney and Duval 1993). I use bootstrapping to avoid the potential problem of non-normality of the data, which renders significance tests invalid. In contrast to 'regular' standard errors, the approximate standard errors generated by bootstrapping do not rely on the

\footnotetext{
${ }^{1}$ Amos is short for Analysis of Moment Structures. Amos uses the general approach to data analysis known as stmomral equation modeling (Arbuckle and Wothke 1999).
} 
assumptions of multivariate nomality or whether the correct model is employed, which leads to more robust results. The applied bootstrapping method replicates the original model a given number of times (in this case 500) using random samples of the original data (with replacement). The sample size of all random samples is equal to the original sample size, i.e., $n=105$.

Figure 6.1

Empirical molel

EU
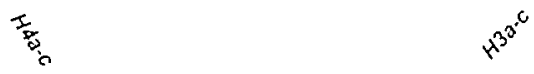

DEC

CON

INF

ACC

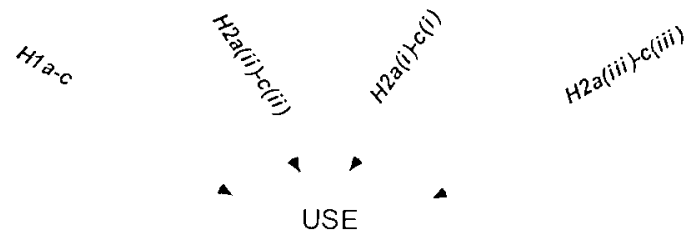

Notes:

a [D] $=:$ envirommental uncertainty:

$\mathrm{T} \mathrm{U}=$ = task uncertainty:

D) $: \mathrm{C}=$ decision-making authority:

$\mathrm{CON}=$ controllability of performance measures:

$\mathrm{N} i \mathrm{~F}=$ informativeness of performance measures;

$A C C^{\prime}=$ measurement accuracy of performance measures:

LISl: = use of perfomance measures.

For presentation purposes, I discuss the empirical results by hypothesis. However, for a discussion of the empirical results by structural equation model see appendix $C$. The empirical results with respect to the factors explaining the use of performance measures, i.e., hypotheses 1-2, are presented in table 6.1.

Hypotheses la-le

Hypothesis la predicts that decision-making authority has a positive effect on the use of thancial performance measures. The empirical results, shown in 
table 6.1. indicate that decision-making authority is positively related to the use of hinancial performance measures (one-tail $p<0.05$ ). which provides support for hypothesis la. The effect of decision-making authority on the use of internal and external non-financial performance measures is unknown a priori, as reflected by the null-hypotheses 16 and $l e$. The empirical results show that decisionmaking authority does not affect the use of either internal or external nonfinancial performance measures. Therefore, hypotheses $1 \mathrm{~b}$ and $1 \mathrm{c}$ are supported.

\section{Table 6.1}

Empirical results of the effects of decision-making anthority, informativeness. controllability. and measurement accuracy on the use of performance measures

\begin{tabular}{|c|c|c|c|}
\hline \multirow[b]{2}{*}{ Independent Variable } & \multicolumn{3}{|c|}{ Dependent Variable } \\
\hline & $\begin{array}{c}\text { lscof } \\
\text { Financial } \\
\text { Performance } \\
\text { Heasmes }\end{array}$ & 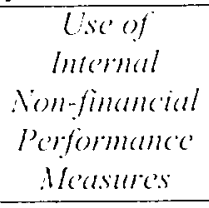 & $\begin{array}{c}\text { Escof } \\
\text { External } \\
\text { Non-financiul } \\
\text { Performance } \\
\text { Measures }\end{array}$ \\
\hline Decision-making Authority & $0.16^{\circ}$ & -0.09 & -0.08 \\
\hline Informativeness ${ }^{:}$ & $0.30^{-\infty}$ & $0.48^{* * *}$ & $0.46^{\cdots}$ \\
\hline Controllability: & $-0.32^{\cdots *}$ & -0.09 & -0.09 \\
\hline Mcasurcmont Accuracy & $0.16^{\circ}$ & $0.15^{*}$ & -0.07 \\
\hline Squared Multiple Correlation & 0.23 & 0.27 & 0.24 \\
\hline
\end{tabular}

Noles:

$\therefore . \because$ is significant at respectively the $1 \%$. 21\%. $5 \%$ and $10 \%$ level (one-tailed) using coefficient estimates and standard errors generated from 500 random bootstrap samples (with replacement).

"The performance measure characteristics relate to cach type of perfomance measure.

" Parameters are maximum likelihood estimates.

\section{Hypotheses 2a(i)-2c(i)}

The performance measure characteristic informativeness is hypothesized to have a positive effect on the use of the three types of performance measures, as predicted by the informativeness principle. The empirical results show that informativeness is positively related to the use of all three types of performance measures (one-tail $p<0.01$ ) and therefore provide strong support for hypotheses $2 \mathrm{a}(i), 2 \mathrm{~b}(i)$, and $2 \mathrm{c}(i)$.

\section{Hypotheses $2 a($ ii) $-2 c($ ii)}

Hypotheses $2 \mathrm{a}($ ii $)$-2c(ii) state that the use of perfomance measures increases with its controllability, as predicted by the controllability principle. Table 6.1, however, indicates that these hypotheses are not supported by the 
dati. The empirical results show that controllability is not related to the use of internal and external non-linancial performance measures, while it is negatively related to the use of financial performance measures. This last finding is actually contrary to my expectations and I discuss some plausible explanations in the final chapter.

\section{Mypotheses 2a(iii)-2c(iii)}

The last performance measure characteristic that is expected to positively affect the use of the three types of performance measures is measurement accuracy. The empirical results show that measurement accuracy is positively related to the use of financial and internal non-financial performance measures (one-tail $p<0.05$ ) but not related to the use of external non-financial performance measures. $\Lambda$ s a result, hypotheses $2 \mathrm{a}($ iii) and $2 \mathrm{~b}($ iii) are supported, while hypothesis $2 \mathrm{c}(\mathrm{iii})$ is not supported by the data.

\section{Hypotheses $3 a-3 c$}

The empirical results with respect to the effect of task uncertainty on the informativeness of the three types of performance measures are summarized in table 6.2. The results provide strong support for hypotheses $3 a-3 c$. That is, task uncertainty increases the informativeness of financial performance measures (one-tail $p<0.025$ ) and internal non-financial performance measures (one-tail $p<0.01$ ) but it does not affect the informativeness of external non-financial performance measures. Therefore, financial and internal non-financial performance measures become more uscful as task uncertainty increases.

\section{Table 6.2}

Empirical results of the effect of task uncertainty on the informativeness of performance measures

\begin{tabular}{|c|c|c|c|}
\hline \multirow[b]{2}{*}{ Independent Variable } & \multicolumn{3}{|c|}{ Dependent Variable } \\
\hline & $\begin{array}{c}\text { Informativeness of } \\
\text { Financial } \\
\text { Performance } \\
\text { Measures }\end{array}$ & $\begin{array}{c}\text { Informativeness } \\
\text { Internal } \\
\text { Non-financial } \\
\text { Performance } \\
\text { Measures }\end{array}$ & $\begin{array}{c}\text { Informativeness of } \\
\text { External } \\
\text { Non-financial } \\
\text { Performance } \\
\text { Measures }\end{array}$ \\
\hline Task Uncertainty & $0.24^{* *}$ & $0.37^{*+*}$ & -0.10 \\
\hline Squared Multiple Comelation & 0.04 & 0.08 & 0.01 \\
\hline
\end{tabular}

Voles:

$\cdots . \because$ is significant at respectively the $1 \%$. 2\%. $2 \%$. $5 \%$ and $10 \%$ level (one-lailed) using coefticient estimates and standard crors gencrated from 500 random bootstrap) samples (with replacement).

Parameters are maximum likelihood estimates. 
Hypotheses $4 a-4 c$

linally, hypotheses ta-4e predict that the level of environmental uncertainty negatively affects the controllability of the three types of performance measures. The empirical results, presented in table 6.3 . provide strong support for these hypotheses. The analysis show's that environmental uneertainty is negatively related to the controllability of all three types of performance measures (one-tail $p<0.01$ ). That is. the controllability decreases as environmental uncertainty increases.

Tuble 6.3

Empirical results of the effect of emvironmental uncertainty on the controllability of performance measures

\begin{tabular}{|c|c|c|c|}
\hline \multirow[b]{2}{*}{ Independent Variable } & \multicolumn{3}{|c|}{ Dependent Variable } \\
\hline & $\begin{array}{c}\text { Comtrollability of } \\
\text { Financial } \\
\text { Performance } \\
\text { Measures } \\
\end{array}$ & $\begin{array}{c}\text { Combollability of } \\
\text { Mnternal } \\
\text { Non-finameial } \\
\text { Perfommance } \\
\text { Mecusures } \\
\end{array}$ & $\begin{array}{c}\text { Comtrollability of } \\
\text { External } \\
\text { Non-financial } \\
\text { Performance } \\
\text { Measures }\end{array}$ \\
\hline Environmental Uncertainty & $-0.38^{* *}$ & $-0.28^{n+*}$ & $-0.23^{* * *}$ \\
\hline Squared Multiple Correlation & 0.18 & 0.08 & 0.06 \\
\hline
\end{tabular}

Noles:

$\cdots, \because .+$ is significant at respectively the $1 \% .2 \%$. $2 \%$, and $10 \%$ level (one-tailed) using coeflicient estimates and standard crrors generated from 500 random bootstrap samples (with replacement).

- Parameters are maximum likelihood estimates.

In sum, the empirical results first indicate that decision-making authority is positively related to the use of financial performance measures but not related to the use of the non-financial performance measures. Therefore hypotheses lalc are supported. Second, informativeness and measurement accuracy are the most important performance measure characteristics, with informativeness being related to the use of all three types of performance measures and measurement accuracy being related to the use of financial and internal non-financial performance measures. The performance measure characteristic controllability, on the other hand, does not have the proposed positive effect on performance measure use. The only relationship that is significant shows an opposite effect, indicating that the use of financial perfomance measures is negatively related to their controllability. As a result, hypotheses $2 a_{i}, 2 a_{i i i}, 2 b_{i}, 2 b_{i i i}$, and $2 c_{i}$ are supported and hypotheses $2 \mathrm{a}_{i i}, 2 \mathrm{~b}_{i i}, 2 \mathrm{c}_{i i}$, and $2 \mathrm{c}_{\mathrm{iii}}$ are not supported. Third, the results also provide evidence that task uncertainty increases the informativeness of financial and internal non-financial performance measures, but is not related 
to the informativeness of external non-financial performance measures. Therefore, hypotheses $3 a-3 c$ are supported, which suggests that the usefulness of linancial and internal non-financial performance measures increases with task uncertainty. Finally, the controllability of all three types of performanee measures decreases with increased environmental uncertainty, which lends support for hypotheses $4 a-4 c$. That is, the non-financial performance measures contain the same defects as the linancial performance measures when environmental uncertainty is high. The results of the hypothesis testing are summarized in table 6.4 .

Table 6.4

Results of hypothesis testing

\begin{tabular}{|c|c|c|c|c|c|}
\hline Relationship & & Iypothesis & $\begin{array}{c}\text { Expected } \\
\text { sign }\end{array}$ & $\begin{array}{c}\text { Path } \\
\text { coefficients }\end{array}$ & Test results \\
\hline DEC & $\rightarrow$ USE FPM & $111 \mathrm{a}$ & $\because-$ & $0.16^{\circ}$ & Supporled \\
\hline DEC & $\rightarrow$ USE_INFPM & $\mathrm{HIb}$ & $?$ & -0.09 & Supported \\
\hline DEC & $\rightarrow$ USE ENFPM & HC & $?$ & -0.08 & Supported \\
\hline INF FPM & $\rightarrow$ USE_FPM & $\mathrm{H} 2 \mathrm{a}_{t}$ & $\therefore$ & $0.30^{*+*}$ & Supported \\
\hline CON_FPM & $\rightarrow$ USE FPM & $112 \mathrm{a}_{\mathrm{ii}}$ & + & $-0.32^{\cdots *}$ & Vot supported \\
\hline$\triangle C^{\prime}$ FPM & $\rightarrow$ USE $F P M$ & $H 2 a_{i i i}$ & $\therefore$ & $0.16^{\circ}$ & Supported \\
\hline INE_INFPM & $\rightarrow$ USE_INFPM & $H_{2} b_{1}$ & + & $0.48^{* \cdots}$ & Supported \\
\hline CON INPPM & $\rightarrow$ USE FPM & $112 b_{11}$ & $\therefore$ & -0.09 & Not supported \\
\hline$\triangle C C$ INFPM & $\rightarrow$ USE INFPM & $\mathrm{H} 2 b_{i \mathrm{i}}$ & + & $0.15^{\circ}$ & Supported \\
\hline INF ENIPM & $\rightarrow$ USE_ENFPM & $\mathrm{H} 2 \mathrm{c}_{j}$ & $t$ & $0.46^{* *}$ & Supported \\
\hline CON ENFPM & $\rightarrow$ USE_ENFPM & $112 c_{i 1}$ & $\therefore-$ & -0.09 & Not supported \\
\hline ACC ENIPM & $\rightarrow$ USE_ENFPM & $\mathrm{H} 2 \mathrm{c}_{\mathrm{iii}}$ & $\because$ & -0.07 & Not supported \\
\hline TU & $\rightarrow \mathbb{I N F} F \mathrm{FP}$ & H3a & $\therefore$ & $0.24^{\circ}$ & Supported \\
\hline lu & $\rightarrow I N F$ INFPM & $\mathrm{H} 3 \mathrm{~b}$ & 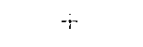 & $0.37^{\cdots *}$ & Supported \\
\hline TU & $\rightarrow$ INF_ENFPM & $H 3 \mathrm{c}$ & ? & -0.10 & Supponed \\
\hline $\mathrm{EU}$ & $\rightarrow \mathrm{CON}_{-} \mathrm{FPM}$ & $114 a$ & - & $-0.38^{\cdots \cdots}$ & Supported \\
\hline $\mathrm{EL}$ & $\rightarrow$ CON_INFPM & $114 b$ & - & $-0.28^{* *}$ & Supported \\
\hline EL & $\rightarrow$ CON ENFPM & $\mathrm{H} 4 \mathrm{C}$ & - & $-0.23^{\cdots *}$ & Supported \\
\hline
\end{tabular}

Notes:

$\cdots, \cdot ?$ is significant at respectively the $1 \%, 2 \frac{1}{2} \%, 5 \%$ and $10 \%$ level (one-tailed) using coefficient estimates and standard errors generated from 500 random bootstrap samples (with replacement).

- Parameters are maximum likelihood estimates.

\subsubsection{Sensitivity analysis and additional tests}

In the empirical analysis, I implicilly tested the prediction that uncertainty has an indirect effect, rather than a direct effect, on the use of performance measures. Simple correlation analysis shows that environmental uncertainty and 
the use of financial performance measures are positively related (one-tail $p<0.01$ ) and that task uncertainty and the use of internal non-financial performance measures are positively related (one-tail $p<0.025$ ). T'o cxamine whether the relationship between the perlormanee measure characteristics and the use of performance measures are due to the omission of the direct effect of uncertainty. I perform two tests. ${ }^{2}$ First, I incorporate the direct effects of environmental uncertainty and task uncertainty into the empirical model in ligure 6.1 with respect to the two types of performanee measures. For both models, the direct effects of both types of uncertainty are not significant. white all other relationships are identical to those presented in the previous section. Second. I test whether the indirect model or the direct model, which is nested in the indirect model. has a better fit to the data. By constraining the relevant relationships to zero, I calculate the chi-square difference statistic between both models for the financial and internal non-financial performance measures. The chi-square difference statistics with respect to financial and internal nonfinancial performance measures are respectively 32.33 and 43.13 (for all $p<0.01$ ), which indicates that for both types of performance measures the indirect model has a better lit to the data. As a result, the relationship between the performance measure characteristics and the use of performance measures is not due to the omission of a direct effect of uncertainty.

According to economic theory, organizations should simultancously select organizational design variables, such as decision-making authority and the use of performance measures (e.g., Milgrom and Roberts 1995; Brickley et al. 1997). To examine whether decision-making authority and the use of performance measures are simultaneously determined, I estimate for each type of performance measure the non-recursive model presented in ligure 6.2. T'o allow the model to be estimated, the model includes, in addition to the hypotheses stated previously and the non-recursive nature, the relationship between environmental uncertainty and decision-making authority. Simple correlation analysis shows that environmental uncertainty and decision-making authority are positively related (one-tail $p<0.05$ ). ${ }^{3}$

The results related to the use of the non-financial performance measures indicate that decision-making authority has no effect on performance measure use and vice versa. The model with respect to the use of financial performance

2 Especially the unexpected significant negative relationship between controllability and the use of financial performance measures might be due to an omitted variable problem. There is cvidence that suggests that the use of financial controls increases with uncertainty (e.g., Khandwalla 1972; Simons 1987) and uncertainty might therefore be the omitted variable.

"This relationship is to some extent consistent with the predictions made by organization theory, which states that organizations become more decentralized when the enviroment is more uncertain. 
measures is not stable, implying that the empirical model is misspecified. From these results, I conclude that there is no evidence that decision-making authority and the use of performance measures are simulaneously determined, which is consistent with Nagar (1999).

Figure 6.2

Non-recursive model

EU

TU

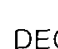

DEC

CON

INF

$\mathrm{ACC}$
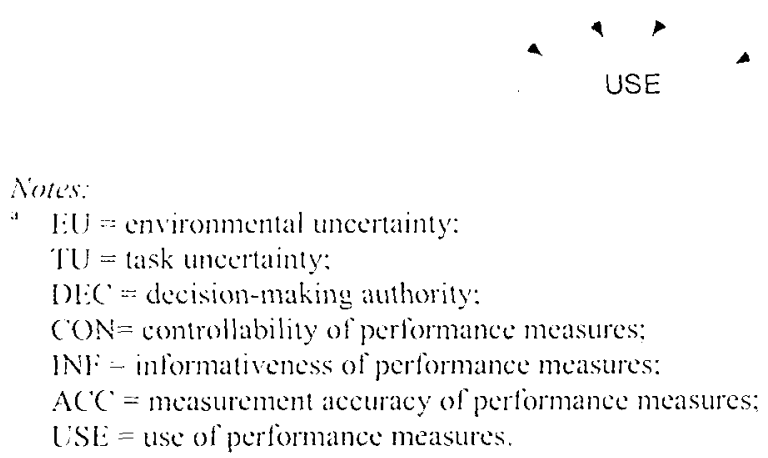

Finally. I split the model, presented in figure 6.1 , into two parts, i.e., (1) hypotheses $1 \mathrm{a}-2 \mathrm{c}$ and (2) hypotheses $3 \mathrm{a}-4 \mathrm{c}$, and estimate each part for all three performance measures simultaneously. In testing hypotheses $1 \mathrm{a}-2 \mathrm{c}$, I allow the performance measures to be simultaneously determined. The results from these additional tests are qualitatively similar to those presented in tables $6.1-6.3$. 


\section{Part B}

\subsection{The Effects of Performance Measures and Performance Targets}

\subsubsection{Hypotheses}

The hypotheses that are tested in Part B are hypotheses 5 through 8. For completeness. I restate these hypotheses below.

H.5: The use of financial performance measures for incentive purposes increases managerial short-term orientation.

H.5b: The use of external non-financial performance measures for incentive parposes decreases managerial short-term orientation.

Hoa: The difficulty of financial performance targets increases managerial short-term orientation.

Hob: The difficulty of external non-financial performance targets decreases managerial short-term orientation.

H7: The use of financial (external non-financial) performance measures for incentive purposes increases the difficulty of the financial (external non-financial) performance target.

HS: The effect of the use of financial (external non-financial) performance measures for incentive purposes on the difficulty of the financial (external non-financial) performance target is less positive for higher levels of managerial risk aversion.

\subsubsection{Empirical results ${ }^{+}$}

The hypotheses 5 through 7 are tested by estimating the empirical model presented in figure 6.3 using $A M O S 4.0$. Because of sample size limitations, I treat all variables in the model as obscrved variables rather than latent variables. The empirical results related to the structural equation model are presented in appendix $C$. Table 6.5 summarizes the results with respect to the effect of the financial and external non-financial performance measures and targets on managerial short-term orientation.

+ As stated in chapter 4, the non-financial performance measures used in the empirical analysis are the external non-financial performance measures. The results presented in this section are not affected by the inclusion of the internal non-financial performance measures. 
Figure 6.3

Eimpirical model

USE_FPM

USE_ENFPM

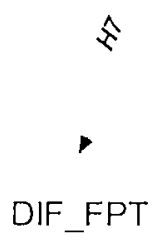

$\hat{-1}$

$\Xi$

DIF_FPT

志

DIF_ENFPT

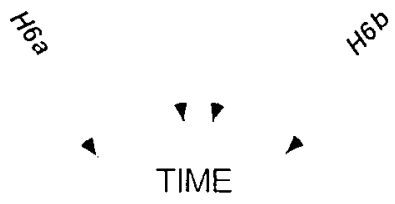

Notes:

aSE:FPM = use of tinancial performance measures;

USE_LNFPM = use of external non-financial performance measures;

DII $1: \mathrm{P}^{\prime} \mathrm{l}=$ difficulty of hinancial performance target:

DHF FNPPT = difficulty of external non-tinancial perfomance target:

$T \mathrm{TME}=$ managerial short-ierm orientation.

\section{Hypotheses $5 a-5 b$}

Hypotheses $5 \mathrm{a}$ and $5 \mathrm{~b}$ predict that the use of financial performance measures increases the manager's short-term orientation, while the use of external non-financial performance measures decreases this type of behavior. The empirical results indicate that the use of both types of performance measures does not affect managerial short-term orientation. Therefore, hypotheses $5 \mathrm{a}$ and $5 \mathrm{~b}$ are not supported by the data, which seems to be inconsistent with previous research.

\section{Hypotheses oa and $6 b$}

Although the use of performance does not affect managerial short-term orientation, performance targets seem to have a significant impact. Table 0.5 shows that the difficulty of financial performance targets increases managerial short-term orientation (one-tail $p<0.01$ ), while the difficulty of the external nonfinancial performance targets decreases managerial short-term orientation (one- 


\section{Table 6.6}

Empirical results of the effect of the use of performance measures for incentive purposes on the difficulty of performance targets

\begin{tabular}{|c|c|c|}
\hline \multirow[b]{2}{*}{ Independent Variable } & \multicolumn{2}{|c|}{ Dependent Variable } \\
\hline & $\begin{array}{l}\text { Difficulty of } \\
\text { Financial } \\
\text { Performance } \\
\text { Targets }\end{array}$ & $\begin{array}{c}\text { Difficuly' of } \\
\text { External } \\
\text { Non-financial } \\
\text { Performance } \\
\text { Targets }\end{array}$ \\
\hline Use of Financial Performance Measures & $0.500^{4 * *}$ & \\
\hline Use of External Non-financial Performance Measures & & $0.31^{\cdots-}$ \\
\hline Squared Multiple Correlation & 0.25 & 0.12 \\
\hline
\end{tabular}

Nises:

$\cdots . .{ }^{+}$is significant at respectively the $1 \%, 2 \frac{1}{2} \%, 5 \%$, and $10 \%$ level (one-tailed) using coefficient estimates and standard errors generated from 500 random bootstrap samples (with replacement).

Parameters are maximum likelihood estimates.

Table 6.7

Empirical results with respect to the effect of managerial risk aversion on the relationship between the use of financial (external non-financial) performance measures for incentive purposes and the difficulty of financial (external non-financial) performance targets

\begin{tabular}{lccc}
\hline & Low risk aversion & High risk aversion & Difference \\
\cline { 2 - 4 } & $0.60^{* * *}$ & $0.35^{* * *}$ & $0.25^{*}$ \\
USE_FPM $\rightarrow$ DIF_FPT & $0.38^{* *}$ & $0.29^{* * *}$ & 0.09 \\
\hline
\end{tabular}

Noles:

$\cdots . \cdots+$ is significant at respectively the $1 \%, 2 \% . \% \%$ and $10 \%$ level (one-lailed) using coefficient estimates and standard errors generated from 500 random bootstrap samples (with replacement).

- USIE FPM = use of financial performance measures:

USE ENLPM = use of external non-linancial performance measures;

DIF_LPT = difliculty of financial performance target:

DIF ENPT' $=$ difficulty of external non-financial performance target.

b Parameters are maximum likclihood estimates.

The results with respect to the relationship between the use of performance measures and performance target difficulty for high and low risk averse managers are presented in table 6.7. For both groups of managers, the use of financial (external non-financial) performance measures for incentive purposes increases the difficulty of the financial (external non-financial) 
performance target (one-tail $p<0.01$ ). Furthermore. the regression coelficients for the high risk aversion group are lower than those for the low risk arersion group. However, the difference between the regression coeflicients is not significant for the external non-fimancial perfomance measures and only marginally significant for the financial performance measures (one-tail $p<0.10$ ). These results provide only weak support for hypothesis 8, which states that managerial risk aversion moderates the relationship between the use of performance measures for incentive purposes and the difficulty of performance targets.

\subsubsection{Sensitivity andisis}

The finding that the use of financial performance measures and the use of external non-financial performance measures for incentive purposes are not related to managerial short-term orientation seems to be inconsistent with previous evidence (e.g., Merchant 1990). However, previous research neglects the effect of the difficulty of performance targets, which is positively related to the use of performance measures. To test if the results of previous research might be driven by target difficulty, I examine the effect of the use of performance measures on managerial short-term orientation without taking into account the effect of performance targets. The results (not reported) show that the use of financial performance measures is positively related to managerial short-term orientation (one-tail $\mathrm{p}<0.05$ ) and the use of external non-financial performance measures is negatively related to managerial short-term orientation, though not significant. These findings provide some evidence that the results of previous research might be driven by performance arget difficulty and that the use of performance measures only indirectly affects managerial short-term orientation.

I tested hypotheses 7 and 8 by analyzing the effect of financial performance measures and external non-financial performance measures separately. However, the predictions stated in hypotheses 7 and 8 are identical for both types of performance measures. A more direct test of the hypotheses is to examine the effect of the use of performance measures in general on the difficulty of performance targets. Therefore, I treat each observation with respect to the use of financial (external non-financial) performance measures and financial (external non-financial) performance target difficulty as respectively an observation with respect to the use of performance measures and performance target difficulty. The results of the regression analysis, presented in panel A of table 6.8 , indicate that the difficulty of performance targets and the use of performance measures for incentive purposes are positively rclated (onetail $p<0.01$ ), which is consistent with the findings of the original analysis and provides further support for hypothesis 7 . 


\section{Table 6.8}

Empirical results with respect to the relationship between the use of performance measures for incentive purposes and the difliculty of performance targets for the total sample and subgroups of managerial risk aversion

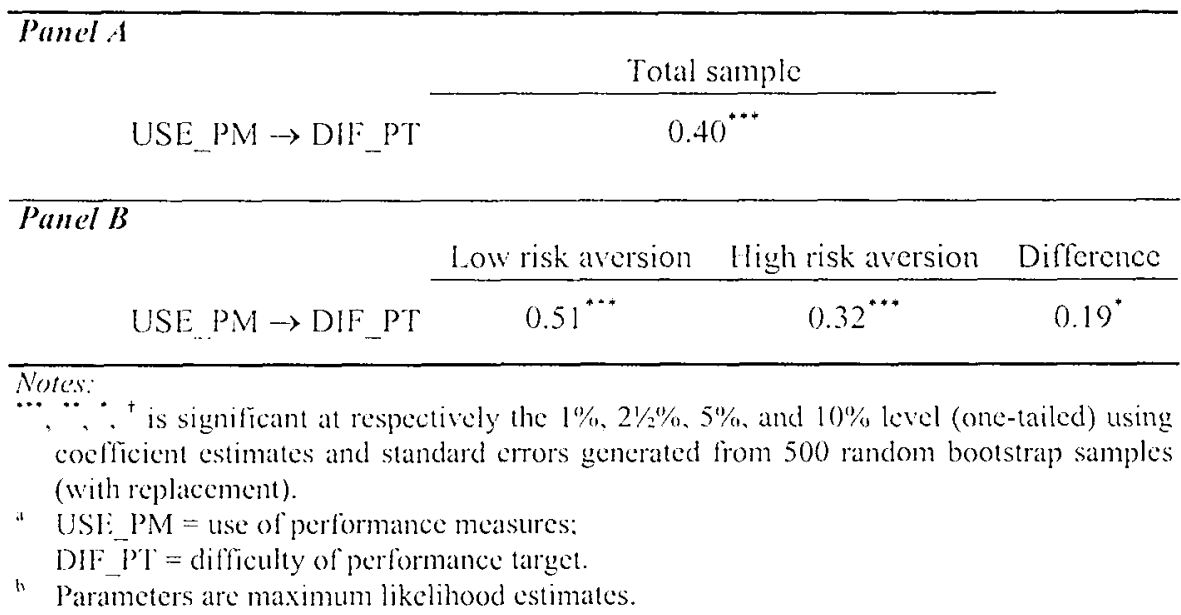

To test hypothesis 8 , I repeat the analysis for the low risk aversion group and the high risk aversion group. The results, presented in panel B of table 6.8 , show that for both groups of managers, the relationship is positive and significant (onc-tail $p<0.01$ ). Furthermore, the coefficient for the high risk aversion group is significantly lower than the coefficient for the low risk aversion group (one-tail $p<0.05$ ). These findings provide stronger support for hypothesis 8 than the results from the original analysis and suggest that superiors take the manager's risk aversion into account when setting performance targets.

Finally, in a preliminary analysis, I found that risk aversion and environmental uncertainty are positively correlated (one-tail $p<0.05$ ). That is, the higher the environmental uncertainty the higher the risk aversion of the manager. The effect of risk aversion on the relationship between the use of performance measures and performance target difficulty might therefore be driven by environmental uncertainty. However, the empirical results (not reported) indicate that envirommental uncertainty has no effect on the relationship between performance measures and performance targets.

In sum, the empirical results show that managerial short-term orientation is determined by the difficulty of performance targets. More specifically, difficult financial performance targets increase managerial short-term orientation, while difficult external non-financial performance targets decrease 
managerial short-1erm orientation. The use of cither financial or extemal nonfinancial performance measures for incentive puposes affects the manager's time horizon only indirectly through its effect on the difficulty of performance targets. Finally, the empirical results provide evidence for the hypothesis that risk aversion moderates the relationship between the use of performance measures and the difficulty of performance targets. The results of the hypothesis testing are summarized in table 6.9 .

Table 6.9

Results of hypothesis lesting

\begin{tabular}{|c|c|c|c|c|c|}
\hline Rolationship & & Hypothesis & $\begin{array}{c}\text { Expected } \\
\text { sign }\end{array}$ & $\begin{array}{c}\text { Path } \\
\text { coefficients }\end{array}$ & Test results \\
\hline USE_FPM & $\rightarrow$ ThMl: & $115 a$ & $\because$ & 2.30 & Not supported \\
\hline USE_ENFPM & $\rightarrow$ TIMI: & $\mathrm{H} 5 \mathrm{~b}$ & - & 2.81 & Nol supported \\
\hline DlF FPT & $\rightarrow$ TLME & $H 6 a$ & $\because$ & $1.3 .06^{\circ *}$ & Supporled \\
\hline DIF ENEPT & $\rightarrow$ TIME & $\mathrm{Hob}$ & - & $-11.05^{\cdots}$ & Supported \\
\hline USE PN & $\rightarrow \mathrm{DHF} \mathrm{PT}$ & $\mathrm{H7}$ & $\because$ & $0.40^{* *}$ & Supported \\
\hline (LSE_PM $\times$ RISK) & $\rightarrow \mathrm{DHF}_{-} \mathrm{PT}$ & HS & - & $-0.19^{*}$ & Supported \\
\hline
\end{tabular}




\section{chapter 7}

\section{SUMMARY AND CONCLUSION}

\subsection{Introduction}

In this final chapter, I summarize the empirical results of this dissertation. Further, I provide conclusions and implications based on the empirical results and discuss some limitations of the study. I end this chapter with directions for future research, which result from the theoretical and empirical analysis presented in previous chapters.

\subsection{Summary}

The two general research questions that are empirically addressed in this dissertation are:

(1) What factors explain the use of performance measures?

(2) How do performance measures and performance targets, as part of the incentive system, affect behavior?

More specifically, this dissertation examines the factors that are related to the use of performance measures and the difficulty of performance targets with respect to three different performance dimensions: (1) financial, (2) internal non-financial, and (3) external non-financial. Further, it examines the effect of 
the use of performance measures and the difficulty of performanee targets on managerial short-term oricntation.

The research questions are theoretically analyzed using multiple disciplines that are applied in the incentive literature. The empirical analysis is based on a sample of 105 subordinate managers for which complete survey data are available.

\subsubsection{The use of performance measures}

The theoretical analysis indicates that the most diree factors affecting the use of performance measures are the level of information asymmetry (need) and the characteristics of performance measures (feasibility). It further indicates that uncertainty affects the use of performance measures indirectly through its effect on performance measure characteristics.

\section{Information asymmetmy}

The effect of information asymmetry on the use of the three types of performance measures is examined by using decision-making authority as a proxy for information asymmetry. Increased decision-making authority not only increases the information asymmetry between superiors and subordinates with respect to the decisions made by the subordinate managers, but it also increases the range of decisions made. Since it is too costly to have performance measures for each type of action, there exists an increased preference for performance measures that provide (some) information about an increased number of actions. Therefore, decision-making authority does not increase the demand for any performance measures, but it specifically increases the demand for more aggregated performance measures, like financial performance measures.

The empirical results show that decision-making authority is positively related to the use of financial performance measures for incentive purposes. Further, decision-making authority is not related to the use of intemal nonfinancial and extemal non-financial performance measures. These results, summarized in table 7.1 , are consistent with the hypothesis that decision-making authority increases the demand for more aggregated performance measures.

\section{Performance measure characteristics}

Based on an analysis of the economics-based and behavioral-based incentive literature, I deduce three general performance measure characteristics: (1) informativeness, (2) controllability, and (3) measurement accuracy. Informativeness reflects the extent to which the manager has an impact on performance. Controllability, on the other hand, reflects the extent to which uncontrollable factors have an impact on performance. Finally, measurement accuracy reflects the degree to which the performance measure measures 
performance with error. The feasibility of a specific performance measure increases when it becomes more informative and more controllable and is measured more accurately. Therefore, I predict that the use of a performance measure for incentive purposes increases with its informativeness, controllability, and measurement accuracy.

The empirical results, summarized in table 7.1 , indicate that the most influential performanee measure characteristic is informativeness. The use of all three types of performance measures is positively related to their inlormativeness. The second most important performance measure characteristic is measurement accuracy. The empirical results show that the use of financial and intemal non-financial performance measures is positively related to the extent that they are measured in an accurate way. However, the use of external non-financial performance measures is unaffected by its measurement accuracy. Finally, controllability does not have the proposed positive effect on performance measure use. The use of internal non-financial and external nonfinancial performance measures is unaffected by the measures' controllability, while the use of financial performance measures is negatively related to controllability, which is inconsistent with my expectations.

Table 7.1

Summary of empirical relationships between decision-making authority, performance measure characteristics and performance measure use

\begin{tabular}{|c|c|c|c|c|c|c|}
\hline \multirow[b]{3}{*}{$\begin{array}{l}\text { Decision-making } \\
\text { atuhority }\end{array}$} & \multicolumn{6}{|c|}{ Use of ... } \\
\hline & $F P M$ & Hyp. & INFPM & Hyp. & ENFPM & Hyp. \\
\hline & Positive & lat & n.s. & $16 \checkmark$ & n.s. & $10 \checkmark$ \\
\hline Informativeness & Positive & $2 a_{i} \checkmark$ & Positive & $2 b_{i} \checkmark$ & Positive & $2 c_{i} \checkmark$ \\
\hline Controllability & Negative & $2 a_{i i} x$ & n.s. & $2 b_{i i} x$ & n.s. & $2 c_{i i} \times$ \\
\hline Accuracy & Positive & $2 \mathrm{a}_{i i i} \checkmark$ & Positive & $2 b_{\mathrm{iii}} \checkmark$ & n.s. & $2 c_{i j i} x$ \\
\hline
\end{tabular}

Notes:

- FPM: financial performance measures

INFPM: intemal non-tinancial performance measures

ENFPM: external non-financial performance measures

b n.s.: not significant

$\checkmark$ : hypothesis supported

$x$ : hypothesis not supported

\section{Uncertainty}

Uncertainty is one of the most important variables in organizational design frameworks. The contingency literature identifies two types of uncertainty: task uncertainty and environmental uncertainty. Task uncertainty is defined as the uncertainty due to the complexity and diversity of the task 
performed, while environmental uncertainty is defined as the uncertainty due to factors in the organization's environment. Uncertainty is, first of all, assumed to affect the feasibility of different performance measures. The general assumption made in previous research is that both task uncertainty and environmental uncertainty negatively affect the usefulness of financial performance measures because uncertainty decreases the controllability of these measures. However, I argue that both types of uneertainty have an effect on different performance measure characteristics. First, in task uncertain situations, task performance is highly affected by the manager's decisions and the ability of the manager to inlluence performance increases with the amount of feedback received. Therefore, task uncertainty has a positive effect on the informativeness of performance measures that are internal oriented and related to the task and for which feedback can be provided on a frequent basis, i.e., financial and intemal non-financial performance measures. Environmental uncertainty, on the other hand, increases the unpredictable impact of uncontrollable factors on performance. Since all three types of performance measures relevant to this dissertation can be affected by uncontrollable factors, environmental uncertainty decreases the controllability of these measures.

Table 7.2

Empirical relationships between uncertainty, informativeness, and controllability

\section{Panel A}

Informativeness of ...

\begin{tabular}{lcccccc} 
& Hyp & HNFPM & Hyp. & ENFPM & Hyp. \\
\cline { 2 - 3 } & Positive & $3 \mathrm{a} \checkmark$ & Positive & $3 \mathrm{~b} \checkmark$ & n.s. & 3c $\checkmark$
\end{tabular}

\section{Panel B}

\section{Controllability of ...}

Environmental

FPM Hyp. INFPM Hyp. ENFPM Hyp.

\section{Uncertainty}

Negative

$4 \mathrm{a}$

Negative

4b $\checkmark$ Negative

$4 c \checkmark$

Note:

A I:PM: financial performance measures

INIPM: internal non-financial performance measures

LNFPM: extemal non-financial performance measures

n.s.: not significant

$\checkmark$ : hypothesis supported

$x$ : hypothesis not supported

The empirical results regarding the effect of task uncertainty are shown in panel $A$ of table 7.2. The results indicate that, consistent with my expectations, 
task uncertainty increases the informativeness of linancial and internal nonfinancial performance measures, but is not related to the informativeness of extemal non-financial performance measures. Panel B of table 7.2 presents the empirical results with respect to the effect of envirommental uncertainty and shows that environmental uncertainty decreases the controllability of all three lypes of perfornance measures.

\subsubsection{The difficulty of performance targets}

Empirical research with respect to factors affecting the difficulty of performance targets is limited. In the current empirical study, I examine the effect of the use of performance measures and the level of managerial risk aversion on the difficulty of performance targets.

\section{Use of performance meesures}

Previous empirical rescarch in the budgetary control literature finds that the use of budgets for evaluation purposes decreases the amount of budgetary slack and thus the probability of achieving the budget. Applying these results to performance measures and performance targets in incentive systems means that the use of performance measures for incentive purposes increases the difficulty of performance targets. Two explanations are given for this prediction. First, given the rational expectations of superiors, performance targets will be more difficult when linked to rewards in order to offset the incentives given to subordinates to build in slack to maximize their rewards. Second, an increased use of performance measures for incentive purposes increases the likelihood of detecting and curtailing slack, which results in more difficult targets.

The empirical results are summarized in panel $A$ of table 7.3 and show that the use of performance measures for incentive purposes increases the difficulty of performance targets, which is consistent with my expectations.

\section{Riskaversion}

Performance-contingent rewards do not only provide managers with incentives, they also provide these managers with risk they have to bear. If the performance targets become more difficult, then the manager bears even more risk because it becomes more difficult to receive the rewards. The difficulty of performance targets is therefore expected to be affected by the trade-off between incentives and risk sharing and more specifically by the risk aversion of the manager. Superiors can either set performance targets taking into account the risk aversion of the manager (top-down) or they can allow risk averse managers to build in 'some' slack (bottom-up). Given that the use of performance measures positively affects the difficulty of performance targets, it is expected 
that this positive effect will be lower the higher the risk aversion of the manager as a result of the trade-off between incentives and risk sharing.

Table 7.3

limpirical relationships beween the use of performance measures, risk arersion and the difficuly of performance targets

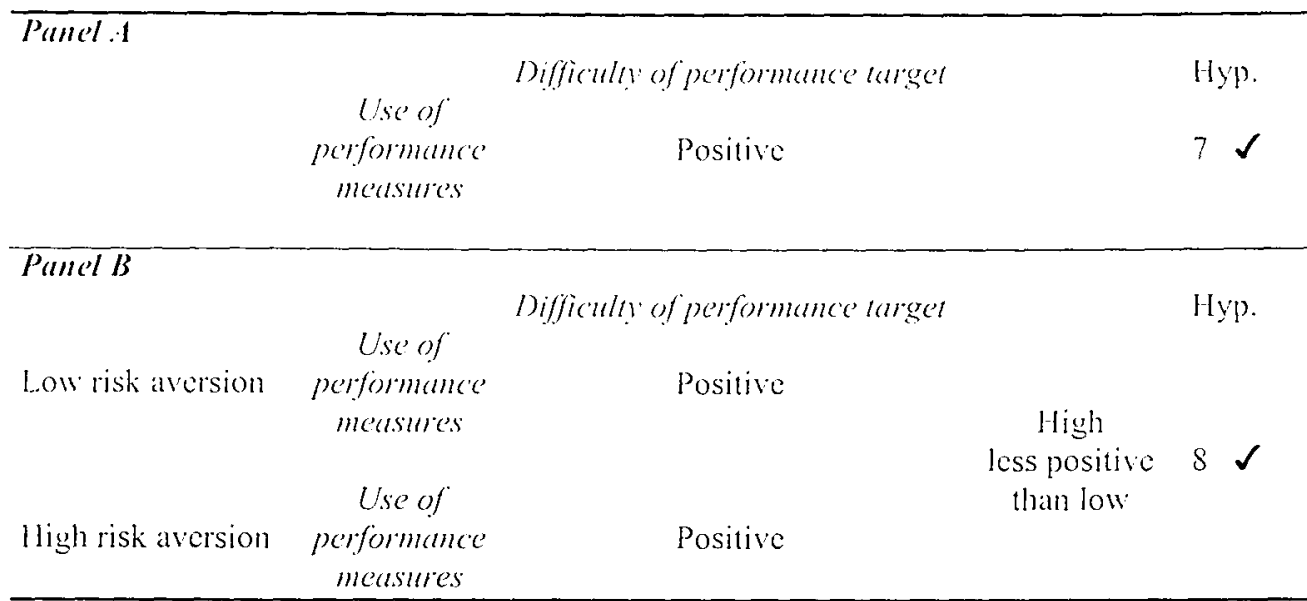

Notes:

* n.s.: not significant

$\checkmark$ : hypothesis supponed

$x$ : hyporhesis not supponted

Panel $B$ of table 7.3 presents the empirical results of the effect of risk aversion and indicates that the positive effect of the use of performance measures on the difficulty of performance targets is lower the higher the manager's risk aversion.

\subsubsection{Managerial short-term orientation}

The number of firms using non-financial performance measures for incentive purpose is increasing. The primary reason for using non-financial performance measures is that some of them are leading indicators of financial performance and provide managers with long-term incentives. Financial performance measures, on the other hand, are predominantly backward-looking and provide managers with short-term incentives. However, the empirical evidence regarding these claims is limited. Therefore, this dissertation tests the prediction that financial performance measures provide managers with shortterm incentives, while external non-financial performance measures, which are assumed to be leading indicators, provide managers with long-term incentives. Furthermore, an analysis of the principal-agent literature and the goal-setting 
literature shows that the use of performance measures and the difficulty of performance targets have similar incentive effects. This means that the difficulty of performance targets affects managerial short-term orientation in the same way as the use of performance measures for incentive purposes. More specifically, difficult financial (external non-financial) performance targets increases (decreases) managerial short-term orientation.

\section{Table 7.4}

Fimpirical relationships between performance measures. performance largets and managerial short-term orientation

\begin{tabular}{|c|c|c|c|}
\hline & $\begin{array}{c}\text { Managerial short-tem } \\
\text { oricentation }\end{array}$ & Hyl & \\
\hline Wse of $\mathrm{FP}$ & n.s. & $5 a$ & \\
\hline USC of LNFPM & n.s. & $5 b$ & $x$ \\
\hline Difficalty of $F P T$ & Positive & $6 a$ & $\checkmark$ \\
\hline Difficulty on ENFPT & Negative & $6 b$ & $\checkmark$ \\
\hline \multicolumn{4}{|c|}{ 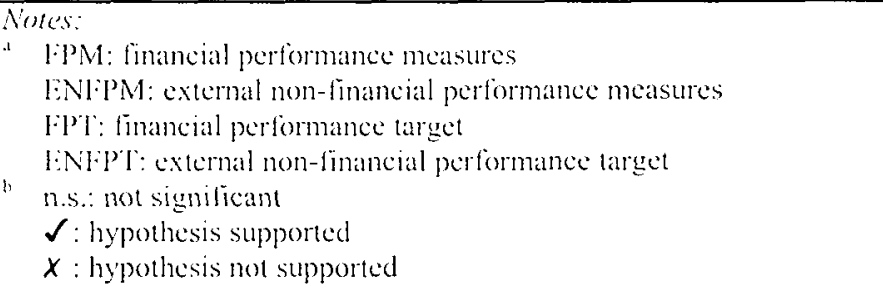 } \\
\hline
\end{tabular}

The empirical results, summarized in table 7.4 , show that managerial short-term orientation is not affected by the use of either financial or external non-financial performance measures for incentive purposes. The results further show that the difficulty of performance targets does have an effect on managerial short-term orientation. That is, difficult financial performance targets increase short-term orientation, while difficult external non-financial performance targets decrease short-term orientation. As a result, the results suggest that performance measures have an indirect effect on behavior due to their effect on the difficulty of performance targets.

\subsection{Conclusions and Implications}

The use of multiple disciplines to study the use and effects of performance measures and performance targets in incentive systems has turned out to be a useful excreise. First, the empirical results related to the factors that explain the use of performance measures shed a different light on the behavioral-based RAPM literature. Although I find that environmental uncertainty decreases the 
controllability of financial performance measures, as assumed in the RAPM literature, the same result holds for the non-financial performance measures. This indicates that the assumed defects of financial performance measures also apply to the non-financial performance measures. Interestingly, the degree of controllability is actually negatively related to the use of financial performance measures for incentive purposes. $\Lambda$ plausible explanation for this relationship might be that superiors want their managers to be aware of the uncontrollables so that they take these into account when making decisions. The finding that controllability is not related to the use of the non-financial performance measures suggests that the creation of 'awareness' is especially relevant if the uncontrollables affect the financial results. As a result, the usefulness of financial performance measures might actually increase with environmental uncertainty because it creates this awareness.

The degree to which the performance measures are measured in an accurate way is positively related to the use of performance measures for incentive purposes. The empirical results indicate that 'noise' due to the measurement process is more important for using performance measures than 'noise' due to uncontrollable factors (controllability). A plausible explanation for this finding might be that it is less costly for the firm to adjust for the extent to which they accurately measure performance than it is to adjust for uncontrollables. The fact that measurement accuracy does not affect the use of external non-financial performance measures, which are often measured by third parties, provides some evidence for this explanation.

The most important performance measure characteristic related to the use of performance measures is informativeness. The empirical results provide strong evidence of the use of the informativeness principle by firms. That is, rather than using performance measures that are controllable (controllability principle), firms seem to choose performance measures that provide information about manager's actions, even if these are (partly) uncontrollable. Furthemore, the RAPM literature generally states that the usefulness of financial performance measures decreases with increased task uncertainty because it affects the controllability of these measures. However, I find that task uncertainty increases the usefulness of financial performance measures because it increases their informativeness.

Overall, the RAPM literature is too narrowly focused on the controllability of financial performance measures and the negative impact of uncertainty on the controllability and therefore the usefulness of these measures. This dissertation indicates that performance measure characteristics other than controllability are more important for choosing performance measures and that uncertainty actually increases the usefulness of linancial performance measures. 
With respect to the effects of performance measures and performance targets, the empirical results shed a different light on the economics-based incentive effect studies. The empirical results show that performance measures do not directly affect managerial behavior. Rather, the use of performance measures for incentive purposes increases the difficulty of the performance targets related to these measures, which subsequently affect behavior. Therefore, the two components of the incentive system seem to simultaneously affect managerial behavior. This suggests that the focus of the economics-based studies on the incentive effects of performance measures is too namow. The general linding in these studies is that performance measures 'positively' affect managerial behavior and performance. However, these results might be spurious, in the sense that the results are driven by the difficulty of performance largets.

The empirical results further suggest that the prediction of the principalagent model that risk aversion affects the use of performance measures for incentive purposes does not apply to managers lower in the organization. The results show that risk aversion negatively arfects the relationship between the use of performance measures and the difficulty of performance targets. This implies that superiors take the risk aversion of managers into account by adjusting the difficulty of performance targets rather than by adjusting the use of performance measures for incentive purposes.

The empirical results have also several practical implications. First, assuming that the firms that participated in this study have made efficient choices on average, the results suggest that informativeness and measurement accuracy are of key importance to the use of performance measures for incentive purposes, while controllability is of minor or no importance. That is, performance measures that can be influenced by subordinate managers should be used, because it is impossible to construct performance measures that are totally controllable. This suggests that superiors should identily areas where they want to sce performance improvements and develop performance measures that are sensitive to subordinate managers' decisions. Furthermore, to reduce the opportunity of subordinate managers to manipulate these measures, superiors have to make sure that these measures are objective and veriliable. Second, incorporating certain performance measures in incentive contracts without emphasizing targets does not affect managerial behavior. Superiors have to set specilic targets for managers to shoot for and choose the difficulty of these targets dependent on how powerful they want the incentives to be. Thus, the type of performance measure used determines the 'direction' of effort, while the difficulty of the performance target determines the 'amount' of effort provided. In terms of 'what you measure is what you get', the performance measure determines 'what you get', while the performance target determines 'how much 
you get'. Third, it superiors want their subordinates to be more long-term oriented, then incorporating non-financial performance information in incentive systems can achieve this goal. Although not all non-financial performance measures provide long-term incentives, the type of performance measures used in this study, i.e., market-oriented measures, lengthen the manager's time horizon. Therefore, these measures increase the amount of time that managers spend on activities that affect future financial performance, which reduces the myopia problem. Finally, risk aversion affects the trade-off between incentives and risk sharing in the sense that fewer incentives can be given to risk averse managers. This means that it is more difficult to use incentive systems to promote certain types of behavior the higher the risk aversion of the manager. To make sure that these managers make congruent decisions, firms need to implement alternative control mechanisms.

\subsection{Limitations}

As with any empirical study, this study has its limitations. In this section, I analyze the extent to which this dissertation is subject to the following important limitations generally associated with survey questionnaires (Podsakoff and Organ 1986; Young 1996): (1) use of perceptual measures, (2) commonmethod problem, and (3) non-random sampling. Further, I discuss some linitations that are more specific.

(1) First, the variables used in the empirical analysis are based on the perceptions of the respondents. Although this is true for any study using survey questionnaires, it could specifically be a problem in this study with respect to the measurement of performance measure characteristics. The implicit assumption underlying the empirical analysis is that the performance measure characteristics perceived by the subordinate manager are identical to the 'objective' performance measure characteristics and/or to those perceived by the superior. However, in my opinion this assumption does not seem to be a problem in the current study for the following reason. The analysis in chapter 5 shows that the perceived use of performance measures is consistent with the actual incentive contract used by the firms. Given this 'validation' of the dependent variable, if the perceived performance measure characteristics are inconsistent with the objective performance measure characteristics, then this would lead to a bias against the predicted relationships, i.e., I would not find any significant results. Although the empirical results with respect to 'controllability' are inconsistent with my hypotheses, it is not likely that this is due to a measurement problem, since the empirical results further show that controllability is significantly 
negatively related to envirommental uncertainty, a relationship traditionally assumed throughout the whole RAPM literature.

2. Second, a related problem to the use of survey questionnaires is the 'common-method' problem. The common-method problem occurs when respondents report 'consistent' and 'socially desirable' answers, which leads to a bias in favor of the predicted relationships (Podsakofl and Organ 1986). Although it is impossible to rule out this problem, I believe that it is not likely to be an issue in the current study. The procedures used in designing the study and in gathering the data control for most of the reliability and validity problems that can occur when using survey questionnaires (cf. Young 1996). Further, given the multi-disciplinary nature of this study, it is unlikely that respondents know what to answer'.

Q. A third potential limitation of this study is the non-random selection of lirms. In chapter 5, I stated that, since eligible firms must have incentive systems, random selection is inappropriate for the purpose of this dissertation. However, the non-random selection applied might have led to abias in the selected firms. All of the firms that participate in this study are, or once were, clients of Hay Management Consultants (IMC). As a result, these firms might have incentive systems that are different from the incentive systems of other firms that are not clients of HMC. Because it is unclear how this potential bias affects the results presented in this dissertation, the findings might not be gencralizable to firms that have not been 'assisted' by compensation consultants. (4) Fourth, the predictions relating decision-making authority to the use of perfomance measures are based on the 'information asymmetry' aspect and the 'aggregation aspect' of decision-making authority. However, I do not separately account for these aspects in this dissertation. That is, these aspects of decisionmaking authority remain untested assumptions. As a result, the relationship between decision-making authority and the use of (financial) performance measures might be due to other reasons than those proposed in this disscrtation. 3 Fifth, the current study is limited in the number of contingency variables used. Although uncertainty is the dominant contingency variable underlying contingency theory in organization and accounting (Hartmann 2000), there might be 'other' factors associated either with the use of performance measures or the performance measure characteristics. If these other factors are correlated with task and/or environmental uncertainty, then this study might be subject to an omitted variable problem.

Finally, I only examine the effect of incentive systems on managerial short-term orientation. Although this is an important consideration in designing incentive systems, these systems can affect other types of behavios, such as gaming, influence tactics, and job-related attitudes. Furthermore, the measurement of managerial short-term orientation does not allow any 
conclusions to be made about the importance of the manager's decisions (Van der Stede 2000). For example, if managers focus on the long-term, this does not necessarily mean that long-term performance is improved.

Overall, although this study is subject to a number of limitations, I believe that the contributions of the current study, in terms of theory and empirical results, significantly outweigh the limitations.

\subsection{Directions for Future Rescarch}

The results of the theoretical and empirical analysis in this dissertation provide some interesting directions for future research. First, the finding that controllability is not positively related to the use of performance measures deserves some additional attention. The accounting literature stresses the importance of the controllability principle and identilies the costs that are associated with the use of uncontrollable performance measures. However, if firms make efficient choices on arerage, then there must be increased benefits of not adjusting for the effect of uncontrollable factors. This is particularly interesting since the results indicate that the 'noise' due to the measurement process does affect the use of performance measures for incentive purposes. Future research should address the costs and benefits associated with the adjustments made with respect to the 'noise' due to the measurement process and 'noise' due to the effect of uncontrollable factors.

Second, in this study, I examine the effect of the performance measure characteristics informativeness, controllability, measurement accuracy, and performance target difficulty. Although these characteristics dominate the theoretical literature, it is unlikely that these are the only (theoretically) relevant performance measure characteristics. One opportunity for future research is to identify additional characteristics that play a role in designing incentive. systems and to examine how these characteristics change with specific contextual factors.

Third, although the empirical results show that the difficulty of performance targets depends on the degree to which the performance measure is used for incentive purposes and the manager's risk aversion, the picture is far from complete. Since performance targets have significant incentive effects, future research should identify other factors that determine the difficulty of targets.

i. Fourth, firms use different types of non-financial performance measures of which not all are leading indicators and provide managers with long-term incentives. An opportunity for future research is to examine which non-financial 
performance measures provide long-term incentives and which do not and what kind of incentives these latter performance measures do provide.

F. Fifth, the finding that incentive systems become less useful the higher the manager's risk aversion raises the question what altemative control tools firms use to promote goal congruent behavior. Almost no empirical evidence exists of how alternative control mechanisms can be used as substitutes and how these apply to managers who are highly risk averse. Future rescarch should examine whether, for example. behavior monitoring, social control, or selection and training can substitute for the use of incentive systems.

6 Sixth, this dissertation examines the design and effects of incentive systems for subordinate managers and the discussion so far has focused on this organizational level. However, as summarized in table 2.1 (chapter 2), there are ample research opportunities at the (1:O level. Especially the use and effects of performance targets at the (EO level seems to be an important area for future research. Recently this topic has received some attention (e.g., Murphy 1999b; Indjejikian et al. 2000) but much more research is needed about this component of the incentive system at the CEO level.

Finally, this dissertation uses multiple disciplines to study the design and effects of incentive systems. More specifically, it combines the implications of the economics-based and behavioral-based incentive literature. This multidisciplinary approach has led to predictions and empirical results that extend the behavioral-based RAPM literature and the cconomics-based incentive effects litcrature. Although this dissertation takes a multi-disciplinary approach to the design and effects of incentive systems, other areas in accounting might equally benefit from this approach. In my opinion, taking a multi-disciplinary perspective is the most fruitul way to do research and advance knowledge. 


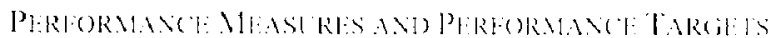




\section{appendix $A$}

\section{LINEAR PRINCIPAL-AGENT MODEL}

\section{A.0 Introductory Remark}

This appendix discusses the linear-principal agent model developed by Ilolmström and Milgrom (1987). The purpose of this appendix is to explain the model in a way that a reader with no background in analytical modeling can understand the basic set-up and analytics of these models and more importantly can understand the deductions made.

The use of the linear principal-agent model in accounting research has grown over the last few years. The model is used by, for example, Bushman and Indjejikian (1993a, 1993b), Feltham and Xic (1994), and Hemmer (1995, 1996:a, 1996b, 1998). The major reason for this increase in use is its (relative) simplicity and as a result the possibility of deriving empirical implications from these models.

\section{A.I Introduction}

In their seminal paper. Holmström and Milgrom (1987) (hereafter HM) cxamine the provision of incentives over time for an agent with constant absolute risk aversion. 'They use a dynamic setting in which the agent frequently makes decisions, which are also dependent on the leedback of past performance. In this setting, they tind that a simple linear contract is optimal and outperforms any complex contract due to its robustness. Although the analysis of HM is mathematically complex, their result is surprisingly simple. The dynamic model 
can be reduced to a static one by imposing the following ad hoc restrictions: (1) the incentive contract is linear and (2) the agent makes a once-and-for-all decision on how he will allocate his effort during the employment relationship. IIM show that these wo assumptions are exactly offsetting, which means that the solution of the static model is identical to that of the dynamic model in which (1) the agent continuously makes decisions and (2) receives information about past performance before choosing his effort.

\section{A.2 Linear Principal-Agent Model}

The linear P/A model has the following assumptions. The principal employs an agent to do a certain job; for example, 'run a firm'. Both the principal and the agent have a negative exponential utility function over wealth. which means that both prefer more wealth to less. The measure of absolute risk aversion of the principal and agent are respectively $t$ and $r$. Consequently, their utility functions are

$$
\begin{array}{ll}
\text { principal: } & \left(j\left(w_{p}\right)=-\exp \left(-t w_{p}\right)\right. \\
\text { agemt: } & U\left(w_{i}\right)=-\exp \left(-w_{u}\right)
\end{array}
$$

The negative exponential utility function implies constant absolute risk aversion (CARA). 'This means that a change in wealth does not affect the level of risk aversion. Thus, by using these utility functions, the model abstracts from wealth effects. Assuming that the principal is risk neutral, her utility function is represented by $G\left(w_{p}\right)=w_{p}$.

The agent chooses action a after the contract is signed and providing effort is costly to the agent because he is work averse. The work aversion of the agent is reflected by his personal cost of effort $C(a)$, which is convex $\left(C^{\prime \prime}>0\right)$ and increasing $\left(C^{\prime}>0\right)$. For reasons of simplicity, I assume that the personal cost of effort is

$$
c(a)=\frac{1}{2} a^{2}
$$

1 The measure of absolute risk arersion is $r=-U^{\prime \prime} / U^{\prime}$ (see e.g., Kreps 1990), which is constant for a negative exponential utility function. 
can be reduced to a static one by imposing the following ad hoc restrictions: (1) the incentive contract is linear and (2) the agent makes a once-and-for-all decision on how he will allocate his effort during the employment relationship. IIM show that these two assumptions are exactly offsetting, which means that the solution of the static model is identical to that of the dynamic model in which (1) the agent continuously makes decisions and (2) receives information about past performance before choosing his effort.

\section{A.2 Linear Principal-Agent Model}

The linear P/A model has the following assumptions. The principal employs an agent to do a certain job; for example, 'run a firm'. Both the principal and the agent have a negative exponential utility function over wealth, which means that both prefer more wealth to less. The measure of absolute risk aversion of the principal and agent are respectively $t$ and $r$. Consequently, their utility functions are

$$
\begin{array}{ll}
\text { principul: } & \left(i\left(w_{p}\right)=-\operatorname{cxp}\left(-r w_{p}\right)\right. \\
\text { ugent: } & U\left(w_{a}\right)=-\exp \left(-w_{a}\right)
\end{array}
$$

The negative exponential utility function implies constant absolute risk aversion $(C A R \Lambda) . '$ This means that a change in wealth does not affect the level of risk aversion. Thus, by using these utility functions, the model abstracts from wealth effects. Assuming that the principal is risk neutral, her utility function is represented by $G\left(w_{p}\right)=w_{p}$.

The agent chooses action a after the contract is signed and providing effort is costly to the agent because he is work averse. The work aversion of the agent is reflected by his personal cost of effort $C(a)$, which is convex $\left(C^{\prime \prime}>0\right)$ and increasing $\left(C^{\prime}>0\right)$. For reasons of simplicity, I assume that the personal cost of effort is

$$
C^{\prime}(a)=\frac{1}{2} a^{2}
$$

'The measure of absolute risk aversion is $r=-U / U$ ' (see c.g., Kreps 199()), which is constant for a negative exponential utility function. 
Because the action of the agent cannot be observed, the principal has to rely on jointly observable signals for incentive purposes. These signals about the agent's action are normally distributed. Technically, the agent controls the mean of the normal distribution. This means that the agent can affect the expected value of the signal. If outcome $x$ is used for incentive purposes, then the expected value of $x$ can be characterized by

$$
E[x]=h(a)
$$

where $h(a)$ is increasing in $a$ and either concave or linear, i.e., $h h^{\prime}>0$ and $h " \leq 0$. In the following, $I$ assume that $h(a)$ is linear and more specifically

$$
E[x]=f i
$$

In figure A.1, it is graphically shown that an increase in effort moves the distribution to the right because it increases the expected value of $x$.

\section{Figure A.I}

The impact of an increase in effort on the mean of the Normal Distribution

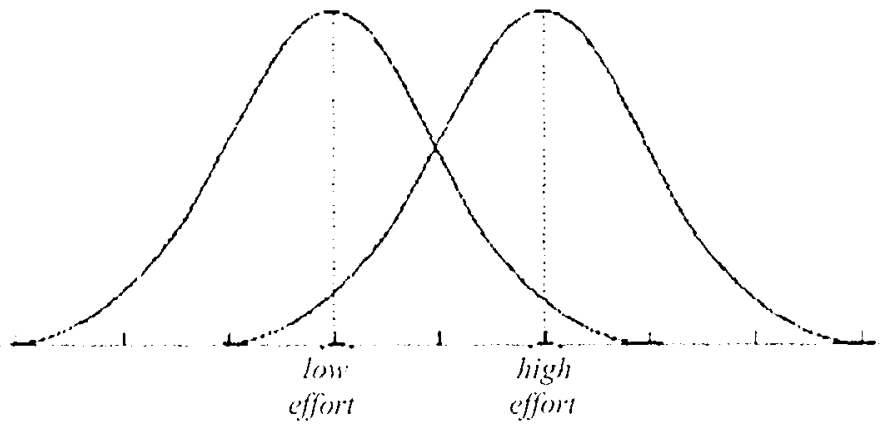

The actual outcome $x$ is not only affected by the agent's action but also by uncontrollable factors. The degree to which the outcome $x$ is affected by uncontrollable factors is represented by the variance of the nomal distribution; the higher the variance, the greater the impact of uncontrollable factors (see figure A.2 for a graphical representation). The actual outcome $x$ can therefore be characterized by

$$
x=E[x]+\theta=f a+\theta
$$

where $O$ is the uncontrollable component, which is normally distributed with mean zero and variance $\sigma^{2}$, i.e., $O \sim N\left(0, \sigma^{2}\right)$. Any linear transformation of a 
nomally distributed random variable is itself nomally distributed. As a result, the outcome $x$ is normally distributed.

\section{Figure 4.2}

The impact of uncontrollable factors on the variance of the Normal Distribution

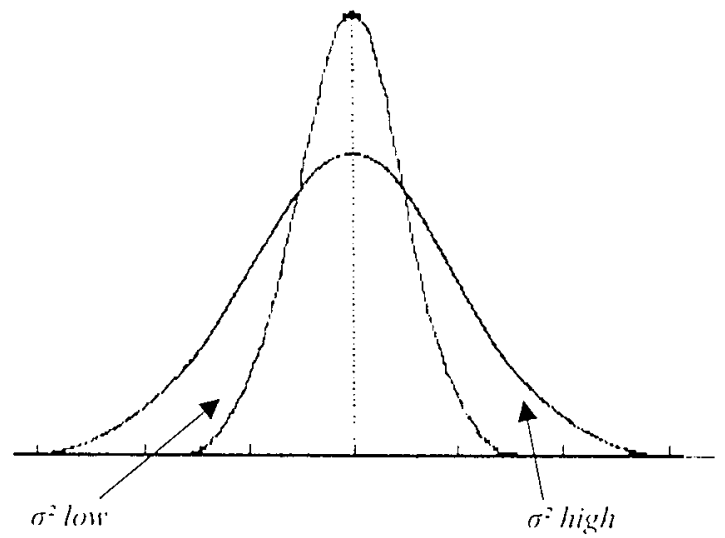

A final assumption of the model is the ad hoc restriction of the shape of the incentive contact. The incentive contract is linear and of the following form

$$
s(x)=\alpha+\beta x
$$

where $\alpha$ is a lixed payment and $\beta$ is the incentive weight. The assumption of CARA is important to the linearity assumption, which can be explained by the following example. Assume that two possible outcomes exist, $x_{1}$ and $x_{11}$, and the agent is compensaled accordingly, i.e., $s_{1}$ or $s_{11}$ (see figure A.3). Because there are two points in the graph, a line can be drawn through these points. This implies that the contingent-compensation of the agent can be written as a linear incentive contract. Further, remember that the static model described here is the result of a dynamic model concerned with providing intertemporal incentives. The agent's wealth in the dynamic model changes over time. If the agent's risk aversion would increase or decrease with increases in wealth, the slope of the line would change. 'However, by assuming CARA, the agent's risk aversion is not affected by changes in wealth, which means that the slope is stationary. As a result, the same linear incentive contract holds for aggregation of returns over time.

2 If the agent becomes risk neutral, the slope will be one. If the agent becomes extremely risk averse, the slope will be zero and he is only paid a fixed wage. 
Figure . 1.3

CARA and lincar incentive contrats

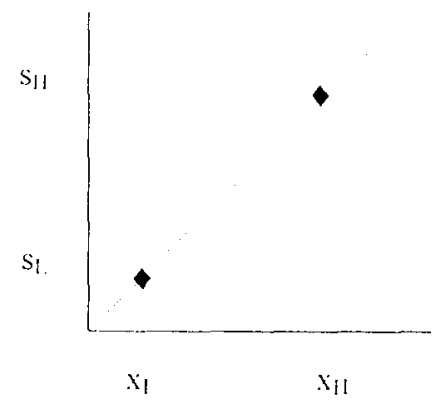

The benefit of having a negative exponential utility function, normally distributed performance measures, and linear incentive contracts is that the model can be solved using certainty equivalents. liollowing these assumptions, the expected utility can be written as (see e.g., Hirschleifer and Riley 1995)

$$
E[U \mid s(x), a]=-e^{-r\left(a+\beta u(t a)^{r} / \beta^{2} a^{2}\right)}
$$

where $\mu$ is the expected value of the outcome $x$. Maximizing this expected utility is equal to maximizing the agent's certainty equivalent (expected value minus risk premium), represented by

$$
E[w]-\frac{r}{2} \operatorname{V} \alpha r[w]=\alpha+\beta \mu-C(\alpha)-\frac{r}{2} \beta^{2} \sigma^{2}
$$

The P/A model can be used to characterize the incentive weight. To find the optimal incentive weight, the following program needs to be solved

$$
\begin{array}{cc}
\max & E\left[-\operatorname{cxp}\left(-r w_{p}\right)\right] \\
\text { subject to } \quad E\left[-\operatorname{cxp}\left(-r w_{a}\right)\right] \geq-1 \\
a_{i} \in \arg \max \quad E\left[-\operatorname{cxp}\left(-r w_{a}\right)\right]
\end{array}
$$

where $w_{p}=x-s(x)$ and $w_{a}=s(x)-C(a)$. Thus, the agent maximizes his action given the incentive contract (second constraint; incentive compatibility) and this optimal action is the input of the objective function. Further, the agent's 
compensation is constrained at zero." The solution to the problem of characterizing the incentive weight can be found by taking the following steps:

1. Define the certainty equivalent of the agent (CEA);

2. differentiate (EA with respect to the agent's action and solve for the optimal action;

3. define the certainty equivalent of the principal (CEP) and the total certainty equivalent (TCE); ${ }^{*}$

4. Fill in the optimal action into TCE, differentiate TCE with respect to the incentive weight and solve for this incentive weight.

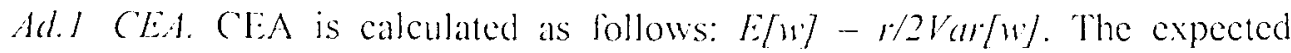
value of wealth, E/W/, is the expected compensation minus the expected personal cost. Because the expected value of $\theta$ is zero, the expected value is

$$
a+\beta \mu-C(a)=a+\beta \beta a-\frac{1}{2} a^{2}
$$

The variance of wealth, $V a r[w]$, is calculated using the following matrix notation: $\mathbf{B}^{\mathbf{t} \Sigma} \mathbf{B}$, where $\mathbf{B}$ is the matrix of incentive weights and $\Sigma$ is the covariance matrix. Thus, the variance of wealth is $\beta^{2} \sigma^{2}$. CEA is therefore

$$
\alpha+\beta f a-\frac{1}{2} u^{2}-\frac{r}{2} \beta^{2} \sigma^{2}
$$

Ad.2 Optimal action. To find the optimal action, differentiate CEA with respect to the agent's action.

$$
\frac{\partial C E A}{\partial a}=B f-a
$$

The optimal action is represented by

$$
a^{\circ}=\beta f
$$

3 The first constraint is the individual rationality constraint, which states that the agent is preserved from getting a negative wealth by stating that the cxpected value should at least be

1. If $w_{n}=0$, then the expected value is equal to -1 . Generally, this constraint is assumed to be satislied and therefore not used in solving the model.

t The assumption of "no wealtl effects", i.c. CARA, implies that an allocation among the principal and agent is efficient if and only if it maximizes their total valuc, i.c., ICE. See Milgrom and Roberts (1992, pp. 35-38) for a discussion of 'no wealth effects' and (total) value maximization. 
Ad.3 CEP and TCE. Because the principal is risk neutral, i.e., $t=0$, CEP is simply the residual claim

$$
E[x]-E[s(x)]=j a-\alpha-\beta f a
$$

The TCE is the aggregate of CEP and CEA, i.c.

$$
f a-\frac{1}{2} a^{2}-\frac{1}{2} \beta^{2} \sigma^{2}
$$

Ad.4 Oprimal incentive weight The action a in TCE should be replaced by the optimal action $a$, which leads to

$$
f \beta f-\frac{1}{2}(\beta f)^{2}-\frac{r}{2} \beta^{2} \sigma^{2}
$$

Differentiating the above equation with respect to $\beta$ leads to

$$
\frac{\partial T C E}{\partial \beta}=\rho^{2}-\beta f^{2}-r \beta \sigma^{2}
$$

Solving this for $\beta$ provides the optimal incentive weight, characterized by

$$
\beta=\frac{f^{2}}{f^{2}+r \sigma^{2}}
$$

This characterization of the incentive weight allows an examination of the effect of the performance measure characteristics informativeness $(f)$ and noise $\left(\sigma^{2}\right)$ on the incentive weight. These effects are stated in the following observation;

Observation: the optimal incentive weight increases with informativeness and decreases with noise, as implied by the partial derivatives below

$$
\begin{aligned}
& \partial \beta>0 \\
& \partial \beta \\
& \partial \sigma^{2}<0
\end{aligned}
$$




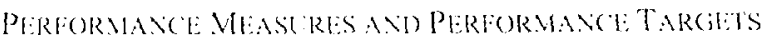




\section{appendix $B$}

\section{MEASUREMENT INSTRUMENTS}

\section{B.0 Introductory Remark and Measurement Instruments}

This appendix presents the measurement instruments used in this study that are not discussed in detail in chapter 5. For the sources of these instruments and the descriptive statistics, I refer to section 5.5. The notation (R) indicates reverse coding.

\section{Task uncertainty}

\begin{tabular}{|c|c|}
\hline Items $(R)$ & Answering format $(1-5)$ \\
\hline a. My tasks are the same from day-10-day & fully disagree - fully agree \\
\hline b. In general I would say that my work is fairly routine & fully disagree - fully agree \\
\hline $\begin{array}{l}\text { c. People in my unit do about the same job in the same } \\
\text { way most of the time }\end{array}$ & - fully agree \\
\hline $\begin{array}{l}\text { d. Basically, unit members perform repetitive activities in } \\
\text { doing their jobs }\end{array}$ & agree \\
\hline c. My duties are repetitious & fully disagrec - fully agree \\
\hline $\begin{array}{l}\text { f. There is a clearly known way to do the major types of } \\
\text { work I nomally encounter }\end{array}$ & fully disagree - fully agree \\
\hline $\begin{array}{l}\text { y. There is a clearly defined body of knowledge of subject } \\
\text { matter which can guide me in doing my work }\end{array}$ & fully disagrec - fully agrec \\
\hline $\begin{array}{l}\text { h. There is an understandable sequence of steps that can be } \\
\text { followed in doing my work }\end{array}$ & fully disagree - fully agree \\
\hline $\begin{array}{l}\text { i. To do my work, I can rely on established procedures } \\
\text { and practices }\end{array}$ & fully disagrec - fully agree \\
\hline
\end{tabular}


Emirommental uncertainty.

\section{Items}

1. Impact of ... on functioning and performance

a. Behavior and or buying pallerns of customers

b. Behavior and/or strategies of competitors

c. Techmological derelopments in your profession

d. Beharior and or strategies of your suppliers

c. l.egal andion political dorelopments
Answering format $(0 /$ N.R. $/ ; 1-5)$

no impacl very high impact no impact - very high impact no inpact - very high impact no impact - very high impact no impace very high impact

\section{Predictubition of relumges iit) ... (R)}

a. Behavior and/or buying pallerns of customers

b. Behavior and/or strategies of competitors

c. Technological developments in your profession

d. Behavior and/or strategies of your supplices

e. I.egall and/or political developments

very unpredictable -.- very predictable very unpredictable very predicable very umpredictable very predictable very unpredictable very predictable very unpredictable -... very predictable

\section{Decision-making anthority.}

\begin{tabular}{ll}
\hline Items & Answering format (1-5) \\
\hline Who has the derision-making anthority with respect to... & \\
a. Development of new products & superior's decision my decision \\
b. Hiring and firing of personnel & superior's decision my decision \\
c. Selection of large investments & superior's decision my decision \\
d. Budget allocations & superior's decision - my decision \\
c. Pricing decisions & superior's decision - my decision \\
\hline
\end{tabular}

\section{Performance measure use}

\begin{tabular}{|c|c|}
\hline Itemis & Answering format $(1-5)$ \\
\hline \multicolumn{2}{|l|}{ How much importance does your superior attach to } \\
\hline wx performance measures in... & \\
\hline a. The cvaluation of your performance & no importance - very high importance \\
\hline b. Periodic performance reports & no importance - very high importanco \\
\hline c. Officially rating your performance & no importance -... very high importance \\
\hline d. Periodic discussions with you & no importance very high importance \\
\hline e. Determining your salary increases & no importance - very high importance \\
\hline f. Detcrmining your annual bonus & no importance very high importance \\
\hline g. Increasing your chance of promotion & no importance very high importance \\
\hline h. Increasing your authority within the organization & no importance - very high importance \\
\hline
\end{tabular}


It'ms

Answering format (1-5)

a. I do not hase much trouble achiesing my xax performance targets. they secm somew hat casy (R)

b. My xxe performance targets require a fair amount of effort to achieve them

c. It reguires a tot of my talent and know-how to achieve the xix performance targets

d. The $x x$ performance targets are fairly easy to attain (R)

c. The xxx performance targets force me to continuously improve my elficiency

fully disagree fully agree

fully disagree -- fully agree

fully disagrec - fully agreo

fully disagree - fully agree

fully disagree - fully agree

\section{Managerial risk aversion}

- Lssume that your current anmual fived salary equals 100.000 . You are given the possibility to choose between the following two alternatives:

Alternative 1: you keep your annual fixed salary of $100,000($ with certainty

Alternative 2: your annual lixed salary becomes 80,000 and you have a chance (probability) to carn an additional bonus of 40,000

How large should the probability of earning the additional bonus of 40,000 be before you prefer alternative 2 to alternative 1 ? $(0-100 \%)$

\section{Managerial short-term orientation}

Indicate the percentage of your time that is devored to working on matters that will show up in your financial results within...
a. one month or less
b. one month to one quarter
c. one quarter to one year
d. one ycar to five ycars

Total

$100 \%$ 


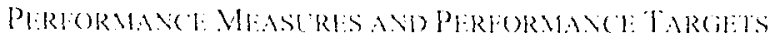




\section{appendix $\mathbf{C}$}

\section{Structural Equation MOdel Results}

\section{C..0 Introductory Remark}

This appendix discusses the empirical results by each structural equation model used. Section C.I presents the results of the structural equation models (SEM) related to Part A of chapter 6, while section C.2 presents the SEM results related to Part $B$ of chapter 6.

\section{C.1 SEM Results Part A}

The empirical results with respect to the use of financial performance measures are shown in figure C.I. The results indicate that the use of financial performance measures increases with decision-making authority (Hla; one-tail $p<0.05$ ), its informativeness $\left(12 a_{i} ;\right.$ one-tail $p<0.01$ ), and measurement accuracy $\left(\mathrm{H} 2 \mathrm{a}_{\mathrm{iil}}\right.$; onc-tail $\left.\mathrm{p}<0.05\right)$ and decreases with its controllability $\left(\mathrm{H} 2 \mathrm{a}_{i 1}\right.$; one-tail $p<0.01$ ). Second, consistent with my expectations, task uncertainty increases the informativeness of financial performance measures ( $\mathrm{H} 3 \mathrm{a}$; onc-tail $\mathrm{p}<0.025$ ), while environmental uncertainty decreases the controllability of financial performance measures $(\mathrm{H} 4 \mathrm{a}$; one-tail $\mathrm{p}<0.0 \mathrm{H})$. Finally, the CFI and the IFI of the model are 0.94 and 0.95 respectively indicating good fit.'

\footnotetext{
1 The comparative fit index (Clil) and the incremental fit index (IFl) are measures of goodness-ol-fit, where values close to 1 indicate a very good fit. Both measures are based on
} 


\section{Figure C.1}

Empirical results with respect to the use of linancial performance measures

EU

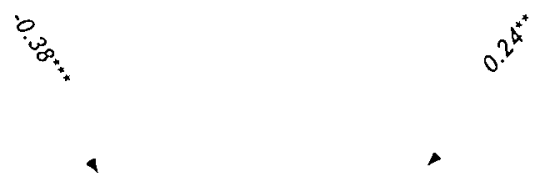

DEC CONFPM INF_FPM ACC FPM

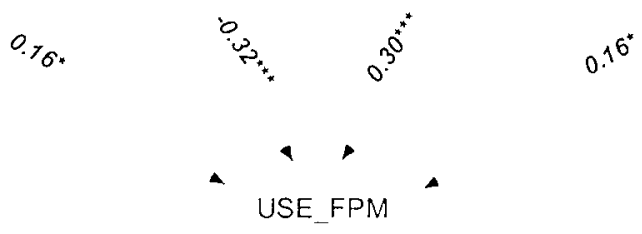

Nores:

$\cdots . . \div$ is signiticant at respectively the $1 \% .2 \%$. $2 \%$. $5 \%$ and $10 \%$ level (one-tailed) using cocticient estimates and standard errors generated from 500 ) andom bootstap samples (with replacement).

: $\quad$ : $U=-$ envirommental uncertainty:

TU = lask uncertainty:

$1) I: C^{\prime}=$ decision-making atuhority:

CON_FP = controllability of tinancial pertomance measures:

INF_PPM := informativeness of financial performance measures:

$A C C_{-}$PPM - measurement accuracy of tinancial performance measures:

USl: $\mathrm{FPM}=$ use of financial performance measures.

b Parameters are maximum likelihood estimates.

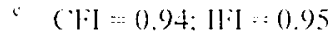

The results related to internal non-financial performance measures are presented in figure (.2. The effect of decision-making authority on the use of internal non-financial performance measures was unknown a priori. The results indicate that decision-making authority is not related to the use of internal nonfinancial performance measures ( $\mathrm{H} / \mathrm{b}$ ). Further, the use of internal non-financial performance measures is positively related to its informativeness (112b $b_{1}$; one-tail $p<0.01$ ) and measurement accuracy $\left(\mathrm{H}_{2} \mathrm{~b}_{1: i}\right.$; one-tail $\left.\mathrm{p}<0.05\right)$, but not related to its controllability $\left(H_{2} \mathrm{~b}_{i i}\right)$. Finally, similar to the financial performance measures,

a comparison of the model employed with a baseline model of independence. Although no specific standard exists, it is generally recommended that these indexes should exceed 0.90. 
task uncertainty increases the informativeness of internal non-financial performance measures (H3b; one-tail $p<0.01$ ), while envirommental uncentainty decreases the controllability of these measures ( $\mathrm{H} 4 \mathrm{~b}$; one-tail $\mathrm{p}<0.01$ ). The model fit measures ('FI and IFI are respectively 0.91 and 0.93 reflecting good lii.

\section{Figure' C.2}

Empirical resuls with respect to the use of internal non-linancial performance measures

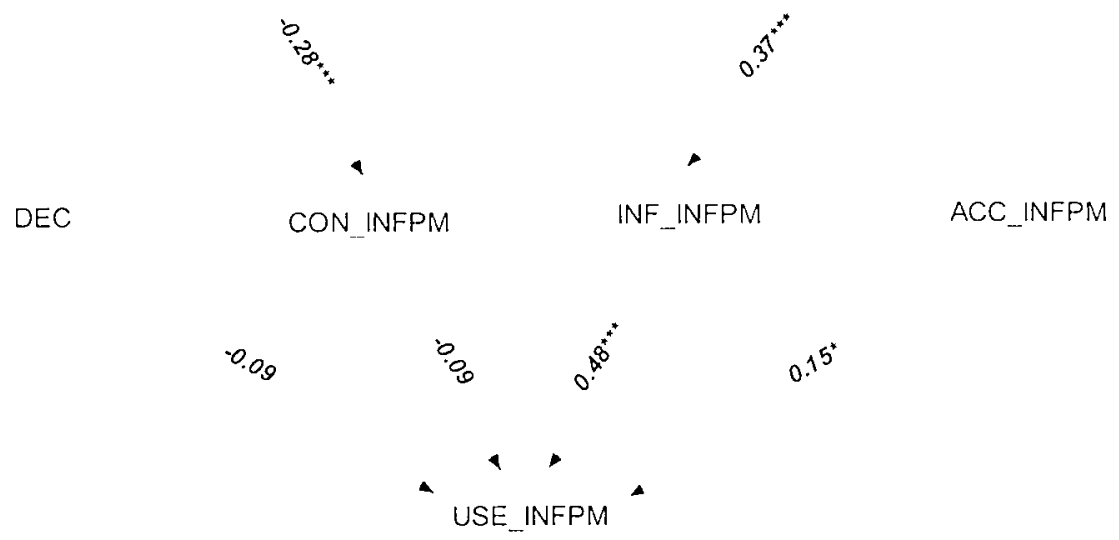

Notes:

$\cdots . . .{ }^{\dagger}$ is significant at respectively the $1 \%, 2 \frac{2 \%}{2} \%, 5 \%$ and $10 \%$ level (one-tailed) using coefficient estimates and standard errors generated from 500 random boostrap samples (with replacement).

* $\mathrm{EU}=$ envirommental uncertainty:

TU $=$ talsk uncertainty:

$\mathrm{DIEC}=$ : decision-making authority:

CON INFPM $=$ controllability of internal non-financial performance measures:

INE INFPM = informativeness of internal non-financial performance measures:

$A C C_{\text {INIPM }}=$ measurement aceuracy of internal non-financial performance measures:

USL INIPY = use of internal non-linancial performance measures.

b Paranneters are maximum likelihood estimales.

$\therefore \quad(F I=0.91: I F I=0.93$.

Figure C .3 shows the results of the empirical model examining the use of external non-financial performance measures. As with internal non-linancial performance measures, the effect of decision-making authority on the use of external non-financial performance measures was unknown a priori. The empirical analysis shows that decision-making authority is not related to the use of external non-financial performance measures $(\mathrm{H} / \mathrm{c})$. The results further 
indicate that the use of external non-financial performance measures is only related to its informativeness $\left(12 c_{i}\right.$ : one-tail $p<0.01$ ) and is not related to its controllability $\left(12 c_{i i}\right)$ and measurement accuracy (12 $\left.\mathrm{a}_{i i}\right)$. Finally, the results show that lask uncertainty is not related to the in formativeness of external nonfinancial performance measures ( $\mathrm{H} 3 \mathrm{c})$, while environmental uncertainty decreases the controllability of external non-financial performance measures $(H 4 c$; one-tail $p<0 .(01)$. The goodness of fit measures show that the model fit is inadequate $(\mathrm{CFI}=0.60 ; \mathrm{IF}=0.68)^{2}$

\section{Figure C.3}

Empirical results with respect to the use of external non-financial performance measures

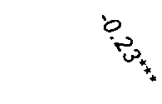

DEC $+\frac{1}{10}$

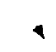

CON_ENFPM

INF ENFPM
ACC ENFPM

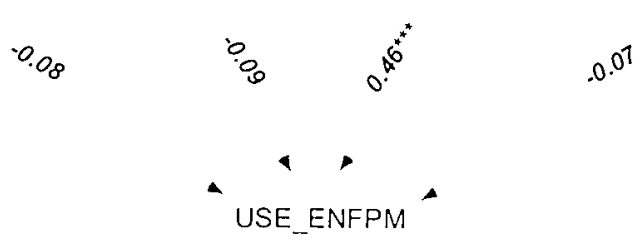

Notes:

....${ }^{+}$is signilicant at respectively the $1 \%, 2 \% \%, 5 \%$, and $10 \%$ level (one-tailed) using coetficient estimates and standard errors generated from 500 random botstrap samples (with replacenent).

a $\quad$ I:U = covironmental uncertainty;

$\mathrm{TU}=$ task uncertainty:

DI:C = decision-making atuthority:

CON_ENFPM = controllability of external non-tinancial performance measures;

INF FNIPM = informativeness of external non-financial performance measures;

$A C C$ C NIPPM = measurement accuracy of extemal non-financial performance measures:

USE_L $[$ NIPPM = use of external non-financial performance measures.

Parameters are maximum likelihood estimates.

$C \mathrm{CI}=0.60: \mathrm{HI} \mathrm{I}=0.68$.

2 Rerunning the model without incorporating the effect of lask uncertainty on informativeness, which was expected to be absent, leads to good fit, as indicated by the $\mathrm{CF}$ $(0.91)$ and IFI (0.93). 


\section{Figure C.t}

Empirical results with respect to the effects of performance measures and perfomance targets

USE_FPM USE_ENFPM
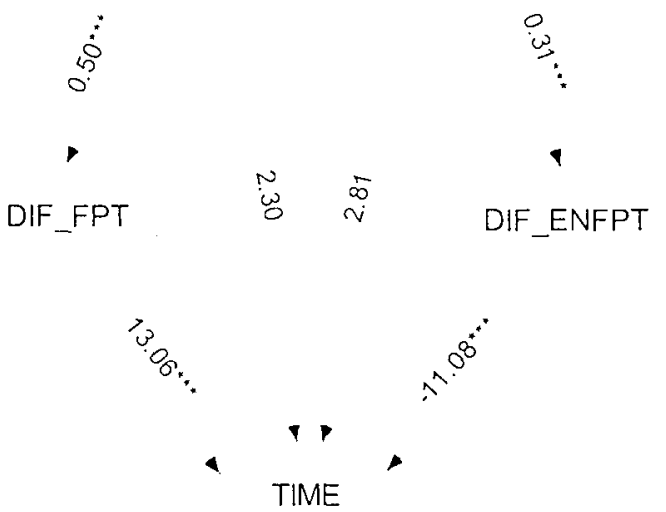

Notes:

$\cdots . \cdot{ }^{\dagger}$ is significant at respectively the $1 \%$. $2 \% .2 \% .5 \%$, and $10 \%$ level (one-tailed) using cocthicient estimales and standard crrors generated from 500 random bootstrap samples (with replacement).

" USS: $1 \mathrm{PM}=$ uSe of financial performance measures:

USE $1: N F P M=$ use of external non-financial performance measures:

DIF: IF' $=$ - difficulty of financial performance target:

DII: ENFP' = difficulty of external non-financial performance target;

TIMl: = managerial short-term orientation.

barameters are maximum likelihood estimates.

$\therefore \quad(\mathrm{F} 1=0.89: 1 \mathrm{H}=0.89$

\section{C.2 SEM Results Part B}

The empirical results, shown in figure C.4, indicate that both the use of financial performance measures and the use of external non-financial performance measures are not related to managerial short-term orientation. Therefore, hypotheses $5 \mathrm{a}$ and $5 \mathrm{~b}$ are not supported by the data, which seems to be inconsistent with previous research. On the other hand, the results provide strong support for hypotheses $6 \mathrm{a}$ and $6 \mathrm{~b}$. The difficulty of the financial performance target is positively related to managerial short-term orientation (one-tail $p<0.01$ ), while the difficulty of the external non-financial performance target is negatively related to managerial short-term orientation (one-tail $p<0.01$ ). Finally, for both the financial perfomance measures and the external 
non-linancial performance measures. the use of these performance measure for incentive purposes increases the difficulty of the performance targets (one-tail $p<0.01$ ). which supports hypothesis 7. The (FI and IFI of the full model are both 0.89 indicating less than adequate fit. though close to the cut-off value of 0.90 . 


\section{REFERENCES}

Anthony, R.N. (1981), The Management Control Function, Harvard Business School Press, Boston.

Antle, R. and $\Lambda$. Smith (1985), Measuring Executive Compensation: Methods and an Application, Journal of Accounting Research, Vol. 23, pp. 296325 .

Arbuckle, J.L. and W. Wothke (1999), Amos 4.0 User's Guide, Small Waters Corporation.

Argyris, C. (1952), The Impact of Budgets on People, The Controllership Foundation, Ithaca, New York.

Baiman, S. and M.V. Rajan (1995), The Informational Advantages of Discretionary Bonus Schemes, The Accouning Review, Vol. 70, pp. $557-$ 579 .

Banker, R.D. and S.M. Datar (1989), Sensitivity, Precision, and Linear Aggregation of Signals for Performance Evaluation, Journal of Accounting Research, Vol. 27, pp. 21-39.

Banker, R.D., S. Lee, and G. Potter (1996a), A Field Study of the Impact of a Performance-Based Incentive Plan, Joumal of Accounting and Economics, Vol. 21, pp. 195-226.

Banker, R.D., S. Lee, G. Potter, and D. Srinivasan (1996b). Contextual Analysis of Performance Impacts of Outcome-Based Incentive Compensation. Academy of Management Journal, Vol. 39, pp. 920-948. 
Banker, R.D., (j. Potter, and D. Srinivasan (2000), An Empirical Investigation of an Incentive Plan that Includes Nonlinancial Performance Measures, The Accounting Review, Vol. 75, pp. 65-92.

Brickley, J.A, C.W. Smith, and J.L. Zimmerman (1997), Managerial Economics and Organizational Architecture, Richard D. Irwin, Burr Ridge. IL.

Briers, M. and M.K. llirst (1990), The Role of Budgetary Information in Performance Evaluation, Accounting, Organizations and Societr, Vol. 15. pp. 373-398.

Brownell, P. (1985). Budgetary Systems and the Control of Functionally Differentiated Organizational Activities, Journal of Accounting Research, Vol. 23, pp. 502-512.

Brownell, P. (1995), Research Methods in Management Accounting, Coopers \& l.ybrand, Accounting Research Methodology, Monograph No. 2. Melbourne.

Brownell, P. and M.K. Hirst (1986). Reliance on Accounting Information, Budgetary Participation, and Task Uncertainty: Tests of a Three-Way Interaction, Joumal of Accounting Reseerch, Vol. 24, pp. $241-249$.

Bruns, W.J. and J.H. Waterhouse (1975), Budgetary Control and Organization Structure, Joumal of Accounting Research, Vol. 13, pp. 177-203.

Burns, T. and G.M. Stalker (1961), The Management of Innoration, Tavistock, London.

Bushman, R.M. and R.J. Indjejikian (1993a), Accounting Income, Stock Price, and Managerial Compensation, Journal of Accomming and Economics, Vol. 16, pp. 3-23.

Bushman, R.M. and R.J. Indjejikian (1993b), Stewardship Value of 'Distorted" Accounting Disclosures, The Accounting Review, Vol. 68, pp. 765-782.

Bushman, R.M., R.J. Indjejikian, and A. Smith (1995), Aggregate Performance Measures in Business Unit Manager Compensation: The Role of Intrafirm Interdependencies, Joumal of Accounting Research, Vol. 33, pp. $101-128$. Bushman, R.M., R.J. Indjejikian, and A. Smith (1996), CEO Compensation: The Role of Individual Performance Measures, Journal of Accounting and Economics, Vol. 21, pp. 161-193.

(henhall, R.H. and D. Morris (1986), The Impact of Structure, Enviromment, and Interdependence on the Perceived Usefulness of Management Accounting Systems, The Accounting Review, Vol. 61, pp. 16-35.

DeCoster, D.T. and J.P. Fertakis (1968), Budget-Induced Pressure and Its Relationship to Supervisory Behavior, Journal of Accounting Research, Vol. 6, pp. 237-246.

DeFond, M.L. and C.W. Park (1999), The Effect of Competition on CEO Tumover, Jounal of Accounting and Economics, Vol. 27, pp. 35-56. 
Demski. J.S. (1994), Managerial Usess of Accounting Information, Kluwer Publishers, Boston.

Dillman, D.A. (1978). Mail and Telephone Surves: The Total Design Method, John Wiley \& Sons, New York.

Drazin, R. and A.H. Van de Ven (1985). Alternative Forms of Fit in C'ontingency Theory, Administrative Science Quarterly, Vol. 30, pp. $514-$ 539.

Dunk, A.S. (1992), Reliance on Budgetary Control, Manufacturing Process Automation and Production Subunit Performance: $\triangle$ Research Note. Accoumting. Organizations and Socictl, Vol, 17, pp. 195-203.

Dunk, A.S. (1993), The Elfect of Budget Emphasis and Information Asymmetry on the Relation between Budgetary Participation and Slack, The Accounting Review, Vol. 68, pp. 400-410.

Eisenhardt, K.M. (1985), Control: Organizational and Economic Approaches, Management Science, Vol. 31, pp. 134-149.

Feltham, G.A and J. Xie (1994), Performance Measure Congruity and Diversity in Multi-Task Principal/Agent Relations, The Accounting Rerven; Vol. 69 , pp. $429-453$.

Fisher, J. (1995), Contingency-Based Research on Management Control Systems: Categorization by Level of Complexity, Joumal of Accounting Literature, Vol. 14, pp. 24-53.

Flannery, T.P., D.A. Hofrichter, and P.E. Platten (1996), People, Performance. and Pay: Dynamic Compensation for Changing Organizations, The Hay Group, The Free Press.

Galbraith, J.R. (1977), Organization Design, Addison-Wesley, Reading.

Gaver, J.J., K.M. Gaver, and J.R. Austin (1995), Additional Evidence on Bonus Plans and Income Management, Journal of Accounting and Economics. Vol. 19, pp. 3-28.

Gibbons, R. and K.J. Murphy (1990), Relative Performance Evaluation for Chief Executive Officers, Industrial and Labor Relations Revien, Vol. 43 (Special Issue), pp. 30-51.

Gordon, L.A. and D. Miller (1976), A Contingency Framework for the Design of Accounting Information Systems, Accounting, Organizations and Society, Vol. 1, pp. 59-69.

Gordon, L. A. and V.K. Narayanan (1984), Management Accounting Systems, Perceived Environmental Uncertainty and Organizational Structure: An Empirical Investigation, Accounting, Organizations and Society, Vol. 9, pp. 33-47.

Govindarajan, V. (1984), Appropriateness of Accounting Data in Performance Evaluation: An Empirical Investigation of Environmental Unecrtainty as 
an Intervening Variable, Accounting. Organizations and Society, Vol. 9. pp. $125-135$.

Govindarajan, V. and A.K. Guptal (1985), L.inking Control Systems to Business

Unit Strategy: Impact on Performance. Accounting, Organizations and Socicty, Vol. 10, pp. $51-66$.

(irice, J.W. and R.J. Harris (1998). A Comparison of Regression and Loading Weights for the Computation of lactor Scores, Multivariate Behavioral Resecurch, Vol. 33, pp. $221-247$.

Guidry, F., A.J. Lecone, and S. Rock (1999), Earnings-Based Bonus Plans and Earnings Management by Business-Unit Managers, Journal of Accounting and Economics, Vol. 26, pp. 113-142.

Hartmann, F.C.H. (1997), Accounting for Performance Evaluation: Effects of Uncertainty on the Appropriateness of Accounting Performance Measures, Ph.D. Dissentation, Maastricht University.

I Iartmann, F.G.H. (2000), The Appropriateness of RAPM: 'Toward the Further

Development of Theory, Accounting, Organizations and Society, Vol. 25, pp. $451-482$.

I lartmann, F.G.II. and l: Moers (1999), Testing Contingency Hypotheses in Budgetary Research: An Evaluation of the Use of Moderated Regression Analysis, Accounting, Organizations and Societ!, Vol. 24, pp. 291-315.

Hayes, D.C. (1977), The Contingency Theory of Managerial Accounting, The Accolnting Review, Vol. 52, pp. 22-39.

Healy, P.M. (1985), The Effect of Bonus Schemes on Accounting Decisions. Joumal of Accounting and Economics, Vol. 7, pp. 85-107.

Hemmer, T. (1995), On the Interrelation between Production Technology, Job Design, and Incentives, Journal of Accounting and Economics, Vol. 19, pp. 209-245.

Hemmer, 'T' (1996a), On the Design and Choice of 'Modern' Management Accounting Measures, Journal of Management Accouming Research, Vol. 8, pp. 87-116.

Hemmer, '1. (1996b), Allocations of Sunk Capacity Costs and Joint Costs in al Linear Principal-Agent Model, The Accounting Review, Vol. 71, pp. 419 432.

Hemmer, T. (1998), Performance Measurement Systems, Incentives, and the Optimal Allocation of Responsibilities, Journal of Accounting and Economics, Vol. 25, pp. 321-347.

Hirschleifer, J. and J.G. Rilcy (1995), The Analytics of Uncertainty and Information, Cambridge University Press.

Hirst. M.K. (1983), Reliance on Accounting Performance Measures, Task Uncertainty and Dysfunctional Behavior: Some Extensions, Joumal of Accounting Researh, Vol. 21, pp. 596-605. 
Hofstede, G. (1967), The Game of Budget Control, Van Gorcum, Assen.

llogan, C.E. and C.M. Lewis (1999), The Long-Run Performance of Firms Adopting Compensation Plans Based on Economic Profits, Working Paper, Vanderbilt Unirersity.

Holmström, B. (1979). Moral Ilazard and Observability, Bell Journal of Economics, Vol. 10. pp. 74-91.

I Iolmström. B. (1982), Moral I lazard in Teams, Bell Journal of Economics, Vol. 13, pp. 324-340).

IJolmström, B. and P. Milgrom (1987), Aggregation and Linearily in the Provision of Intertemporal Incentives, Econometrica. Vol. 55, pp. 303328.

Ilolmström, B. and P. Milgrom (1991), Multitask Principal-Agent Analyses: Incentive Contracts, Asset Ownership, and Job Design, The Journal of Law, Economics, and Organization, Vol. 7, pp. 24-52.

Ilolthausen, R.W., D.F. Larcker, and R.G. Sloan (1995), Annual Bonus Schemes and the Manipulation of Eamings, Joumal of Accounting and Economics, Vol. 19, pp. 29-74.

Ilopwood, A.G. (1972), An Empirical Study of the Role of Accounting Data in Performance Evaluation, Jounal of Accounting Research, Vol. 10, pp. 156-182.

Imoisili, O.A. (1989), The Role of Budget Data in the Evaluation of Managerial Performance, Accounting. Organizations and Society, Vol. 14, pp. 325335.

Indjejikian, R.J., P. Lenk, and D. Nanda (2000), 'largets, Standards and Performance Expectations: Evidence from Annual Bonus Plans, Working Paper, University of Michigan Business School.

Itner, C.D. and D.F. Larcker (1995), Total Quality Management and the (hoice of Information and Reward Systems, Journal of Accounting Research, Vol. 33, pp. 1-34.

Ittner, C.D. and D.F. Larcker (1998a), Are Nonfinancial Measures Leading Indicators of Financial Performance? An Analysis of Customer Satisfaction, Joumal of Accounting Research, Vol. 36, pp. 1-35.

Ittner, C.D. and D.F. Larcker (1998b), Innovations in Performance Measurement: Trends and Research Implications, Journal of Management Accounting Research, Vol. 10, pp. 205-238.

Ittner, C.D. and D.F. Larcker (1999), The Effects of Performance Measure Diversity on Incentive Plan Outcomes, Working Paper, University of Pennsylvania.

Ittner, C.D. and D.F. Larcker (2000), Assessing Empirical Research in Managerial Accounting: A Value-Bases Management Perspective, Journal of Accoumting and Economics, forthcoming. 
Ittner, C.D., D.F. Larcker, and M.V. Rajan (1997), The Choice of Performance Measures in Annual Bonus Contracts, The Accounting Review, Vol. 72, pp. $23 !-255$.

Janakiraman, S.N., R.A. Lambert, and D.F. Larcker (1992), An Empirical Investigation of the Relative Performance Evaluation Hypothesis, Joumal of Accounting Research, Vol. 30, pp. 53-69.

Kaplan, R.S. and D.P. Norton (1992), The Balanced-Scorecard: Measures that Drive Performance, Harrard Business Review, January-February, pp. 71 79.

Keating, A.S. (1997), Determinants of Divisional Perfomance Evaluation Practices, Joumal of Accomming and Economics, Vol. 24, pp. 243-273.

Kenis, I. (1979), Effects of Budgetary Goal Characteristics on Managerial Attitudes and Performance, The Accounting Review, Vol. 54, pp. 707-721. Khandwalla, P.N. (1972), The Effect of Different Types of Competition on the Use of Management Controls, Journal of Accounting Research, Vol. 10, pp. $275-285$.

Kren, L. and W.M. Liao (1988), The Role of Accounting Information in the Control of Organizations: A Review of the Evidence, Jommal of Accounting Literature, Vol. 7, pp. 280-309.

Kreps, D.M. (1990), A Course in Microeconomic Theory, Harvester Wheatsheaf.

Lambert, R.A. (1993), The Use of Accounting and Security Price Measures of Performance in Managerial Compensation Contracts: $A$ Discussion, Jounal of Accounting and Economics, Vol. 16, pp. 101-123.

Lambert, R.A. and D.F. Larcker (1987), An Analysis of the Use of Accounting and Market Measures of Performance in Executive Compensation Contracts, Journal of Accounting Research, Vol. 25, pp. 85-125.

Lambert, R.A. and D.F. Larcker (1995), The Prospective Payment System, Hospital Efficiency, and Compensation Contracts for Senior-Level Hospital Administrators, Joumal of Accounting and Public Policy, Vol. I4, pp. $1-31$.

Lanen, W.N. (1995), Discussion of Aggregate Performance Measures in Business Unit Manager Compensation: The Role of Intrafirm Interdependencies, Journal of Accounting Research, Vol. 33, pp. 129-134. Larcker, D.F. (1981), The Perceived Importance of Selected Information Characteristics for Strategic Capital Budgeting Decisions, The Accounting Review, Vol. 56, pp. 519-538.

Lawler, E.E. and J.G. Rhode (1976), Information and Control in Organizations, Goodyear, Pacific Palisades.

Lawrence, P.R. and J.W. Lorsch (1967), Organization and Enviromment, Harvard University Press, Boston. 
Leone, A.J. and S. Rock (1999), Empirical Tests of the Ratehet Principle and Implications for Studies of Earnings Management, Working Paper, University of Rochester/University of Colorado at Boulder.

Libby, T. and J.I1. Waterhouse (1996), Predicting (hange in Management Accounting Systems, Joumal of Management Accounting Research, Vol. 8 , pp. 137-150.

Locke, E.A., J.F. Bryan, and L.M. Kendall (1968), Goals and Intentions as Mediators of the Eiffects of Monetary Incentives on Behavior, Journal of Applied Psychology, Vol. 53, pp. 104-121.

Locke, E.A. and G.P. Latham (1990), A Theory of Goal Setting and Task Performance, Prentice Hall, Englewood-Clifts.

Luft, J. and M.D. Shields (2000), Mapping Management Accounting: Making Structural Models from Theory-Based Empirical Research, Working Paper, Michigan State University.

Merchant, K.A. (1985), Budgeting and the Propensity to Create Budgetary Slack, Accounting, Organizations and Society, Vol. 10, pp. 201-210.

Merchant, K.A. (1989), Revarding Results: Motivating Profit Center Managers, l larvard Business School Press, Boston.

Merchant, K.A. (1990), The Effects of Financial Controls on Data Manipulation and Management Myopia, Accounting, Organizations and Society, Vol. 15, pp. 297-313.

Merchant, K.A. (1998), Modern Management Comtrol Systems: Text and Cases, Prentice Hall, Upper Saddle River.

Merchant, K.A. and J.F. Manzoni (1989), The Achicvability of Budget Targets in Profit Centers: A Field Study, The Accounting Review, Vol. 64, pp. 539-558.

Merchant, K.A., W.A. Van der Stede, and L. Zheng (2000), Disciplinary Constraints on the Advancement of Knowledge: The Case of Organizational Incentive Systems, Working Paper, University of Southern California.

Milgrom, P. and J. Roberts (1992), Economics, Organization and Management, Prentice-Hall, Englewood-Cliffs.

Milgrom, P. and J. Roberts (1995), Complementarities and Fit: Strategy, Structure, and Organizational Change in Manufacturing, Joumal of Accounting and Economics, Vol. 19, pp. 179-208.

Mirrlees, J. (1974), Notes on Welfare Economics, Information, and Uncertainty, in Balch, McFadden, and $\mathrm{Wu}$, eds., Essays on Fconomic Behavior and Uncertainty, Amsterdam, North-Holland.

Mirrlees, J. (1976), The Optimal Structure of Incentives and Authority within an Organization, Bell Joumal of Economics, Vol. 7, pp. 105-131. 
Moers, F. and E. Peek (2000), Managerial Risk Aversion and Exceutive Compensation: Measurement Issues and an Empirical Test, Working P(uper, Maastricht University.

Mooney, C.Z. and R.D. Duval (1993), Bootstrapping: A Nonparametric Approach to Statistical Inference. Sage University Paper Series on Quantitative Applications in the Social Sciences, Newbury Park. CA: Sage.

Murphy, K.J. (1999a), Executive Compensation, In: Ashenfelter, O. and D. Card (eds.), Handhook of Labor Economics, Vol. 3, North-Holland (forthcoming).

Murphy, K.J. (1999b), Performance Standards in Incentive Contracts, Working Paper, University of Southern Calilomia.

Nagar, V. (1999), Organizational Design Choices in Retail Banking, Working Paper, University of Michigan Business School.

Noreen, E.W. (1989), Computer-Intensive Methods for Testing Hypotheses, John Wiley \& Sons, New York.

Oppenheim, A.N. (1992), Questionnaire Design, Interviewing, and Athitude Measurement, Pinter, London.

Otley, D.T. (1978), Budget Use and Managerial Performance, Joumal of Accounting Research, Vol. 16, pp. 122-149.

Otley, D.T. (1980), The Contingency Theory of Management Accounting: Achievement and Prognosis, Accounting, Organizations and Society, Vol. 5 , pp. 413-428.

Otley, D.T. and A.J. Berry (1980), Control, Organisation and Accounting, Accounting, Organizations and Society, Vol. 5, pp. 231-244.

Ouchi, W.G. (1979), ^ Conceptual Framework for the Design of Organizational Control Mechanisms, Management Science, Vol. 25, pp. 833-848.

Pavlik, E.L., T.W. Scott, and P. Tiessen (1993), Executive Compensation: Issues and Rescarch, Journal of Accounting Literature, Vol. 12, pp. 131-189.

Perrow, C. (1970), Organizational Analysis: A Sociological View, Tavistock, London.

Podsakoff, P.M. and D.W. Organ (1986), Self-Reports in Organizational Research: Problems and Prospects, Joumal of Management, Vol. 12, pp. $531-544$.

Prendergast, C. (1999), The Provision of Incentives in Firms, Journal of Economic Literature, Vol. 37, pp. 7-63.

Puffer, S.M. and J.B. Weintrop (1991), Corporate Performance and CEO Turnover: The Role of Performance Expectations, Administrative Science Quarter/y, Vol. 36, pp. 1-19.

Rogerson, W.P. (1985), The First-Order Approach to Principal-Agent Problems, Econometrica, Vol. 53, pp. 1357-1368. 
Schoonhoven. ('B. (1981). Problems with Contingency Theory: Testing the Assumptions llidden Within the Language of Contingency "Theory'. Administrative Science Quarterly, Vol. 20, pp. 349-377.

Shields, M.D., F.J. Deng, and Y. Kato (2000). The Design and Effects of Control Systems: Tests of Direct- and Indirect-Effects Models, Accounting, Organizations and Society, Vol. 25, pp. 185-202.

Simons, R. (1987), Accounting Control Systems and Business Strategy: An Empirical Analysis, Accounting, Organizations and Society, Vol. 12, pp. $357-374$.

Simons, R. (1988), Analysis of the Organizational Characteristics Related to Tight Budget Goals, Contemporaly Accounting Research. Vol. 5, pp. 267283.

Sloan, R.G. (1993), Accounting Earnings and Top Executive Compensation, Jounal of Accounting and Economics, Vol. 16, pp. 55-100.

Sprinkle, G.B. (2000), The Effect of Incentive Contracts on Learning and Performance, The Accounting Review, Vol. 75, pp. 299-326.

Stern, J.M., G.B. Stewart III, and D.H. Chew, jr. (1995), The EVA Financial Management System, Journal of Applied Corporate Finance, Vol. 8, pp. 32-46.

Thompson, J. (1967), Organizations in Action, McGraw-Hill, New York.

Van der Stede, W.A. (2000), The Relationship between Two Consequences of Budgetary Controls: Budgetary Slack Creation and Managerial ShortTerm Orientation, Accounting, Organizations and Society, Vol. 25, pp. 609-622.

Venkatraman, N. (1989), The C'oncept of Fit in Strategy Research: Toward Verbal and Statistical Correspondence, Academy of Management Review, Vol. 14, pp. 423-444.

Wallace, J.S. (1997), Adopting Residual Income-Based Compensation Plans: Do You Get what You Pay for?, Jounal of Accounting and Economics, Vol. 24, pp. 275-300.

Watcrhouse, J.H. and P. Tiessen (1978), A Contingency Framework for Managcment Accounting Systems Research, Accounting, Organizations and Society, Vol. 3, pp. 65-76.

Weitzman, M. (1980), The Ratchet Principle and Performance Incentives, Bell Journal of Economics, Vol. 11, pp. 302-308.

Williamson, O.E. (1964), The Economics of Discretionary Beharior: Managerial Objectives in a Theory of the Firm, Prentice-Hall, Englewood-Clifs.

Withey, M., R.L. Dafi, and W.H. Cooper (1983), Measures of Perrow's Work Unit Technology: An Empirical Assessment and a New Scale, Academy of Management Joumal, Vol. 26, pp. 45-63. 
Woodward, J. (1965), Industrial Organization: Theory and Practice, Oxford University Press.

Young. S.M. (1985), Participative Budgeting: The Effects of Risk Aversion and Asymmetric Information on Budgetary Slack. Joumal of Accounting Research, Vol. 23, pp. 829-842.

Young, S.M. (1990), Survel Research in Management Accounting: A Critical Assessment, in: Research Methods in Accounting, A.J. Richardson ed.. C GA Rescarch Foundation, Vancouver. 


\section{Performance Measures and Performance Targets in Incentive Systems: An Empirical Study of Use and Effects}

Dit proefschrifi beschrijft cen empirisch onderzock naar het gebruik van prestatiemaatstaven en prestatiedoelen voor beoordelings- en beloningsdoeleinden en de effecten hiervan op het gedrag van managers. Hoofdstuk 1 bevat de inleiding van het proefschrift en beschrijft hoe het onderzoek past binnen het vakgebied management control. Management control behelst de beheersing van individuen binnen organisaties met als doel de gedragingen van deze individuen in overeenstemming te laten zijn met de doelstellingen van de organisatic. Cruciaal bimen management control is het motiveren van individuen. Een van de vele manieren om managers te motiveren, is het implementeren van beoordelings- en beloningssystemen ('incentive systems'). Deze systemen bestaan uit drie componenten: (1) prestatiemaatstaven, (2) prestatiedoelen, en (3) beloningen. Deze componenten zorgen ervoor dat managers weten wat van hen word verwacht en dat ze gemotiveerd zijn om inzet to leveren aangezien dit tot een bepaalde beloning zal leiden.

De vagen die in dit proefschrift centraal staan, zijn (1) welke factoren kunnen het gebruik van verschillende prestatiemaatstaven voor beoordelings- en beloningsdoeleinden verklaren en (2) welke effecten hebben deze prestatiemaatstaven en de gerelateerde prestatiedoelen op het gedrag van managers. 
In hoofdstuk 2 wordt een beknopt overzicht gegeven van de wetenschappelijke empirische literatuur op het gebied van beoordelings- en beloningssystemen. llet overzicht geeft aan dat, met betrekking tot managers in gedecentraliseerde organisaties, or relatief weing empirisch onderzoek is gedaan naar (1) bcoordelings- en beloningssystemen die gebruik maken van niet-financiële informatic, (2) de factoren die het gebruik van prestatiematataven verklaren, en (3) de effecten van prestatiedoelen. Er wordt een aantal redenen gegeven waarom dit problematisch is.

In hoofdstuk 3 worden de drie theorieën beschreven die ten grondslag liggen aan de empirisch literatuur uit hoofdstuk 2, namelijk: agency theorie, contingentie theorie, en goal theorie. In het hoofdstuk wordt aangegeven dat een multidisciplinaire aanpak de leemtes kan vullen die zijn gë̈dentificeerd in hoofdstuk 2. Ten eerste kunnen de implicaties van de contingentie en agency theorie worden gecombineerd on het gebruik van prestatiemaatstaven te kumen verklaren. Deze combinatie geeft an dat onzekerheid de belangrijkste contingentie variabele is. Verder geeft het aan dat de karakteristieken van de prestatiemaatstaven bepalend zijn voor het gebruik en dat deze karakteristieken worden beïnvloed door onzekerheid. Drie karakteristieken worden onderscheiden: (1) de mate waarin de manager invloed heeft op de prestatiemaatstaf, (2) de mate warin onbeheersbare factoren invloed hebben op de prestatiemaatstaf en (3) de mate waarin de maatstaf objectief en verifieerbaar is.

Ten tweede kunnen de implicaties van de agency en goal theoric worden gecombineerd om de effecten van beoordelings- en beloningssystemen te onderzoeken. Deze combinatie geeft aan dat het enkel en alleen gebruiken van prestatiemaatstaven en het niet benadrukken van prestatiedoelen waarschijnlijk niet erg efficiënt is in termen van voldocnde invloed uitoefenen op het gedrag van managers. Aangezien bcoordelings- en beloningssystemen bestaan uit prestatiemaatstaven en prestatiedoelen en beide een invloed hebben op gedrag is het van belang om het gezamenlijke effect te onderzoeken.

Samenvattend leidt de multidisciplinaire aanpak tot de volgende onderzoeksvragen: (1) welk effect hebben de karakteristieken van prestatiemalataven op het gebruik van deze matstaven?; (2) hoe worden de karakteristieken van prestatiemaatstaven beïnvloed door onzekerheid?; en (3) welk effect heeft het gebruik van prestatiemaatstaven en de haalbaarheid van prestaticdoelen op het gedrag van managers?

In hoofdstuk 4 worden de hypothesen afgeleid op basis van de implicaties van hoofdstuk 3 . Tevens wordt in dit hoofdstuk onzekerheid opgesplitst in wwee typen onzekerheid: (1) taakonzekerheid en (2) omgevingsonzekerheid. Verwacht wordt dat beide een effect hebben op verschillende karakteristieken van prestatiemaatstaven. 
Hoofdstuk 5 beschrijt de onderzocksmethode en specifick het ontwerp en uitvoering van het empirische onderzock. Het onderzock is uitgevoerd door middel van interviews, een schriftelijke enquete en archiefgegevens. In totaal is aan 202 managers cen enquete verstuurd. Waarvan er 114 ingevuld zijn terugontvangen.

In hoofdstuk 6 worden de empirische resultaten besproken en de hypothesen uit hoofdstuk 4 getoetst. Uit de empirische analyse blijkt dat het merendeel van de hypothesen wordt geacepteerd.

Hoofdstuk 7 geeft een samenvatting van de empirische resultaten die zijn besproken in hoofdstuk $6 \mathrm{en}$ stelt dat de multidisciplinaire anpak vruchtbaar is geweest. Op basis van de empirische resultaten worden de volgende conclusies getrokken.

Op de eerste plaats wordt geconcludeerd dat de mate waarin een manager invloed heeft op een prestaticmatstaf de belangrijkste karakteristiek is voor het bepalen van het gebruik van deze maatstaf voor beoordelings- en beloningsdoeleinden. Dit betekent dat de onderzochte beoordelings- en beloningssystemen in overenstemming zijn met het 'informativeness' principe. Dat wil zeggen, prestatiemaatstaven die informatie verstrekken over de beslissingen van managers worden gebruikt, ook al worden deze maatstaven beïnvloed door onbeheersbare factoren. Tevens speelt de mate waarin de prestatiemaatstaf objectief en verifieerbaar is een belangrijke rol bij het bepalen van het gebruik van deze maatstaf. Echter, de mate waarin onbeheersbare factoren invloed hebben op de prestatiemaatstaf heeft niet het verwachte effect op het gebruik en er wordt geconcludeerd dat bedrijven het 'controllability' principe niet toepassen. Dat wil zeggen, het gebruik van een bepaalde prestatiemaatstaf neemt niet af naamate de onbeheersbaarheid toencemt. Het tegenovergestelde is zelfs van toepassing op financiële prestatiemaatstaven. Fr wordt geconcludeerd dat met name financiële prestatiemaatstaven nuttig zijn om een beivustzijn bij managers te creëren met betrekking tot de invloed van onbeheersbare factoren.

Wat betreft de invloed van onzekerheid op de karakteristieken van prestatiemaatstaven wordt geconcludecrd dat onzekerheid eerder een positief effect heeft op de karakteristieken van financiële prestatiemaatstaven dan een negatief effect. Taakonzekerheid blijkt de bruikbaarheid van financiële prestatiemaatstaven te vergroten aangezien het de informatieve waarde van deze maatstaven, met betrekking tot de beslissingen van managers, vergroot. Verder blijkt dat omgevingsonzekerheid niet alleen de behecrsbaarheid van financiële prestatiemaatstaven verlaagt, maar tevens de beheersbaarheid van niet-financiële prestatiemaatstaven. De traditioneel veronderstelde 'tekortkoming' van financiële prestatiemaatstaven blijkt dus evencens een tekortkoming te zijn van niet-financiële maatstaven. Echter, aangezien financiële prestatiemaatstaven 
nuttig zijn om een bewustzijn van onbeheersbare factoren te creëren, neemt de bruikbarheid van deze maatstaven juist toe naarmate er meer omgevingsonzekerheid is.

In relatic tot de derde onderzocksvraag wordt geconcludeerd dat prestatiemaatstaven een indirect effect hebben op het gedrag van managers. Naamate prestaticmaatstaven belangrijker worden voor beoordelings- en beloningsdoeleinden worden de daaraan gerelateerde prestatiedoelen moeilijker haalbaar, wat vervolgens het gedrag bepaalt. Uit het onderzoek blijkt dat het gebruik van linanciële (nict-financiële) prestatiemaatstaven leidt tot moeilijker halbare financiële (niet-financiële) prestatiedoclen en dit leidt vervolgens tot beslissingen die zijn gericht op korte-termijn (lange-termijn) financiële resultaten. Prestatiemaatstaven bepalen dus de 'richting' van het gedrag, terwijl de haalbaarheid van de prestatiedoelen de 'hoogte' van de inzet bepaalt.

Hoofdstuk 7 wordt afgesloten met een bespreking van de tekortkomingen van het empirisch onderzoek en er worden aanbevelingen gedaan voor toekomstig onderzock op het gebied van beoordelings- en beloningssystemen. 


\section{CURriculum VitaE}

Frank Moers was born on August 28, 1972 in Maastricht. From 1991 to 1996, he studied Economics and Business Administration at Maastricht University. After graduation, he worked for a year as a Ph.D. student at respectively the Vrije Universiteit Amsterdam and Maastricht University. Since July, 1997, he is an assistant professor of management accounting at Maastricht University. 
